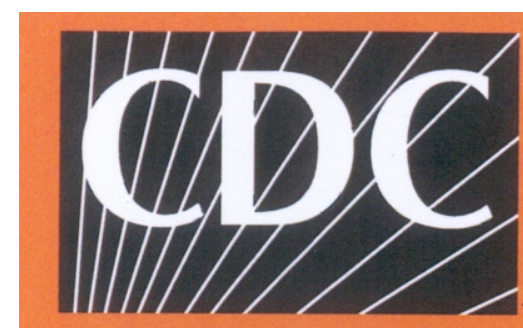

Workplace Safety and Health

\title{
A Compendium of NIOSH Construction
}
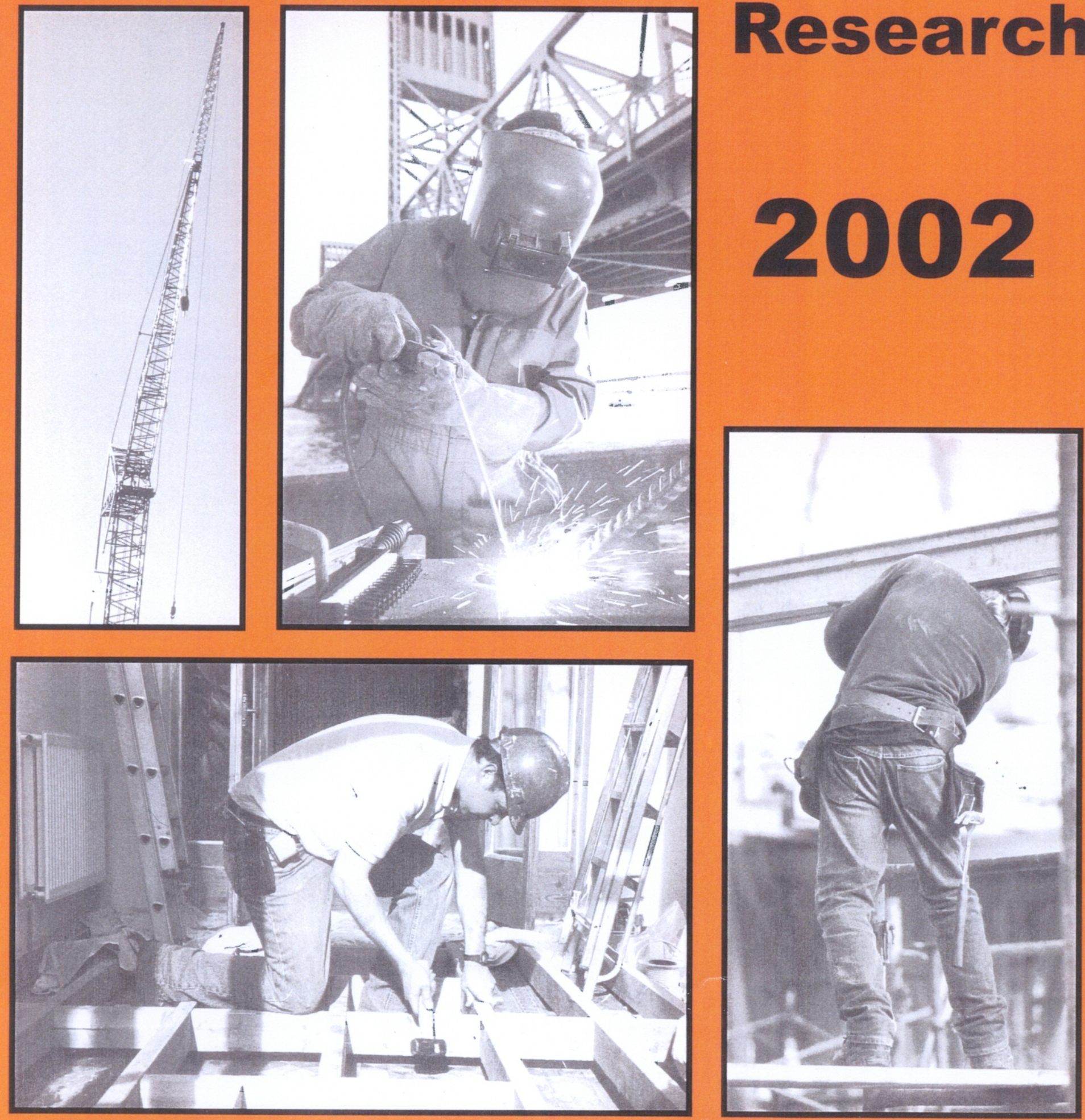

Department of Health and Human Services

Centers for Disease Control and Prevention

National Institute for Occupational Safety and Health

Research
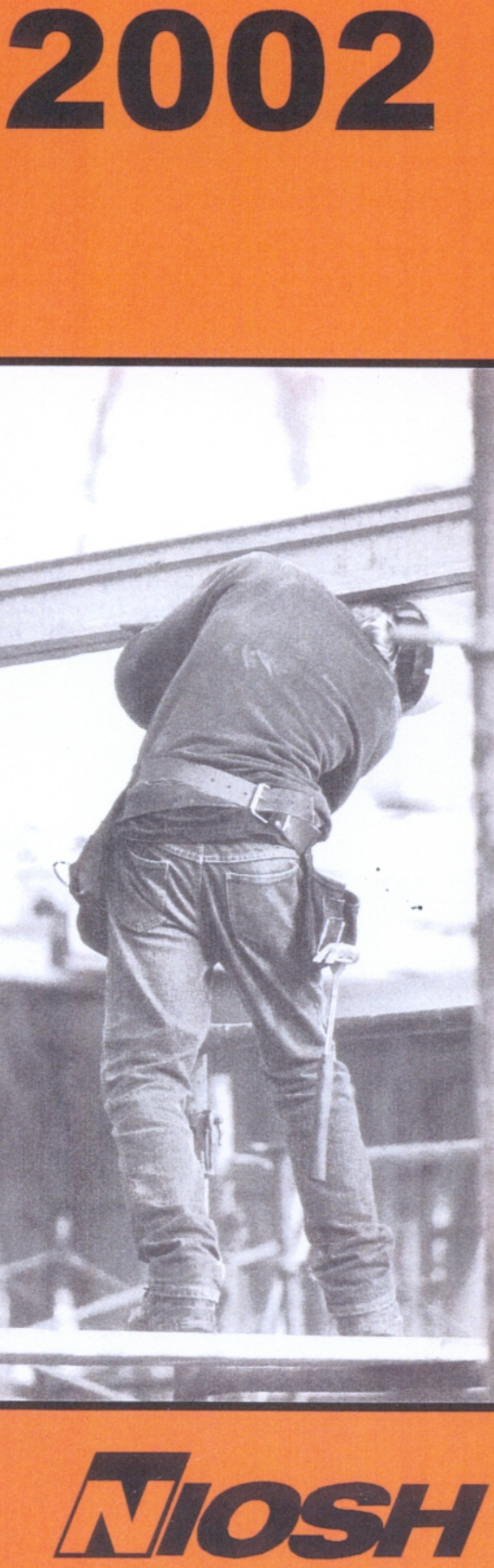


\section{A COMPENDIUM OF NIOSH CONSTRUCTION RESEARCH 2002}

\section{U.S. Department of Health and Human Services}

Public Health Service

Centers for Disease Control and Prevention

National Institute for Occupational Safety and Health

Washington, DC

February 2003 


\section{ORDERING INFORMATION}

Copies of National Institute for Occupational Safety and Health (NIOSH) documents and information about occupational safety and health are available from

NIOSH-Publications Dissemination

4676 Columbia Parkway

Cincinnati, OH 45226-1998

FAX: $\quad 513-533-8573$

Telephone: 1-800-35-NIOSH

(1-800-356-4674)

E-mail: pubstaft@cdc.gov

Web site: www.cdc.gov/niosh

This document is the public domain and may be freely copied or reprinted.

Disclaimer: Mention of any company or product does not constitute endorsement by NIOSH.

DHHS (NIOSH) Publication No. 2003-103 


\section{FOREWORD}

Ensuring the safety and health of America's construction workers continues to be a top priority for NIOSH. Our construction program began in 1990 as Congress began to appropriate funds for the expansion of surveillance, research, and intervention activities for construction safety and health. Since then, NIOSH has developed a national infrastructure to address issues affecting workers in this industry. The program includes intramural research performed by NIOSH staff across a broad range of construction topics, as well as targeted surveillance activities involving a number of state health departments. It also includes extramural projects conducted by academic and related researchers through grants and cooperative agreements, as well as the involvement of two consortia. The first, organized by the Center to Protect Workers Rights in 1990, involves the participation of over 16 universities and organizations. The second, the Construction Safety Alliance, is a consortium of four universities that received initial funding in 2001. Overall, NIOSH supports construction research in 22 states.

The research program described in this compendium addresses a variety of important safety and health hazards and conditions. The projects cover the public health spectrum, from identifying and characterizing problems to quantifying and prioritizing risk factors, developing prevention strategies, evaluating results, and disseminating information to construction industry users.

Significant progress has been made in certain construction performance measures. For example, the rate of occupational injuries and illnesses has declined from 14.2 total cases per 100 full-time workers in 1990 to 8.3 total cases in 2000 . However, challenges remain in many areas. The fatality rate in construction has not improved over time, and the construction sector continues to account for the largest number of fatal injuries. Progress on occupational disease is more difficult to track, and much work remains to be done.

It takes the collaboration of many parties, including labor, industry, academia, private organizations, and government, to maximize the return on research. Construction partners play an important role in translating safety and health knowledge into effective preventive actions.

Partnerships among researchers and the construction industry are essential. By providing brief project descriptions and contact information, we hope this compendium will provide a tool to improve networking among researchers, foster communication between researchers and construction end-users, and stimulate thinking on new research ideas and new ways to apply research results. We all share the same goal: to make a real difference for the health and safety of American construction workers.

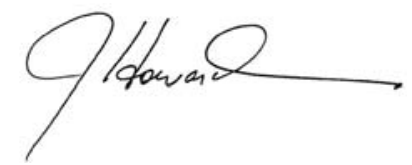

John Howard, M.D.

Director, National Institute for Occupational Safety and Health Centers for Disease Control and Prevention 


\section{CONTENTS}

\section{MUSCULOSKELETAL DISORDERS/ERGONOMICS}

Ergonomic Engineering Interventions for the Construction Industry $\ldots \ldots \ldots \ldots \ldots \ldots \ldots$

Technology Investment Agreement with Advanced Technology Institute $\ldots \ldots \ldots \ldots \ldots \ldots$

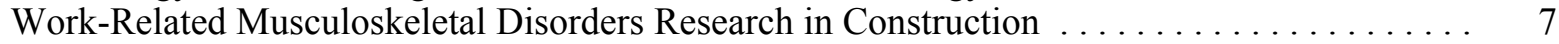

Direct Physical Exposure Assessment Methods for Evaluating Noncyclic Construction Work $\ldots \quad 8$

Evaluation of Tool Design Characteristics for Use in Construction Work . . . . . . . . . . 9

Temporal and Impulsive Characteristics of Hand Tools $\ldots \ldots \ldots \ldots \ldots \ldots \ldots \ldots \ldots \ldots \ldots$

Comparison of Aviation Snip Design for Sheet Metal Workers $\ldots \ldots \ldots \ldots \ldots \ldots \ldots \ldots \ldots . \ldots 11$

Health Effect of Construction Power Tools on the Hand and Wrist $\ldots \ldots \ldots \ldots \ldots \ldots \ldots \ldots . \ldots 12$

Ergonomic Study of Drywall Finishing Tools and Tasks $\ldots \ldots \ldots \ldots \ldots \ldots \ldots \ldots \ldots \ldots$

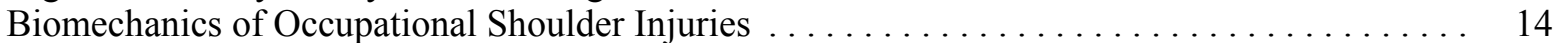

Effects of a Home Exercise Program on Shoulder Pain, Motion, and Muscle Activity in Construction Workers ...................................... 15

Effects of a Home Exercise Program on Preventing Shoulder Pain in Construction Apprentices 16

Effect of Overhead Drilling Position on Shoulder Moment and Electromyography . . . . . . 17

Comparison of Risk Factors in Construction Trades with Contrasting Prevalence of Carpal

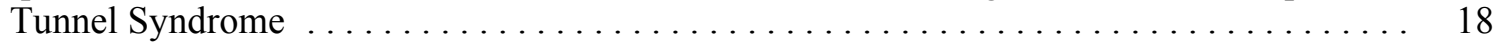

Carpal Tunnel Syndrome Among Apprentice Construction Workers . . . . . . . . . . . . 19

Influence of Physical Workplace Factors on the Development of Carpal Tunnel Syndrome

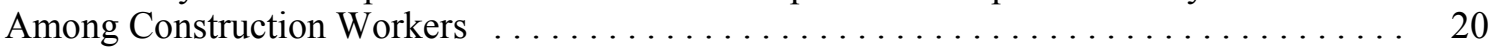

Musculoskeletal Disorders Among Apprentice Construction Workers $\ldots \ldots \ldots \ldots \ldots \ldots .21$

Musculoskeletal Disorders Among Apprentice and Experienced Hungarian Construction

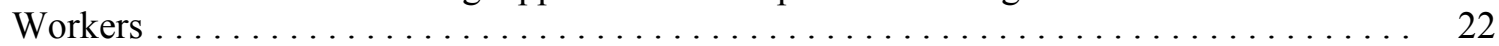

Occupational Low Back Pain in Residential Carpentry: Elements of Posture and Strain . . . . 23

Effect of Lightweight Block on Muscular Load and Cardiovascular Stress in Bricklayers . . . . 24

Evaluation and Intervention in Construction or Demolition of Concrete Structures $\ldots \ldots \ldots 25$

\section{TRAUMATIC INJURY}

Work Organization Issues in Construction: The Relationship Between Overtime and Injury $\quad$. 26

Work Scheduling, Overtime, and Work-Related Injuries in Construction . . . . . . . . . 27

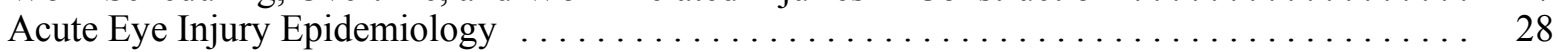

A Study of Ergonomic Interventions in the Drywall Industry $\ldots \ldots \ldots \ldots \ldots \ldots \ldots \ldots \ldots$

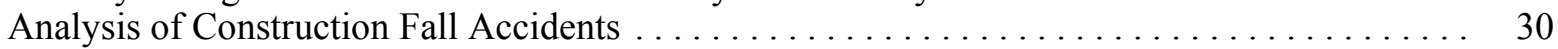

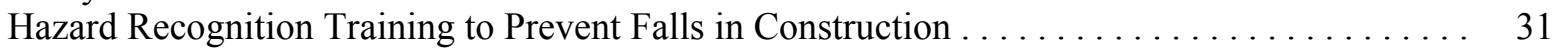

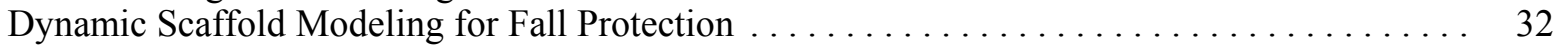

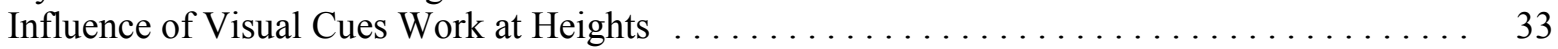

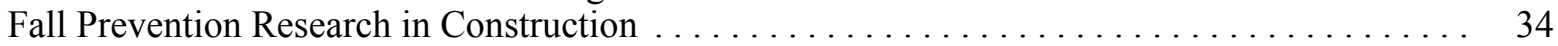

Prevention of Falls from Elevations in the Construction Industry $\ldots \ldots \ldots \ldots \ldots \ldots \ldots \ldots$

Aerial Lift Safety Research in Construction $\ldots \ldots \ldots \ldots \ldots \ldots \ldots \ldots \ldots \ldots \ldots \ldots . \ldots \ldots$

Assessing the Risks of Injury in Trenching and Excavation in the United States . . . . . . . 37

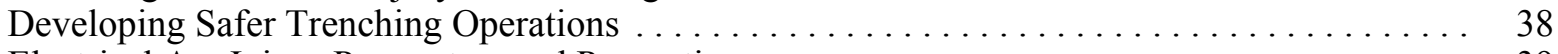

Electrical Arc Injury Parameters and Prevention $\ldots \ldots \ldots \ldots \ldots \ldots \ldots \ldots \ldots \ldots \ldots \ldots$

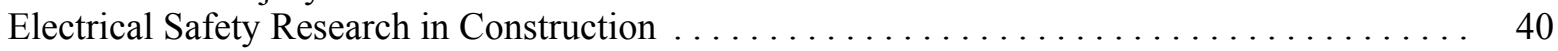

HEARING LOSS PREVENTION

Definition and Assessment of Engineering Noise Controls $\ldots \ldots \ldots \ldots \ldots \ldots \ldots \ldots \ldots$. . . . 41

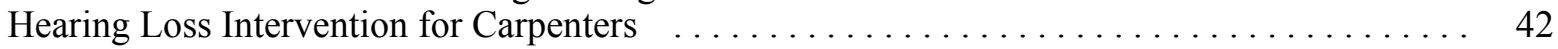


Field Hearing Protector Testing Methods and Rating Schemes $\ldots \ldots \ldots \ldots \ldots \ldots \ldots \ldots$

Hearing Loss Prevention Strategies Program Coordination $\ldots \ldots \ldots \ldots \ldots \ldots \ldots \ldots \ldots .44$

Prospective Study of Hearing Damage Among Newly Hired Construction Workers . . . . . . . 45

Effectiveness of Computer-Based Hearing Test and Training $\ldots \ldots \ldots \ldots \ldots \ldots \ldots \ldots . \ldots 46$

Building Trades Hearing Conservation Programs in Washington State $\ldots \ldots \ldots \ldots \ldots \ldots \ldots .47$

\section{RESPIRATORY DISEASE}

Evaluation of Substitute Materials Used in Construction $\ldots \ldots \ldots \ldots \ldots \ldots \ldots \ldots \ldots$

Molecular Mechanisms of Disease Development with Mixed Dusts $\ldots \ldots \ldots \ldots \ldots \ldots \ldots \ldots . \ldots 9$

Method Development for Fungi in Occupational Diseases $\ldots \ldots \ldots \ldots \ldots \ldots \ldots \ldots \ldots \ldots \ldots$

Initial Respiratory Responses in Welding Apprentices $\ldots \ldots \ldots \ldots \ldots \ldots \ldots \ldots \ldots \ldots \ldots$

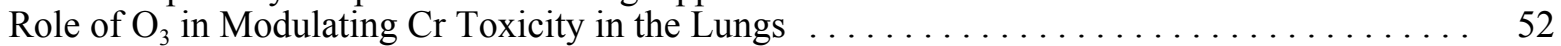

Prevention of Inhalation Hazards in Construction $\ldots \ldots \ldots \ldots \ldots \ldots \ldots \ldots \ldots \ldots \ldots$

Revised NIOSH Guide for Respiratory Protection $\ldots \ldots \ldots \ldots \ldots \ldots \ldots \ldots \ldots \ldots \ldots$

Respiratory Protection for Construction Workers $\ldots \ldots \ldots \ldots \ldots \ldots \ldots \ldots \ldots \ldots \ldots$

\section{ASPHALT}

Asphalt Fumes Characterization and Hazard Identification $\ldots \ldots \ldots \ldots \ldots \ldots \ldots \ldots \ldots \ldots$

Molecular Markers of Asphalt Fume Exposure . . . . . . . . . . . . . . . . . . . . . 57

Asphalt Fumes: Inflammatory Effects and Pulmonary Injury $\ldots \ldots \ldots \ldots \ldots \ldots \ldots \ldots \ldots$

Assessment of Asphalt Fume Exposure from Roofing Kettles … . . . . . . . . . . . . . . 59

Control of Exposure During Application of Asphalt Roofing Materials $\ldots \ldots \ldots \ldots \ldots \ldots . \quad 60$

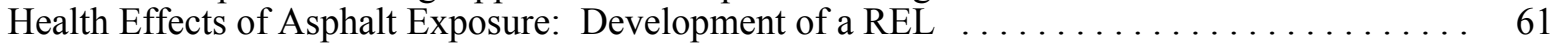

Concise International Chemical Assessment on Asphalt Exposure $\ldots \ldots \ldots \ldots \ldots \ldots \ldots \ldots .62$

ENGINEERING CONTROLS/INSTRUMENTS AND EQUIPMENT

Summary of Blood Lead Monitoring Evaluation Project $\ldots \ldots \ldots \ldots \ldots \ldots \ldots \ldots \ldots$

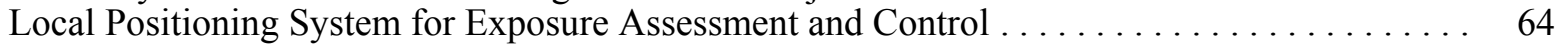

Screening Methods for Airborne Metals in Construction $\ldots \ldots \ldots \ldots \ldots \ldots \ldots \ldots \ldots \ldots$

Environmental Tractor $\mathrm{Cab}$ System Integrity $\ldots \ldots \ldots \ldots \ldots \ldots \ldots \ldots \ldots \ldots \ldots \ldots \ldots \ldots \ldots \ldots$

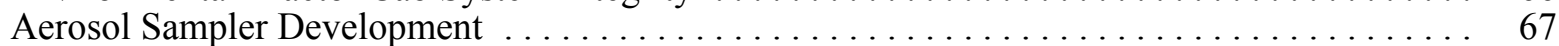

Control of Exposures During Construction $\ldots \ldots \ldots \ldots \ldots \ldots \ldots \ldots \ldots \ldots \ldots$

Economic Analyses of Engineering Control Interventions for Drywall Sanding Construction

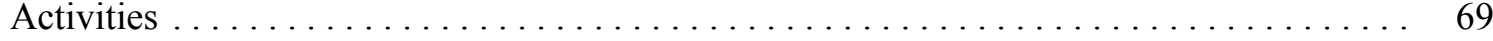

Control of Silica Exposure from Hand-Held Construction Tools $\ldots \ldots \ldots \ldots \ldots \ldots \ldots \ldots \ldots$

Evaluation of Dust Control Technologies in Construction Tasks $\ldots \ldots \ldots \ldots \ldots \ldots \ldots \ldots \ldots$

Electronic Safety Devices for Construction Workers $\ldots \ldots \ldots \ldots \ldots \ldots \ldots \ldots \ldots \ldots \ldots \ldots$

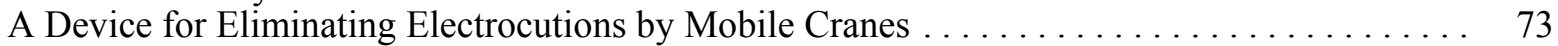

Field Studies with Innovative Safe Excavation Technologies $\ldots \ldots \ldots \ldots \ldots \ldots \ldots \ldots \ldots$

\section{INTERVENTIONS}

Cross-Cutting Research and Interventions in Hazardous Work Environments . . . . . . . . 75

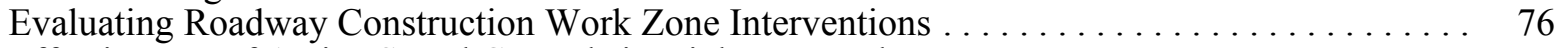

Effectiveness of Active Speed Controls in Highway Work Zones $\ldots \ldots \ldots \ldots \ldots \ldots \ldots \ldots .77$

Economic and Job Hazard Analysis of Sandblasting Substitutes $\ldots \ldots \ldots \ldots \ldots \ldots \ldots \ldots$

A Strong Construction Injury Prevention Intervention at the Subcontractor Level $\ldots \ldots \ldots \ldots$

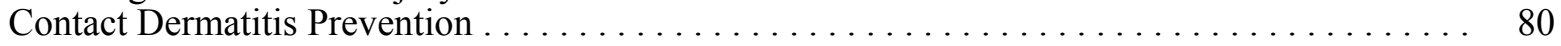

Crew-Based Work Observation Program To Improve Construction Safety Performance . . . . 81

Assessment of a Safety-In-Design Intervention on an Industrial Construction Site $\ldots \ldots \ldots \ldots 82$

Zero-Accident Worksites: The Role of Owners in Construction Safety $\ldots \ldots \ldots \ldots \ldots \ldots . . . . .63$

A Blueprint for Integrating Health Hazard Control Programs into Infrastructure Rehabilitation . 84 
Integrating Safety into Construction CPM Schedules $\ldots \ldots \ldots \ldots \ldots \ldots \ldots \ldots \ldots \ldots$

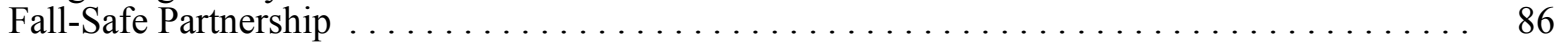

Qualitative Research and Intervention $\ldots \ldots \ldots \ldots \ldots \ldots \ldots \ldots \ldots \ldots \ldots \ldots \ldots \ldots \ldots \ldots \ldots \ldots$

TRAINING /INFORMATION TRANSFER

Evaluating Toolbox Training in Construction and Mining $\ldots \ldots \ldots \ldots \ldots \ldots \ldots \ldots$

Safety Checklists Program for Small Businesses in the Construction Industry $\ldots \ldots \ldots \ldots \ldots 89$

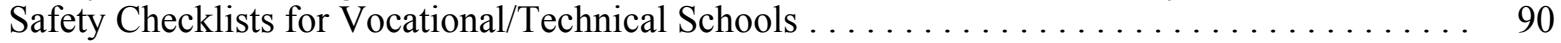

Evaluation of Electrical Safety High School Curriculum $\ldots \ldots \ldots \ldots \ldots \ldots \ldots \ldots \ldots \ldots \ldots$

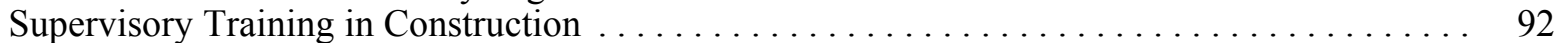

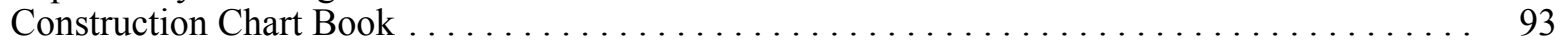

\section{SURVEILLANCE AND SPECIAL POPULATION STUIIES}

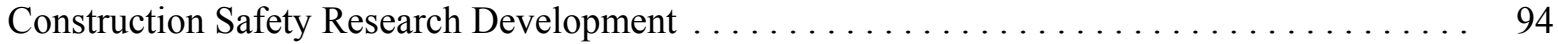

Hazard Prevention in Selected Construction Specialty Trades … . . . . . . . . . . . . . 95

Feasibility Study of Respirator Surveillance in the Construction Industry . . . . . . . . . . . . 96

Adult Blood Lead Epidemiology and Surveillance and Research Program (ABLES) . . . . . . 97

National Surveillance of Nonfatal Occupational Injuries Using NEISS . . . . . . . . . . . . . 98

Surveillance of Nonfatal Work-Related Injuries in Alaska . . . . . . . . . . . . . . . . . . 99

Survey of Small-to-Medium-Sized Construction Companies: Commitment to Safety and Health 100

Research on Young Worker Safety and Health Risks in Construction . . . . . . . . . . . . 101

Worker and Worksite Factors in Denver International Airport Construction Injury . . . . . . 102

Social/Economic Impact of Injury/Illness in Career Roofers $\ldots \ldots \ldots \ldots \ldots \ldots \ldots \ldots \ldots \ldots$

Economic Impact of Occupational Injury and Illness $\ldots \ldots \ldots \ldots \ldots \ldots \ldots \ldots \ldots \ldots \ldots$

Trends of Construction Industry and Workforce $\ldots \ldots \ldots \ldots \ldots \ldots \ldots \ldots \ldots \ldots \ldots \ldots \ldots$

Workplace Safety and Health of Hispanic Construction Workers $\ldots \ldots \ldots \ldots \ldots \ldots \ldots$

Anthropometry of Construction and Agriculture Population $\ldots \ldots \ldots \ldots \ldots \ldots \ldots \ldots$

\section{EXPOSURE ASSESSMENT}

Radiation Grants and Cooperative Agreement Program $\ldots \ldots \ldots \ldots \ldots \ldots \ldots \ldots \ldots$

Occupational Lead Exposure: Risk to the Aging Worker . . . . . . . . . . . . . . . . . 109

Application of a Task-Based Exposure Assessment Model (T-BEAM) to Construction Safety

and Health Programs, Education, and Training $\ldots \ldots \ldots \ldots \ldots \ldots \ldots \ldots \ldots \ldots \ldots \ldots \ldots \ldots$

\section{CONSTRUCTION POLICY RESEARCH}

Construction Policy Research Center at Harvard University $\ldots \ldots \ldots \ldots \ldots \ldots \ldots \ldots \ldots 111$

Construction Policy Research Center at the University of Maryland . . . . . . . . . . . . 112

Construction Policy Research Center on Integrated Safety Systems $\ldots \ldots \ldots \ldots \ldots \ldots \ldots$

DATABASES

Electronic Library of Construction Occupational Safety and Health (eLCOSH) $\ldots \ldots \ldots \ldots \ldots 114$

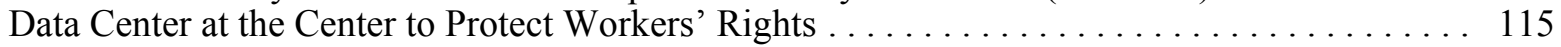

Developing Scalable Database for Construction Safety $\ldots \ldots \ldots \ldots \ldots \ldots \ldots \ldots \ldots \ldots$

Developing Construction Safety Alliance Website . . . . . . . . . . . . . . . . . . . 117

NIOSH SERVICES

Health Hazard Evaluation and Technical Assistance $\ldots \ldots \ldots \ldots \ldots \ldots \ldots \ldots \ldots \ldots \ldots . \ldots$

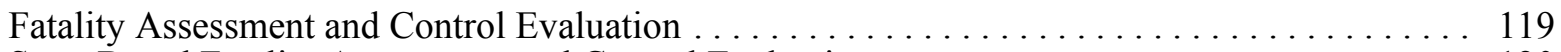

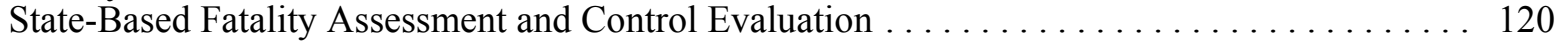


AFL-CIO American Federation of Labor-Congress of Industrial Organizations

CDC Centers for Disease Control and Prevention

EPA Environmental Protection Agency

DOE Department of Energy

HUD Housing and Urban Development

MSHA Mine Safety and Health Administration

NIOSH National Institute for Occupational Safety and Health

OSHA Occupational Safety and Health Administration 


\section{INTRODUCTION}

\section{ABOUT THE COMPENDIUM}

This Compendium of NIOSH Construction Research for 2002 includes 49 NIOSH intramural and 67 NIOSH-funded extramural construction projects. Projects included in this compendium were selected on the basis of their relevance to construction, and each principal investigator was asked to describe their project in one page and submit a graphic of some sort to illustrate the narrative. The descriptions were then grouped by topic categories.

A few explanations and caveats are provided here to assist users of this document.

- The projects in this compendium have construction as the major focus. Projects that look at the etiology of a certain health effect or which address construction as part of a multi-industry approach may not be included even though they may have relevance for construction. In addition, research targeting the agriculture and mining sectors may address hazards (e.g., hand tools, hearing loss, electrical hazards) and produce solutions (e.g., ventilation of equipment cabs) that can be applied to the construction sector and vice versa. NIOSH mining-related projects are described in $A$ Compendium of NIOSH Mining Research 2002 (DHHS, NIOSH Publication No. 2002-110), which can be downloaded from the NIOSH Web site at www.cdc.gov/niosh). Interested readers are encouraged to examine both research compendia for synergistic health and safety projects.

- The one-page format focuses on key items. Projects are included in only one topic category, even though many can be considered as cutting across a number of categories.

- Space limitations may have resulted in some co-investigators or research partners being omitted. Readers should contact the researchers directly for more information or with any questions.

\section{ABOUT NIOSH EXTRAMURAL RESEARCH}

NIOSH extramural projects are based on proposals submitted by academic and other researchers under NIOSH'S "R01" grant program. Applications for these awards are accepted three times a year, and researchers interested in construction are encouraged to apply. Additional details are available on the NIOSH Website.

Many extramural projects are channeled through two consortia - the Center to Protect Workers Rights and the Construction Safety Alliance. The Center to Protect Workers Rights is funded through a 5-year cooperative agreement directed to encourage research on (1) innovative pilot or feasibility studies to reduce injury and illness in construction, (2) evaluations of interventions geared to developing and testing best practices, (3) disseminating information and technology transfer, (4) reviewing preventive systems (e.g., policies, procedures, organizational factors) that affect construction, (5) on-going surveillance, and (6) establishing and reviewing research priorities. The Construction Safety Alliance is funded by a 2-year NIOSH grant to Purdue University and brings together several programs focusing on construction engineering approaches. 


\section{ABOUT NIOSH'S CONSTRUCTION PROGRAM AND STEERING COMMITTEE}

The NIOSH Web page includes a construction topic page with links to many NIOSH construction publications, as well as other useful links such as eLCOSH (the Electronic Library for Construction Safety and Health).

An Institutewide Construction Steering Committee, with representatives from each division and laboratory, oversees the NIOSH construction program and advises NIOSH leadership. The committee serves as an advocate for construction-related activities within NIOSH and acts to facilitate communication, partnering, project planning, and strategic planning on construction issues. Current members include-

Christine (Lani) Boldt, Spokane Research Laboratory

James Cawley, Pittsburgh Research Laboratory

Robert Cutlip, Health Effects Laboratory Division

Cherie Estill, Division of Applied Research and Technology

David Fosbroke, Division of Safety Research

Matt Gillen, Office of the Director

Ted Katz, Office of the Director

Kenneth Linch, Division of Respiratory Disease Studies

Greg Piacitelli, Division of Surveillance, Hazard Evaluations, and Field Studies

Marie Haring Sweeney, Education and Information Division

John Talty, Office of Extramural Programs

The Construction Steering Committee has identified a number of high-priority construction topics and emerging areas of interest where research is most likely to make a difference. The committee is interested in encouraging new intramural and extramural projects in the areas below.

\section{Outcome topics}

- Fatal injuries in construction

- Other traumatic injuries

- Respiratory disease (airway disease, asthma, chronic obstructive pulmonary disease, silicosis)

- Hearing loss

- Low-back injuries

- Cumulative, work-related musculoskeletal disorders

- Psychological and neurological disorders

\section{Overexposure topics}

- Vibration

- Asphalt fumes

- Lead

- Dust and particles

\section{Approach and sector topics}

- Information and technology transfer-how to best translate research into prevention

- Addressing issues affecting small and self-employed contractors

- Evaluating the role of design as a primary prevention tool for addressing construction hazards

- Work organization in construction and how it relates to health and safety

- Special populations at risk - the impacts of diversity and aging 
- Working with building owners and clients (e.g., federal building managers) to promote and evaluate construction best practices

- How to leverage research results from related sectors, such as mining and agriculture, into construction and vice-versa

Please contact the NIOSH Construction Steering Committee chair to share your ideas about research needs and priorities, partnership opportunities, and suggestions for translating research into applications for the construction industry.

\section{ACKNOWLEDGMENTS}

The Construction Steering Committee would like to thank Priscilla Wopat of the NIOSH Spokane Research Laboratory for her terrific assistance with editing and assembling this document, and Herb Linn for his assistance with the cover photos. Very special appreciation also goes to Trish Quinn of the Center to Protect Workers' Rights and Ann Berry and Ann Cronin of the NIOSH Office of Extramural Programs for their assistance in providing current information about projects and investigators.

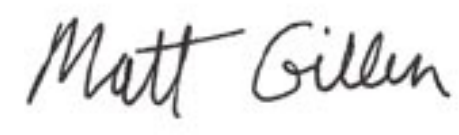

Matt Gillen, MS, CIH

Chair, NIOSH Construction Steering Committee

202-401-2193

mgillen@.cdc.gov 


\section{ERGONOMIC ENGINEERING INTERVENTIONS FOR THE CONSTRUCTION INDUSTRY}

\section{RESEARCHER: Cheryl Estill \\ AFFILIATION: Division of Applied Research and Technology National Institute for Occupational Safety and Health (513) 533-8404}

PURPOSE: Determine engineering controls that can reduce the incidence of musculoskeletal disorders among construction workers, particularly what engineering interventions can reduce workers' exposure to the physical risks that lead to back injuries.

RESEARCH SUMMARY: Back injuries are prevalent in the construction industry. The incidence rate of days away from work because of back injuries is $58 \%$ higher in construction than in general industry. Of these back injuries, $72 \%$ are due to overexertion, and $96 \%$ are classified as back pain or sprains/ strains. There remains a paucity of information in the scientific literature on the effectiveness of engineering controls in reducing or preventing back injuries. More research is needed to determine what engineering interventions are effective for each sector of the construction industry.

The project will be modeled after a highly successful shipyard ergonomics study. It will involve meeting with leaders of companies, unions, and associations and developing a plan for engineering controls to reduce back injuries. Ten or more sites representing many of these construction sectors will be visited to document engineering controls already in use that are found to be effective and to identify jobs with the highest physical risk factors. Controls will be developed, applied, and tested for those occupations and tasks identified as having the highest level of physical risk factors. Production information corresponding to use of the engineering control will also be collected. A compendium of successful engineering controls and good ergonomic practices for the construction industry will be compiled, and during the final year, a series of best-practices workshops will be held to disseminate study findings.
KEYWORDS: Control technology, intervention, musculoskeletal disorders

\section{RECENT CITATIONS:}

\author{
Albers, J.T., C.F. Estill, and L.A. \\ MacDonald. (In press.) In \\ Proceedings: Exploring Ergonomic \\ Interventions in the Mechanical and \\ Electrical Trades (San Jose, CA, Feb. \\ 25-26, 2002). NIOSH.
}

Estill, C.F., and J.T. Albers. 2002. Ergonomic interventions in the construction industry. In Power Through Partnerships: 12th Annual Construction Safety and Health Conference, Proceedings (May 21-23, 2002, Rosemont, IL). 


\section{TECHNOLOGY INVESTMENT AGREEMENT WITH ADVANCED TECHNOLOGY INSTITUTE}

\author{
RESEARCHER: Stephen Hudock
}

\section{AFFILIATION: Division of Applied Research and Technology National Institute for Occupational Safety and Health}

(513) 533-8183

PURPOSE: Devise and implement cost-effective ergonomic controls for a variety of construction, repair, and recycling processes in the shipyard industries.

RESEARCH SUMMARY: The domestic shipbuilding, repair, and recycling industries have historically had much higher injury and illness incidence rates than has general industry, manufacturing, or construction. In 1998, the Bureau of Labor Statistics reported that shipbuilding and repair had an injury/illness incidence rate of 22.4 per 100 full-time employees, whereas the manufacturing, construction, and "all industries" sector reported rates of 9.7 per $100,8.8$ per 100 , and 6.7 per 100 , respectively. Approximately half of all shipyard injuries can be classed as musculoskeletal disorders.

Because of the number of multifaceted job tasks performed by workers in the various trades in ship construction, repair, and recycling, the perception is that fitting the job to the shipyard worker may not be practical. In addition, ergonomic engineering controls employed in general industry, construction, or manufacturing are not necessarily transferrable because tasks in a shipyard are quite diverse.

Nonetheless, it is imperative that the high rates of musculoskeletal disorders and associated job risk factors be better understood. Once an association is clear, effective ergonomic intervention strategies can be developed to prevent such injuries. This study will be conducted in three phases. Phase 1 includes examining trade- or department-specific injury and illness rates for the past 5 years, assessing qualitative job risk factors in various trades or job processes, and determining if individual shipyards are willing to cooperate in data collection and implementation of pilot ergonomic interventions. Phase 2 includes quantifying job risk factors for selected jobs in selected shipyards, recommending unique ergonomic engineering and administrative controls to reduce exposure to the identified risk factors, and implementing pilot ergonomic interventions. Phase 3 includes evaluating the effectiveness of the pilot interventions and disseminating results to the public.

Broader application of the ergonomic interventions will be to transfer the lessons learned in specific shipyards to other shipyards, boatyards, and other industries such as manufacturing and construction.

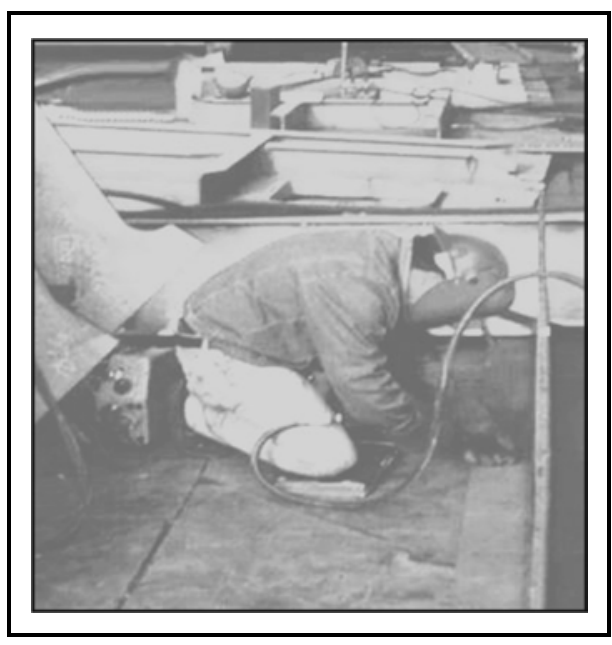

KEYWORDS: Ergonomics, intervention, musculoskeletal disorders

\section{RECENT CITATIONS:}

Wasserman, D.E., S.D. Hudock, J.F. Wasserman, L. Mullinix, S.J. Wurzelbacher, and K.V. Siegfried. 2002. Hand-arm vibration in a group of hand-operated grinding tools. Human Factors and Ergonomics in Manufacturing, v. 12, no. 2, pp. 211226.

Hudock, S.D., S.J. Wurzelbacher, L.D. Reed, T.R. Hales, and K.V. Siegfried. 2001. A precursor of ergonomics best practices for the shipyard industries. Journal of Ship Production, v. 17, no. 13, pp. 145150.

Lowe, B.D., S.J. Wurzelbacher, S.A. Shulman, and S.D. Hudock. 2001. Electromyographic and discomfort analysis of confined-space shipyard welding processes. Applied Ergonomics, v. 32, no. 3. pp. 255269. 


\section{WORK-RELATED MUSCULOSKELETAL DISORDERS RESEARCH IN CONSTRUCTION}

\section{RESEARCHER: Michael McCann}

\section{AFFILIATION: Center to Protect Workers' Rights (301) 578-8500}

PURPOSE: Help develop and implement a work-related musculoskeletal disorder program in construction.

RESEARCH SUMMARY: Strains and sprains are commonly used as a stand-in for work-related musculoskeletal disorders. According to the Bureau of Labor Statistics (BLS), work-related musculoskeletal disorders include cases where the nature of injury or illness involves sprains, strains, tears, back pain, carpal tunnel syndrome, hernia, or musculoskeletal system symptoms, and connective tissue diseases and disorders. These problems occur when the event or exposure leading to the injury or illness involves bending, climbing, crawling, reaching, twisting, overexertion, or repetition.

Analysis of BLS data for all industries for 1999 showed that only $61 \%$ of strains and sprains are actually work-related musculoskeletal disorders as defined by the BLS. The rest included acute injuries resulting from falls, slips and trips, contact with objects, etc. Thus, the event or exposure categories of "overexertion" (96\%), "bending and twisting" (a subcategory of bodily reaction) (93\%), and "repetitive motion" (95\%) are better indicators of workrelated musculoskeletal disorders.

The Center to Protect Workers' Rights is coordinating the investigation of whether use of lightweight (17 lb) cement blocks instead of regular (34-40 lb) cement blocks can reduce lower back injuries among cement masons. This intervention project involves masons from the International Union of Bricklayers and Allied Craftworkers and consists of three separate studies: (1) an on-site evaluation and symptom questionnaire survey of masons using both types of cement block (Medstar Research Institute and George Washington University), (2) a laboratory investigation by the University of Iowa, and (3) a productivity study in collaboration with NIOSH's Division of Safety Research.

The laboratory investigations have been completed. Preliminary analyses suggest a reduction in upper back muscle load while using the lightweight block, but indicate no difference in lumbar or shoulder posture.

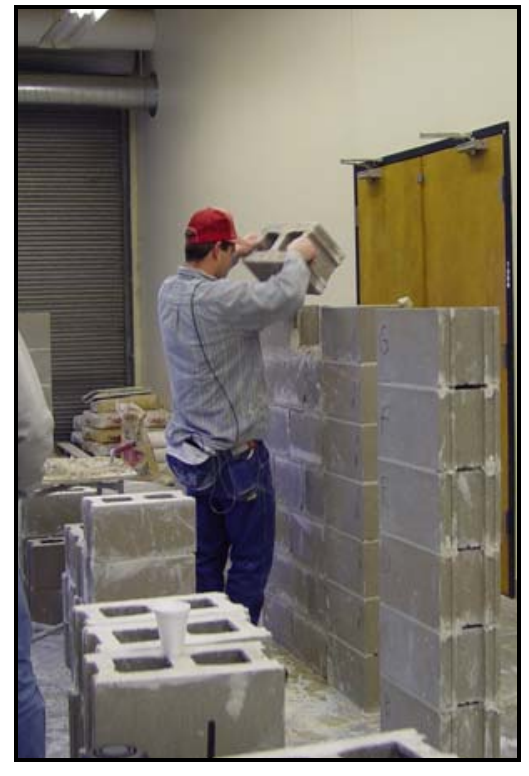

KEYWORDS: Musculoskeletal disorders and injuries, ergonomics, cement masons, lightweight blocks, intervention 


\section{DIRECT PHYSICAL EXPOSURE ASSESS- MENT METHODS FOR EVALUATING NONCYCLIC CONSTRUCTION WORK}

\section{RESEARCHER: Dan Anton}

\section{AFFILIATION: University of lowa \\ (319) 335-4425}

CONSORTIUM: Center to Protect Workers' Rights

PURPOSE: Develop an exposure assessment tool for evaluating forceful exertions in highly variable, noncyclic work settings such as construction.

RESEARCH SUMMARY: There is a need for improved methods for quantifying physical risk factors. Surface electromyography has been used in several ergonomic studies to assess exposure to forceful exertions, and electrogoniometry has been used to evaluate awkward postures. However, exposure assessment and quantification of work such as construction and agriculture have proven to be especially challenging, since the tasks are typically highly variable and noncyclic.

Exposure variation analysis (EVA) is a data-reduction method applicable to electromyography or electrogoniometry. When used with electromyography, EVA describes a certain work period in terms of load or intensity of muscular contraction and period length or duration of muscular contraction. A graph is created that illustrates the percentage of sampled work time at the combined levels of intensity and duration. Although EVA is a beneficial method of quantifying work, examination of the results is a statistically complex process, and the graphs may be difficult to interpret. A simplification of EVA has been developed called "clustered exposure variation analysis," or CEVA. CEVA has been used with dataloggers in studies evaluating exposure to forceful exertions of the flexor forearm (via electromyography) in construction workers. CEVA can quantify highly variable work and simultaneously evaluate multiple dimensions of physical exposure. It appears to be promising as an exposure assessment tool, since nonresearchers would be able to use the technique.

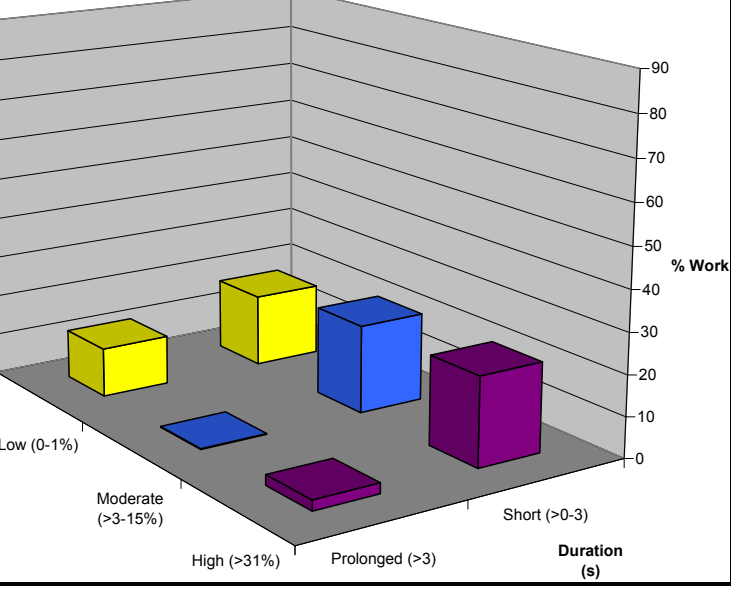

lustered exposure variation analysis (CEVA) graph of mechanic's work.

KEYWORDS: Electromyography, ergonomics, exposure assessment, forceful exertion, musculoskeletal disorders, upper extremity

\section{RECENT CITATIONS:}

Anton, D. 2002. A comparison of risk factors in construction trades with contrasting prevalence of carpal tunnel syndrome. Doctoral dissertation, University of Iowa.

Jansen, J.P, A. Burdorf, and E. Steyerberg. 2001. A novel approach for evaluating level, frequency and duration of lumbar posture simultaneously during work. Scandinavian Journal of Work, Environment, and Health, v. 27, pp. 373-380.

Anton, D., J.L. Clark, P. KrawezykAdamus, T. Cook, J. Rosecrance, and L. Merlino. 2002. Reliability of clustered exposure variation analysis. In Proceedings of the 16th Annual International Occupational Ergonomics and Safety Conference. 


\section{EVALUATION OF TOOL DESIGN CHARACTERISTICS FOR USE IN CONSTRUCTION WORK}

\section{RESEARCHER: Brian Lowe}

\section{AFFILIATION: Division of Applied Research and Technology National Institute for Occupational Safety and Health (513) 533-8161}

PURPOSE: Identify and specify ergonomic design criteria for hand tools used in construction work.

RESEARCH SUMMARY: Construction workers have high exposure to physical stressors, such as awkward postures, repetitive motion, heavy force exertions, and long work hours. Each year musculoskeletal disorders account for more than $60 \%$ of the disabling injuries experienced by approximately 200,000 construction workers. Many of the injuries and physical stresses associated with construction work are recognized to be the direct result of poorly designed hand tools in construction tasks. Ergonomically designed tools can reduce the risk of injury resulting from poor tool design.

Workers, employers, and manufacturers need to know what criteria or features make a tool "ergonomic" and what are the benefits of ergonomic tool design. This project is designed to answer these two questions. This need is increasingly apparent with the proliferation of new hand tools that have recently become available for common construction tasks.

A checklist has been developed by NIOSH for use by construction workers and supervisors to enable them to select the most appropriate nonpowered hand tools. The next step in the development process is to conduct two laboratory studies and a field study to validate the checklist. The laboratory studies will quantitatively examine how tool characteristics, such as slipperiness, handle compliability, handle contour, tool weight, handle crosssectional shape, etc., affect the biomechanical demands of hand tool use. For some hand tool characteristics, the effects of the specific design features on biomechanical demands are well established from published research. For others, the effects are not well grounded in research data. The field component will be an intervention study comparing hand tools that rank at the low and high ends of the checklist in terms of the required posture grip force and subjective discomfort. The validated checklist should differentiate tools that require high levels of musculoskeletal loading and those that require low levels. Results of the laboratory and field validation studies will be used to revise the checklist as needed.

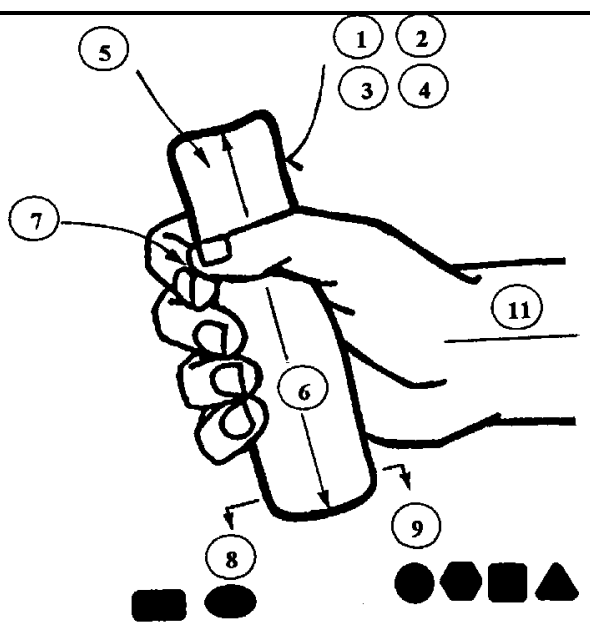

KEYWORDS: Exposure assessment, musculoskeletal disorders, repetitive stress injury, hand tools

\section{RECENT CITATIONS:}

Dababneh, A., and T. Waters. 1999. The ergonomic use of hand tools: Guidelines for the practitioner. Applied Occupational and Environmental Hygiene, v. 14, pp. 208-215. 


\section{TEMPORAL AND IMPULSIVE CHARACTERISTICS OF HAND TOOLS}

KEYWORDS: Vibration, musculoskeletal disorders

\section{RESEARCHER: Martin Cherniak}

\section{AFFILIATION: University of Connecticut (860) 679-4095}

PURPOSE: Explore the effects of tool impulse, temporal pattern, and highand low-frequency acceleration on acute physiological responses among users of hand tools.

RESEARCH SUMMARY: Repetitive shock and vibration are routinely encountered when using both powered and nonpowered hand tools. The use of these tools has been associated with injuries to the arm, shoulder, and neck and with neurologic and neurovascular disorders of the hand. Standards for the control of disease from vibration (in particular ISO 5349) have been shown to be inapplicable to tools having a large impact component (for example, hammers).

Acute physiological responses to repetitive shock and vibration are transient threshold shifts (TTS) in the three major classes of mechano-receptors of the fingertip - slow-acting I (SAI), fast-acting I (FAI), and fast-acting II (FAII) - and changes in surface electromyogram. No prior TTS experiment has attempted to detect response thresholds in the SAI and FAI receptors, which are the two most important mechano-receptor nerves controlling muscle activity.

Understanding the cause of TTS deficits should provide useful insights on the nature of shorter-term functional sensory problems, which may be pertinent to hand-arm dysfunction and acute traumatic injury. Accordingly, construction workers who use powered and nonpowered impact hand tools and who have high rates of hand injury are the target population of this study. Tool characteristics will be simulated in the laboratory, after which laboratory results will be applied to actual tools. Goals include addressing unresolved scientific questions on the risks from extrinsic forces associated with hand tools and the development of reliable, effective field assessment methods. 


\section{COMPARISON OF AVIATION SNIP DESIGN FOR SHEET METAL WORKERS}

\section{RESEARCHER: Dan Anton}

\section{AFFILIATION: University of lowa (319) 335-4425 \\ CONSORTIUM: Center to Protect Workers' Rights}

PURPOSE: Compare musculoskeletal load on sheet metal workers during the use of aviation snips of different designs while the workers are in different positions and different work postures.

RESEARCH SUMMARY: Awkward postures and forceful exertions of the forearm and upper extremity may contribute to work-related musculoskeletal disorders, such as carpal tunnel syndrome, wrist tendinitis, and rotator cuff syndrome. Modification of typical snip designs has been proposed as an intervention that could reduce these work-related physical actions. However, limited research has been conducted on many tools before they are marketed as "ergonomic tools."

Using three different designs of aviation snips, 20 third- and fourth-year apprentice sheet metal workers from Sheet Metal Local 91 cut circular holes repetitively in 24-gauge sheet metal panels positioned waist and shoulder high. One tool was commonly used to make a curved cut (standard snip, also called a right or a left snip). The second tool was a straight-cut design with a modified handle, and the third was an aviation snip with the blade modified to a $90^{\circ}$ angle from the handle (angled blade) to allow easier overhead cuts. Muscular loads on the worker's dominant forearm (finger flexors, wrist extensors) and upper back (upper trapezius) were evaluated with electromyography while the worker made the cuts. Likewise, the posture of the dominant wrist was evaluated with electrogoniometry during the cuts. After making three waist-high and three shoulder-high cuts at random, workers subjectively evaluated the different designs on a 0 -to- 10 scale for such factors as maneuverability, grip feel, and force required to cut.

Preliminary results indicated that the modified-handle snip required over $40 \%$ more exertion of the finger and wrist flexors than the other two snips while used at waist level. The standard snip at waist level required approximately $30 \%$ more exertion of the wrist extensors than the other two snips, while use of the angled-blade snip resulted in more than a $100 \%$ reduction in load on the upper back muscles compared to the other designs. Despite being originally developed for easier overhead cutting and the workers' favorite snip at shoulder level, the angled-blade snip required an increase in load of more than $300 \%$ on the upper back muscles if used at shoulder level. Both the curved and upright snips reduced forearm muscle load if used at shoulder level.

The results indicate that tool modifications may have both beneficial and deleterious effects on different muscles, and that all muscles are not positively affected by interventions. Similarly, an "ergonomic tool" may not reduce load in the way the designer planned. Sheet metal workers may benefit from using a variety of aviation snips, depending on the task, and should be educated in their proper use.
KEYWORDS: Electrogoniometry, electromyography, ergonomics, hand tools, interventions, musculoskeletal disorders, overhead work, posture, upper extremities

\section{RECENT CITATIONS:}

Welch, L.S., K.L. Hunting, and J. Kellogg. 1995. Work-related musculoskeletal symptoms among sheet metal workers. American Journal of Industrial Medicine, v. 27, pp. 783-791. 


\section{HEALTH EFFECT OF CONSTRUCTION POWER TOOLS ON THE HAND AND WRIST}

\section{RESEARCHER: John Rosecrance}

\section{AFFILIATION: Colorado State University (970) 491-1405 \\ CONSORTIUM: Center to Protect Workers' Rights}

PURPOSE: Determine if the use of power grinders (such as those used in a tuck-pointing task) during a 6-hour period alters median and/or ulnar nerve function across the wrist.

RESEARCH SUMMARY: Tasks involving the intensive use of the hands and wrists have been associated with upper limb disorders such as carpal tunnel syndrome and vibration white finger. A slowing of nerve conduction velocity, similar to that found in the electrodiagnosis of carpal tunnel syndrome, may occur as a result of short-term exposure to stressful work activities.

This study investigated changes in nerve conduction velocity of the median and ulnar nerves across the wrist during 6 hours of highly intensive power grinding tasks similar to the task of tuck-pointing. Sensory nerve conduction velocities were measured in hands of workers before work and then at 2-hour intervals during the workday. The conduction velocities slowed across the wrist in the median and ulnar nerves for workers performing the grinding task, but not for control workers performing low-intensity hand tasks.

This investigation demonstrated that short-term exposure to highly intensive hand tasks involving vibration, forceful exertions, and awkward hand positions causes significant slowing of nerve conduction velocity across the wrist.

Prolonged exposure to highly intensive occupational hand tasks, for example, during the use of power grinders, may lead to disorders such as vibration white finger or carpal tunnel syndrome.
KEYWORDS: Musculoskeletal disorders, carpal tunnel syndrome, vibration white finger 
ERGONOMIC STUDY OF DRYWALL FINISHING TOOLS AND TASKS

\section{RESEARCHERS: Gregory Shaw and Tom Joyce}

\section{AFFILIATION: Midstate Education and Service Foundation \\ (607) 277-5670 \\ CONSORTIUM: Center to Protect Workers' Rights}

PURPOSE: Identify the ergonomic risks of drywall finishing and identify and test ways to reduce those risks.

RESEARCH SUMMARY: The drywall finishing trade is physically demanding. The tasks are highly repetitive, require significant force, and involve many awkward postures. Most finishers develop musculoskeletal injuries during their careers. In a recent survey of a small group of drywall finishers, the following symptoms were reported by the workers during the past 12 months: elbow and forearm pain, $88 \%$; back pain, $75 \%$; hand/wrist pain, $63 \%$; neck pain, $38 \%$; and shoulder pain, $38 \%$. Almost all of these workers reported that the pain and discomfort were moderate or severe.

In this study, finishers from Painters Local 178 were surveyed, interviewed, and videotaped to identify the tasks, techniques, and tools most responsible for this high injury rate. We found that all tasks have risks associated with them, but finishing with automatic tools and hand finishing represented the most serious or common problems.

- Automatic tools. Automatic tools include flat boxes, tape guns, tape banjos, and pumps used to fill the tools with drywall compound. A high degree of force is required to use these tools, as well as a combination of pulling, pushing, bending at the waist, and other repetitive physical movements. Several new types of tools were tested and evaluated to study whether they could reduce the amount of force required in finishing yet be accepted by finishers. Results show that they can be both efficient and used more safely than traditional tools.

- Hand finishing. Risk factors in hand finishing include the high frequency of repetitions of the arm and hand movements and awkward leg, torso, shoulder, arm, and wrist postures. Hand finishing requires constant reaching overhead and bending to the floor, often within seconds of one another.

Finishers are also required to adopt extreme wrist postures to smooth the wall joint.

From our analysis of hand finishing, we believe the design of hand knives can significantly alter wrist posture and the forces required to grip the handle and to smooth the joint. We are analyzing the design factors (handle shape, size, composition, and orientation to the blade; blade flexibility, depth, and composition) and finisher techniques, all of which affect the way knives are used. The results will be used to develop recommendations for best practices in the trade.
KEYWORDS: Ergonomics, drywall finishing, best practices 


\section{BIOMECHANICS OF OCCUPATIONAL SHOULDER INJURIES}

\section{RESEARCHER: Andrew Karduna}

\section{AFFILIATION: MCP Hahnemann University (215) 762-5057}

PURPOSE: Determine if repetitive arm motion will lead to altered shoulder kinematics. Develop a simple index of muscle fatigue that is associated with repetitive arm motion and altered scapular kinematics.

RESEARCH SUMMARY: Although NIOSH has identified a clear epidemiological link between repetitive arm motion and shoulder disorders in the workplace, there are few scientific data available regarding the biomechanics of this connection. This is surprising considering that occupational shoulder disorders have a direct medical cost of $\$ 4$ billion annually in the United States.

There is evidence that repetitive motion is associated with muscle fatigue and abnormal shoulder motion, which in turn may lead to damage of the rotator cuff musculature. It is hypothesized that fatigue of the scapular muscles during a repetitive arm motion will result in a decrease in scapular motion. A fatigue index based on a muscle's electromyographic frequency components has been shown to be a good predictor of muscle impairment for low-back muscles. It is hypothesized that a similar index for scapular muscles could be associated with alterations in scapular kinematics after repetitive motion.

These hypotheses will be tested by having healthy volunteers with no shoulder pathologies perform a simulated work activity until they are fatigued. Based on NIOSH findings, this will be a high-repetition, low-load activity.

Kinematics will be measured with a magnetic tracking device that has been found to be both reliable and accurate for measuring scapular motion. Fatigue susceptibility will be identified with a previously established muscle fatigue index. This proposal represents the first step toward developing a screening tool for assessing an individual's ability to resist the potentially harmful consequences of repetitive motion. Ultimately, this information will be used to develop both strategies for modifying work tasks, as well as conditioning programs for workers performing high-risk activities.
KEYWORDS: Ergonomics, repetitive strain injury, musculoskeletal disorders

\section{RECENT CITATIONS:}

Karduna, A., et al. 2002. Effects of low-load, high-repetition motion on scapular kinematics. Presentation at the World Congress of Biomechanics, Calgary, AB, Aug. 2002. 


\section{EFFECTS OF A HOME EXERCISE PROGRAM ON SHOULDER PAIN, MOTION, AND MUSCLE ACTIVITY IN CONSTRUCTION WORKERS}

\section{RESEARCHER: Paula M. Ludewig}

\section{AFFILIATION: University of Minnesota \\ (612) 626-0420}

\section{CONSORTIUM: Center to Protect Workers' Rights}

PURPOSE: Implement and evaluate a therapeutic exercise program to reduce pain and modify previously identified motion and muscle activity alterations in construction workers with shoulder pain related to working overhead.

RESEARCH SUMMARY: Repetitive or sustained elevated shoulder postures have been identified as a significant risk factor for occupationally related musculoskeletal disorders of the shoulder. Construction workers exposed to routine overhead work have high rates of shoulder pain that frequently progresses to functional loss and disability. Exercises may be able to reduce this progression.

One-hundred-eight volunteer workers from the construction trades (Sheet Metal Local 10, Electric Locals 29 and 110, Pipefitters Local 539, Plumbers Local 34, and Heat and Frost Insulators Local 34) were screened by their histories and clinical examinations for criteria consistent with shoulder pain and impingement syndrome. Sixty-seven symptomatic workers were randomized into a treatment intervention group (34 people) and a control group (33 people); 25 asymptomatic people participated as an additional control group. All subjects were male; mean age was 48 . Subjects completed the Shoulder Rating Questionnaire (SRQ), a shoulder satisfaction rating, and answered additional work-related questions about shoulder pain and disability. They were then measured for electromyographic activity of shoulder muscles and shoulder joint kinematics during arm elevation motions. Subjects in the treatment group were given instructions for a standardized 8-week home program consisting of five shoulder stretching and strengthening exercises. Subjects in the control groups received no instruction. After 8 to 12 weeks, the subjects returned for follow-up tests. Four intervention and three control subjects were lost from follow-up.

Two-factor (group by time) analysis of variance was used to compare dependent variables (questionnaire scores, shoulder kinematics, and shoulder muscle activity between groups) over time with a significance level of $p<0.05$. The home exercise group demonstrated significantly greater improvements in the SRQ and shoulder satisfaction scores than did the control groups, as well as significantly greater reductions in pain and disability than the control subjects. Average post-test SRQ scores for the exercise group remained below levels for asymptomatic workers. Preliminary results indicate positive improve-ments in motion and muscle activity variables as well.
These results suggest a home exercise program can be effective in reducing symptoms and improving function in construction workers with shoulder pain.

KEYWORDS: Ergonomic interventions, motion analysis, shoulder musculoskeletal disorders, overhead work, electromyography

\section{RECENT CITATIONS:}

Ludewig, P.M., and T.M. Cook. 2000. Alterations in shoulder kinematics and associated muscle activity in people with symptoms of shoulder impingement. Physical Therapy, v. 80, pp. 276-291.

Ludewig, P.M., and J.D. Borstad. 2002. Effects of a home exercise program on shoulder symptoms and functional status in construction workers. Journal of Orthopedic Sports Physical Therapy, v. 32, p. A-9.

Ludewig, P.M. and T.M. Cook. 2002. Translations of the humerus in persons with shoulder impingement symptoms. Journal of Orthopedic Sports and Physical Therapy, v. 32, pp. 248-259. 


\section{EFFECTS OF A HOME EXERCISE PROGRAM ON PREVENTING SHOULDER PAIN IN CONSTRUCTION APPRENTICES}

\section{RESEARCHER: Paula M. Ludewig}

\section{AFFILIATION: University of Minnesota (612) 626-0420}

\section{CONSORTIUM: Center to Protect Workers' Rights}

PURPOSE: Develop and evaluate an exercise and stretching program for preventing shoulder pain among construction workers involved in overhead work.

RESEARCH SUMMARY: Repetitive or sustained elevated shoulder postures have been identified as a significant risk factor for occupationally related shoulder musculoskeletal disorders. Construction workers exposed to routine overhead work have high rates of shoulder pain that frequently progresses to functional loss and disability. Exercise interventions have the potential for reducing this progression and have been shown to reduce shoulder pain and disability in journeymen construction workers.

Three-hundred apprentice construction workers are being recruited from the electrical, sheet metal, and plumbing and pipefitting trades (Sheet Metal Local 10, Electric Local 110, Pipefitters Local 539, and Plumbers Local 34). The apprentices (matched by trade) will be randomized into an exercise intervention group or a control group. Subjects will complete questionnaires on an annual basis to provide demographic, occupational exposure, and musculoskeletal symptom and injury information. Subjects randomized to the intervention group will be instructed about a standardized home program of shoulder stretching and strengthening exercises, while subjects in the control group will either receive information on stretching and strengthening exercises for the knee joint or no instruction. Subjects will be reevaluated annually for 3 years. Newly reported cases of shoulder pain confirmed by clinical screening will be incorporated annually. Three-year incidence rates will be compared across the intervention and control groups using chi-square analysis to determine if a home exercise program can effectively reduce the development of occupationally related symptoms of shoulder disorders.
KEYWORDS: Ergonomic interventions, overhead work, shoulder musculoskeletal disorders, prevention 


\section{EFFECT OF OVERHEAD DRILLING POSITION ON SHOULDER MOMENT AND ELECTROMYOGRAPHY}

\section{RESEARCHER: Dan Anton}

\section{AFFILIATION: University of lowa \\ (319) 335-4425 \\ CONSORTIUM: Center to Protect Workers' Rights}

PURPOSE: Determine the effects of moving closer to work overhead while standing on a stepladder and performing simulated drilling tasks.

RESEARCH SUMMARY: Forceful exertion during tasks in which the arms are positioned overhead, such as drilling into a ceiling, may be associated with various upper-extremity musculoskeletal disorders. Extended reaches while working overhead may substantially increase upper extremity load. However, little is known whether altering upper body posture changes the load on the shoulder and upper extremity.

Twenty subjects simulated an overhead drilling task using a close-, middle-, and far-reach position while standing on either the lower or higher step of a stepladder. Muscular loads of the dominant side anterior deltoid, biceps brachii, and triceps brachii were recorded with surface electromyography. Shoulder joint moment was determined by two-dimensional static link segment modeling in the sagittal plane with a digital video. The results demonstrated that using the close-reach position significantly decreased the muscular load on the anterior deltoid and biceps brachii, but increased load on the triceps brachii when compared to the far-reach position. Using the higher step significantly decreased anterior deltoid and triceps load as well as shoulder joint moment compared to using the lower step. However, load on the biceps increased when using a close reach while on the higher step. Shoulder joint moment increased monotonically with muscular load.

These findings indicate that construction workers should generally work close to their bodies to minimize shoulder forces when performing overhead tasks.
KEYWORDS: Biomechanics, electromyography, ergonomics, musculoskeletal disorders, overhead work, posture, upper extremities

\section{RECENT CITATIONS:}

Anton, D., L.D. Shibley, N.B. Fethke, J. Hess, T.M. Cook, and J.

Rosecrance. 2001. The effect of overhead drilling position on shoulder moment and electromyography.

Ergonomics, v. 44, pp. 489-501.

Anton, D., L.D. Shibley, N.B. Fethke, J. Hess, T.M. Cook, and J.

Rosecrance. 2002. Effect of step height on overhead drilling in construction. Presentation at 14 th Triennial Congress of the International Ergonomics Association and 44th annual meeting of the Human Factors and Ergonomics Society. 


\section{COMPARISON OF RISK FACTORS IN CON- STRUCTION TRADES WITH CONTRASTING PREVALENCE OF CARPAL TUNNEL SYNDROME}

\section{RESEARCHER: Dan Anton}

\section{AFFILIATION: University of lowa \\ (319) 335-4425}

\section{CONSORTIUM: Center to Protect Workers' Rights}

PURPOSE: Investigate muscle load on the forearms of workers in two construction trades and associate these loads with the prevalence of carpal tunnel syndrome.

RESEARCH SUMMARY: Recent evidence suggests that carpal tunnel syndrome is prevalent among construction workers, particularly among heavy equipment operators (approximately 7\%) and heavy equipment mechanics (27\%). Little is known about exposure to the physical risk factors for carpal tunnel syndrome in these trades and their effects, partly because the work is noncyclic and highly variable. However, it is known that forceful exertion of the forearm may be associated with carpal tunnel syndrome or tendinitis.

Muscular load on the dominant finger flexors of 24 heavy equipment operators and 24 heavy equipment mechanics were recorded using surface electromyography for approximately 1 hour of normal work. Exposure variation analysis and clustered exposure variation analysis (CEVA), a new method of describing work exposure, were used to evaluate the forces produced by the forearm in these two trades.

The results of CEVA indicated that the mechanics spent $9 \%$ of their work time performing high-intensity, short-duration contractions of the forearm, while operators spent only $2 \%$ of their time. Mechanics spent $19 \%$ of their time performing moderate-intensity, short-duration contractions, contrasted to operator time at $7 \%$. Operators spent a disproportionate amount of work time with either low levels of forceful exertion or resting the flexor forearm. The operators and mechanics did not differ significantly in typical nonwork-related variables (e.g., body weight) often associated with carpal tunnel syndrome.

Since mechanics may spend approximately $70 \%$ of their workday using tools, greater efforts to develop ergonomic interventions for this group may be indicated. Other types of intervention, such as increasing the amount of power tool use, may be needed.
KEYWORDS: Carpal tunnel syndrome, electromyography, ergonomics, exposure assessment, operating engineers, mechanics, musculoskeletal disorders, upper extremity.

\section{RECENT CITATIONS:}

Anton, D. 2002. A comparison of risk factors in construction trades with contrasting prevalence of carpal tunnel syndrome. Doctoral dissertation, University of Iowa. 


\section{CARPAL TUNNEL SYNDROME AMONG APPRENTICE CONSTRUCTION WORKERS}

\section{RESEARCHER: John Rosecrance}

\section{AFFILIATION: Colorado State University (970) 491-1405 \\ CONSORTIUM: Center to Protect Workers' Rights}

PURPOSE: Characterize the prevalence of carpal tunnel syndrome among construction apprentices.

RESEARCH SUMMARY: Symptom surveys and nerve conduction studies used to identify carpal tunnel syndrome were administered to 1,142 construction apprentices from four trades (sheet metal, electrical, plumbing and pipefitting, and operating engineers). The prevalence of carpal tunnel syndrome among all apprentices was $8.2 \%$. Within the operating engineer trade, the prevalence of carpal tunnel syndrome was seven times greater among the mechanics working on heavy equipment than among drivers of that equipment. Body mass index, age, and self-reports of working overhead were associated with prevalent carpal tunnel syndrome. Less than $15 \%$ of the apprentices with carpal tunnel syndrome sought medical attention for their disorder. Many construction workers begin developing carpal tunnel syndrome before or during their apprenticeship training. Few apprentices seek medical attention for the hand symptoms characteristic of carpal tunnel syndrome. The results of this study indicate a public health need for the implementation of prevention strategies for carpal tunnel syndrome in the construction industry.

This study provides a better understanding of the specific work factors associated with carpal tunnel syndrome, supplies data for planning future projects to study the natural history of this disease, and assists in the development of strategies for its prevention in construction and nonconstruction workplaces.
KEYWORDS: Carpal tunnel syndrome, musculoskeletal disorders

\section{RECENT CITATIONS:}

Rosecrance, J., T.M. Cook, D. Anton, and L. Merlino. (In press.) Prevalence of carpal tunnel syndrome among apprentice construction workers. American Journal of Industrial Medicine. 


\section{INFLUENCE OF PHYSICAL WORKPLACE FACTORS ON THE DEVELOPMENT OF CARPAL TUNNEL SYNDROME AMONG CONSTRUCTION WORKERS}

\section{RESEARCHER: John Rosecrance}

\section{AFFILIATION: Colorado State University (970) 491-1405}

\section{CONSORTIUM: Center to Protect Workers' Rights}

PURPOSE: Gain insight into the etiology of carpal tunnel syndrome and determine the physical factors at construction workplaces that contribute to carpal tunnel syndrome.

RESEARCH SUMMARY: Construction is consistently ranked among the most dangerous industries and accounts for a disproportionately large percentage of occupational illnesses and injuries. Of all work-related disabling conditions in the United States, carpal tunnel syndrome accounts for the largest number of missed workdays on a per-case basis. Previous research into the prevalence of carpal tunnel syndrome among construction workers indicates it is nearly three times that of the general population. However, the causes and consequences of carpal tunnel syndrome among the 8 million people employed in the U.S. construction industry have not been investigated.

The central hypothesis of this study is that carpal tunnel syndrome will increase as exposure to stressful physical factors in the workplace increases. This hypothesis will be tested by (1) estimating the incidence rate of carpal tunnel syndrome among 1,100 construction trade workers and stratifying the incidence estimates by specific construction trades, (2) characterizing exposures to physical workplace factors among construction workers quantitatively using methods developed specifically for the highly variable noncyclic tasks common among the construction trades, and (3) estimating the risk of carpal tunnel syndrome associated with exposure to physical workplace factors while controlling for confounding variables (such as age, body mass index, gender).

The research will build on an established cohort of more than 1,100 construction workers and will be the first cohort study of incident carpal tunnel syndrome among construction workers. It will also be one of the few studies of musculoskeletal disorders that will incorporate a stringent epidemiologic classification of carpal tunnel syndrome and a direct quantitative exposure assessment. One outcome of the research will be a useful quantitative exposure assessment tool for measuring physical risk factors in a variety of work environments. The knowledge gained from this research will provide a better understanding of the etiology of carpal tunnel syndrome and lead to the development of interventions that have a positive impact on the prevention of carpal tunnel syndrome and other musculoskeletal disorders.

Collaborators on this project include Quad Cities Electrical Joint Apprenticeship and Training Committee, Operating Engineers Local 150,
Sheet Metal Local 91, and the Plumbers and Steamfitters Local 290 Training Center.

KEYWORDS: Carpal tunnel syndrome, apprentices, prevalence 


\section{MUSCULOSKELETAL DISORDERS AMONG APPRENTICE CONSTRUCTION WORKERS}

\section{RESEARCHER: John Rosecrance}

\section{AFFILIATION: Colorado State University (970) 491-1405 \\ CONSORTIUM: Center to Protect Workers' Rights}

PURPOSE: Examine the frequency of self-reported musculoskeletal disorder symptoms, the frequency of work missed due to these symptoms, and factors that may be associated with these conditions in four construction trades.

RESEARCH SUMMARY: Musculoskeletal disorders are a major cause of work-related disabilities and lost-time illnesses. Workers in the construction trades have the second highest incident rate for reported illnesses and injuries. With about 8 million people employed in the construction industry, this represents a substantial problem. Data are limited on the prevalence of musculoskeletal disorders among construction workers and the factors that may be associated with these disorders. In addition, determination of what factors contribute to lost time by workers who do report musculoskeletal symptoms is lacking. Information on these factors may contribute to finding solutions to reduce absenteeism.

Self-administered surveys among a cohort of apprentice construction workers in four trades (plumbing, electrical, sheet metal, and operating engineer) from four states were obtained. The results indicate that the low back was the body area most commonly reported for job-related musculoskeletal injuries among all workers in all trades. Pain in the low back was also the most common reason for missing work among construction workers. The wrist/hand and knee also appear to be sites of problems for apprentice construction workers. Continuing to work with an injury is the factor most commonly identified with missing work.

Musculoskeletal disorders are a significant problem among young construction workers at the beginning of their careers. Primary and secondary prevention strategies are needed early in the apprentice training program to reduce disabilities associated with work-related musculoskeletal disorders.

Construction trade collaborators include the Quad Cities Electrical Joint Apprenticeship and Training Committee, Operating Engineers Local 150, Sheet Metal Local 91, and the Plumbers and Steamfitters Local 290 Training Center.
KEYWORDS: Musculoskeletal disorders, job risk factors, injury

\section{RECENT CITATIONS:}

Merlino, L., J.C. Rosecrance, D. Anton, and T.M. Cook. (Jan. 2003. In press.) Musculoskeletal disorders and job factors among apprentice construction workers. Applied Occupational and Environmental Hygiene. 


\section{MUSCULOSKELETAL DISORDERS AMONG APPRENTICE AND EXPERIENCED HUNGARIAN CONSTRUCTION WORKERS}

\section{RESEARCHER: John Rosecrance}

\section{AFFILIATION: Colorado State University (970) 491-1405}

PURPOSE: Determine the prevalence of occupationally related musculoskeletal disorders and carpal tunnel syndrome among construction workers in Hungary.

RESEARCH SUMMARY: Symptoms of occupational musculoskeletal disorders and the job factors contributing to these symptoms were determined through an administered symptom and job factors survey. The prevalence of carpal tunnel syndrome was assessed among apprentices on the basis of a case definition that included hand symptoms and nerve conduction studies of the median nerve across the carpal tunnel. The participation rate was $96 \%$ among the 201 eligible construction apprentices and 65 experienced construction workers. The average ages of the apprentices and experienced construction workers were 17 and 48 years, respectively.

More than $50 \%$ of the apprentices reported occupationally related musculoskeletal symptoms in the previous 12 months. Job tasks that required awkward postures and working in a static position were the two factors that contributed most to musculoskeletal disorders. No cases of carpal tunnel syndrome were found in this sample of apprentices. In a pilot project of 65 Hungarian journeyman construction workers, the prevalence of musculoskeletal disorders in all parts of the body, number of missed work days, and visits to physicians were nearly twice as high for experienced workers as compared to apprentices. For example, $58 \%$ of the 65 experienced construction workers reported work-related musculoskeletal disorders in the low back as compared to $30 \%$ of the apprentices. (It was surprising, however, that apprentices in their late teens reported work-related musculoskeletal disorders at such an early age.) Whereas $42 \%$ of experienced Hungarian construction workers missed work due to low back symptoms, only $12 \%$ of the apprentices missed work for this reason. This difference suggests that the musculoskeletal disorders among apprentices may be less severe than those among experienced construction workers.

The higher prevalence of symptoms among experienced construction workers is likely to be related to a combination of factors, including general health, age, and the cumulative physical stresses involved with construction tasks.

Although disorders of the musculoskeletal system are more prevalent among experienced construction workers, this study indicates that symptoms of musculoskeletal disorders are present among young workers. Assessing the magnitude and nature of occupation-related musculoskeletal disorders is the first step in promoting a healthier, safer, and more efficient workforce.
KEYWORDS: Carpal tunnel syndrome, musculoskeletal disorders, Hungary

\section{RECENT CITATIONS:}

Rosecrance. J.C., J. Proszasz, T. Cook, D. Anton, E. Fekecs, and T.T. Karacsony. 2000. Musculoskeletal disorders among young apprentices and journey-level construction workers in Hungary. Ergonomics, v. 43 , no. 7 , pp. $640-643$.

Rosecrance, J., J. Proszasz. E. Fekecs T. Karacsony, L. Merlino, D. Anton, and T. Cook. 2001. Musculoskeletal disorders among Hungarian construction apprentices. Central European Journal of Public Health, v. 9, no. 4 , pp. 183-187. 


\section{OCCUPATIONAL LOW BACK PAIN IN RESIDENTIAL CARPENTRY: ELEMENTS OF POSTURE AND STRAIN}

\section{RESEARCHERS: David Gilkey and Robin Herron}

\section{AFFILIATION: Colorado State University} (970) 491-7138

PURPOSE: Identify and measure potential ergonomic job-task-related causes of occupational back pain among carpenters engaged in residential construction framing.

RESEARCH SUMMARY: Occupational back pain is America's No. 1 workplace safety challenge. Back pain is second only to the common cold as a cause of lost gainful employment. Estimates of primary and secondary costs to the nation's economy because of back pain range from $\$ 50$ to $\$ 100$ billion annually.

Ergonomic elements have been implicated in the onset of back pain in many industries, and construction has been identified as an industry with excessive numbers of sufferers of back pain because it requires heavy physical demands to complete many tasks.

The relationship of personal and worksite characteristics to work practices, environmental exposures, job tasks, and back pain will be evaluated among 350 carpenters engaged in residential framing. The study will involve focus groups, job site ergonomic analyses, and surveys to identify job tasks being performed and perceived exertion rating, and establish quantitative measures of spinal loading. The immediate, 12-month, and lifetime prevalence of low back pain among workers will be determined. The software programs ErgoMaster and Ovako Working Posture Analysis will be used to assess posture and loading. The forces perceived by workers as they complete tasks will be compared to measured demands. An integrated model for the prediction of back pain in residential carpentry will be developed using subjective and objective variables.

The ultimate goal of this study is to lay the groundwork for preventing back injuries among residential construction workers by a better understanding of the actual causes.
KEYWORDS: Low back disorders, carpenters, residential construction 


\section{EFFECT OF LIGHTWEIGHT BLOCK ON MUSCULAR LOAD AND CARDIOVASCULAR STRESS IN BRICKLAYERS}

\section{RESEARCHER: Dan Anton}

\section{AFFILIATION: University of lowa \\ (319) 335-4425}

\section{CONSORTIUM: Center to Protect Workers' Rights}

PURPOSE: Determine the effects of using lightweight concrete blocks on muscle activity, physiological variables, and fatigue compared to using standard-weight concrete blocks.

RESEARCH SUMMARY: Work-related musculoskeletal disorders of the low back, shoulder, and upper extremity are common in the masonry trade. Repetitive heavy lifting of concrete blocks and awkward postures may contribute to these disorders. However, few interventions have been proposed that could reduce these risk factors. An 8- by 8- by 16-in (20.3- by 20.3- by $40.6-\mathrm{cm})$ standard concrete block weighs approximately $38 \mathrm{lb}(17.2 \mathrm{~kg})$. A similar-sized lightweight concrete block weighs approximately $10 \mathrm{lb}(4.5 \mathrm{~kg})$ less. Little is known about the physiological effects of laying lightweight block compared to laying standard block.

Twenty-one third- and fourth-year apprentices or journeyman bricklayers from the International Union of Bricklayers and Allied Craftworkers Local No. 3 of Iowa participated in the study. Each subject constructed two walls 80 in wide by 55.5 in high ( 203.2 by $141.0 \mathrm{~cm}$ ), seven courses high, in a running bond pattern in the laboratory. One wall was constructed with standard concrete block and one with lightweight concrete block. The bricklayers were instructed to lay the block at their usual work pace and to lay mortar in the typical fashion. The musculoskeletal load of the bricklayers' bilateral low back (erector spinae), upper back (upper trapezius), and finger flexors, as well as the dominant side wrist extensors, were recorded telemetrically with surface electromyography while the wall was constructed. Heart rate was also telemetrically recorded.

Preliminary results suggest a substantial reduction in muscle load on the upper back while laying lightweight block, especially at the higher courses. No difference was noted in posture using either type of block. The bricklayers in the study constructed the wall slightly faster using the lightweight block.
KEYWORDS: Bricklaying, electromyography, ergonomic interventions, low back and upperextremity musculoskeletal disorders 


\section{EVALUATION AND INTERVENTION IN CONSTRUCTION OR DEMOLITION OF CONCRETE STRUCTURES}

\section{RESEARCHER: Bryan Buchholz}

\section{AFFILIATION: University of Massachusetts- Lowell (978) 934-3241}

CONSORTIUM: Center to Protect Workers' Rights

PURPOSE: Evaluate the methods, tools, and work reorganizations designed to reduce exposure to risks for musculoskeletal disorders in concrete work and other stages of construction.

RESEARCH SUMMARY: Construction workers have the highest rates of musculoskeletal disorders of any industrial population. Evaluation of the risk factors for developing musculoskeletal disorders is difficult because of the dynamic nature of the industry. Previous work within the Construction Occupational Health Program at the University of Massachusetts led to the development of an ergonomic assessment tool that enabled the quantification of risk in the nonroutine work environments characteristic of construction. The present 5-year study continues to develop the PATH (posture, activities, tools, handling) method for studying the postural risk associated with various tasks in the construction or demolition of concrete structures and examines the impact of ergonomic improvements on defined construction tasks by comparing tasks with and without interventions.

Tasks identified as having high risks for musculoskeletal injury were considered for possible ergonomic interventions. These tasks were selected on the basis of outcomes of construction ergonomics training in the trades, informal interviews and data collection, observations by trained ergonomics professionals, and health and safety committees. For example, two alternative methods for manually moving slickline (concrete hose) were compared using 530 pre- and post-PATH observations. An articulated arm attached to the end of the slickline showed a decrease in trunk flexion and a decrease in force. A slide skid showed an increase in trunk deviation, and forces are still being calculated. Other on-going investigations include studies of abrasive blasting, rebar tying, concrete reinforcement construction, and concrete form construction. Information from this study is being disseminated in local newsletters and project-related networks in the area for practical use by industry.
KEYWORDS: Musculoskeletal disorder, highway construction, constructing or deconstructing concrete structures

\section{RECENT CITATIONS:}

Buchholz, B., V. Paquet, H. Wellman, and M. Forde. (In press.) Quantification of ergonomic hazards for ironworkers performing concrete reinforcement tasks during heavy highway construction. American Industrial Hygiene Association Journal. 


\section{WORK ORGANIZATION ISSUES IN CONSTRUCTION: THE RELATIONSHIP BETWEEN OVERTIME AND INJURY}

\section{RESEARCHER: Linda Goldenhar}

\section{AFFILIATION: Division of Applied Research and Technology National Institute for Occupational Safety and Health \\ (513) 558-6936}

PURPOSE: Examine the relationship between working overtime and injury among construction workers.

RESEARCH SUMMARY: Research has shown that working extended periods of overtime may be detrimental to the safety and health of workers. This feasibility study will look at the relationship between working extended periods of overtime and injuries among construction workers through secondary data analysis and interviews with construction workers. This project alone will not provide definitive answers as to the associations between construction-work-related organizational issues and health and safety.

However, it should provide some understanding of important relationships that can be further explored in larger studies.

The specific research questions to be investigated are (1) What is the relationship between working extended overtime hours and injury among construction workers? (2) Do injury rates increase after working a particular number of hours per week? (3) Is the relationship between hours worked and injury greatest among workers in high-risk trades or in jobs requiring heavy manual labor? (4) Are there specific trades that require more overtime? (5) What are the major factors that affect workers' schedules? (6) What are workers' perceptions of the hazards of working overtime?

This study includes a quantitative and a qualitative component. The quantitative component will be an analysis of data from the National Longitudinal Survey of Youth 1979-1996. This is a study of a representative sample of people who have been surveyed on annual basis from the time they were 14 to 22 years old in 1979 through 1996. The survey provides detailed information on work histories, work scheduling, and work-related injuries and illnesses. It is unique in that it includes data on the self-employed and both union and nonunion workers.

Qualitative data obtained from interviews with construction workers will be used to supplement the quantitative findings to provide some insights into issues not identified through quantitative statistical methods. The qualitative analyses should provide a more comprehensive picture of the relationship between the work organization variables of interest and safety and health, for example, how workers' experiences and perceptions of working overtime affect health and safety on the job or whether self-employment is related to the ability to self-regulate hours worked and therefore to quit when fatigued.

KEYWORDS: Work organization, injuries

\section{RECENT CITATIONS:}

Goldenhar, L.M., S. Hecker, S. Moir, and J. Rosecrance. Developing a model of overtime in construction: Not too much, not too little, but just right. Journal of Safety Research (submitted).

Goldenhar, L.M., S. Hecker, S. Moir and J. Rosecrance. 2002. Developing a model of overtime in construction: A qualitative investigation. Presentation at 8th annual Qualitative Health Research Conference, Banff, AB, April 4, 2002.

Goldenhar, L.M., S. Hecker, S. Moir and J. Rosecrance. 2002. A model of overtime in construction: Not too much, not too little, but just right. In Power Through Partnerships: 12th Annual Construction Safety and Health Conference, Proceedings (May 21-23, 2002, Rosemont, IL). 


\section{WORK SCHEDULING, OVERTIME, AND WORK- RELATED INJURIES IN CONSTRUCTION}

\section{RESEARCHER: Sue Dong}

\section{AFFILIATION: Center to Protect Workers' Rights (301) 578-8500}

PURPOSE: Examine work scheduling in construction and identify any association between work scheduling and overtime and work-related injuries.

RESEARCH SUMMARY: Research has shown that work organization factors, including work schedules and working extended periods of overtime, may be detrimental to the safety and health of workers. As described in the National Occupational Research Agenda, these factors may contribute to occupational injury, work-related musculoskeletal disorders, cardiovascular disease, and other occupational health concerns. Very few studies, however, have looked at this particular work organization variable within the construction environment and identified whether it has any negative impact on the safety and health of construction workers.

This study tries to answer the following research questions: (1) What are typical work schedules in construction and what differences in work scheduling exist between construction and other industries, (2) how is work scheduling influenced by factors such as economic conditions, technology, demographics, and employment performance, and (3) how does work scheduling and overtime affect the safety and health of construction workers.

The National Longitudinal Survey of Youth (1979 cohort) was used for this study. Initial findings are that (1) work scheduling in construction is different from scheduling in other industries, (2) hours worked per week and weeks worked per year increased steadily for all workers (construction and other industries) in this cohort during the study period, (3) injured workers were more likely to have worked overtime before being injured, and (4) overtime was significantly associated with work-related injuries in construction, especially for construction laborers, after controlling for sex, age, occupation, employment size, and other potential confounders.
KEYWORDS: Work hours, overtime, work organization

\section{RECENT CITATIONS:}

Dong, X. 2002. Scheduling/overtime and work-related injuries in construction. In Power Through Partnerships: 12th Annual Construction Safety and Health Conference, Proceedings (May 21-23, 2002, Rosemont, IL).

Dong, S., with R. Chowdhury, M. McCann, C. Trahan, and J. Gettleman. J. Seegal, editor. 2002. The Construction Chart Book: The U.S. Construction Industry and Its Workers, 3rd ed. Silver Spring, MD: The Center to Protect Workers' Rights. 


\section{ACUTE EYE INJURY EPIDEMIOLOGY}

\section{RESEARCHER: Larry Jackson}

\section{AFFILIATION: Division of Safety Research National Institute for Occupational Safety and Health \\ (304) 285-5980}

PURPOSE: Characterize occupational eye injuries through epidemiologic investigations of surveillance and workers' compensation data, conduct detailed telephone interviews with injured workers and industrial groups, and assess protective eyewear equipment use.

RESEARCH SUMMARY: Eye injuries account for about $5 \%$ of workrelated injuries. Based on data from the National Electronic Injury Surveillance System (NEISS), more than 260,000 occupational eye injuries were treated in emergency departments in FY96 and FY97. The highest rate of eye injuries, $16 \%$, was to construction workers. A majority of the injuries were due to foreign bodies in the eye and could have been prevented by appropriate use of personal protective equipment. However, in most cases, safety eyewear was not used or inappropriate eyewear was worn.

The primary focus of this work is on understanding the causes of and preventing acute eye injuries in the construction industry. Results will include a series of epidemiologic publications that will help define the nature of eye injuries in the workplace and the specific risk factors for injury. In addition, data will be collected to support the development of standards on eye and face protection and health communications for effective intervention techniques to prevent eye injuries. Through this work, we hope to assist the American National Standards Institute in developing new standards to best protect workers from occupational eye injuries.

The NEISS database was used to gain an all-industry perspective of eye injuries in the workplace and to focus attention on eye injuries among construction workers. A follow-back study and telephone interviews investigating the use of personal protective equipment and failure were conducted. The evaluation of injury reports and investigations from a large database of project compensation among construction workers is continuing. In addition, we are collaborating with West Virginia University to study eye injuries identified in the West Virginia Workers' Compensation database.

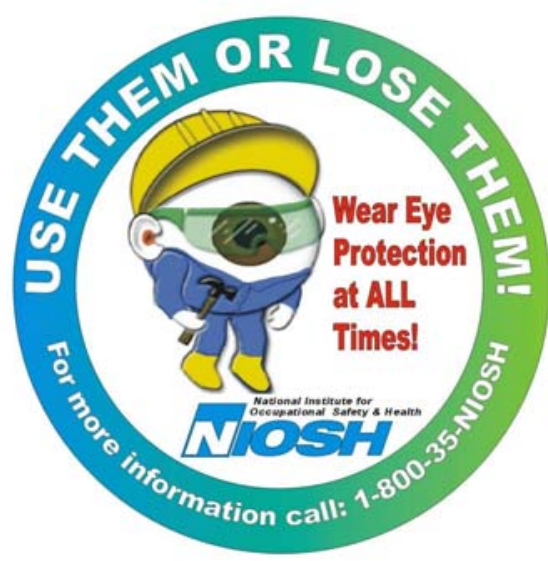

KEYWORDS: Eye injury, protective equipment

\section{RECENT CITATIONS:}

Disaster rescue and recovery worker-eye safety, available at (in English)

www.cdc.gov/niosh/eyesafe.html; (in Spanish) www.cdc.gov/spanish/niosh/docs/eye safeSP.html.

Sweeney, M.H., D. Fosbroke, L. Goldenhar, L.L. Jackson, K. Linch, B.D. Lushniak, C. Merry, S. Schneider, and M. Stephenson. 2000. Health consequences of working in construction. In Construction Safety and Health Management, R.J. Coble, J. Hinze, and T.C. Haupt, eds. Upper Saddle River, NJ: Prentice-Hall, pp. 211-234. 


\section{A STUDY OF ERGONOMIC INTERVENTIONS IN THE DRYWALL INDUSTRY}

\section{RESEARCHER: Christopher Pan}

\section{AFFILIATION: Division of Safety Research National Institute for Occupational Safety and Health \\ (304) 285-5978}

PURPOSE: Access the ability of current interventions to reduce the magnitude of biomechanical stresses induced on a body during handling, hanging, and finishing drywall sheets.

RESEARCH SUMMARY: On the basis of workers' compensation data from 21 states, drywall installers were ranked as one of the top four occupations at increased risk for occupational injury among 30 common construction specialties.

- A recent NIOSH study indicated that nearly half the injured drywall installers suffered sprains, strains, and tears, mostly to the back. About onethird of the trunk injuries occurred while lifting solid building materials, mainly drywall.

- In a survey of drywall installers, concern was expressed by workers that wearing stilts put them at greater risk for overexertion and increased the likelihood they would be involved in a fall than when they were using a ladder or scaffolding. The causal relationship between stilt use and fall and overexertion injuries will be evaluated using a dynamic biomechanical modeling approach to evaluate different loads and impacts (e.g., joint forces) from various hazards while using stilts and two-man lifts. Secondly, gait analyses of hanging/finishing tasks using stilts will be conducted.

- It is hypothesized that teamwork techniques may reduce disc compression forces in workers. However, two-man lifts may create coordination problems between two workers, which might lead to additional fall and trip injuries. Therefore, biomechanical stress levels when workers perform two-man lifts to handle drywall sheets will be assessed.

- Another component of the project is to measure the interface between the skin on the hand and the drywall sheet by measuring friction coefficient and grip force. A measurement device will be developed as a prototype tool for measuring grip and feed forces. If the grip force and duration of handling are identified as having the potential to cause injuries, a protective glove will be recommended to accompany handling methods.

The project includes both field and laboratory studies. The field component included on-site observations and videotaping to evaluate ergonomic hazards. Findings will provide feasible strategies for controlling physical stresses and fall hazards in drywall installation work, thereby promoting the safety and health of this sector of the construction population.

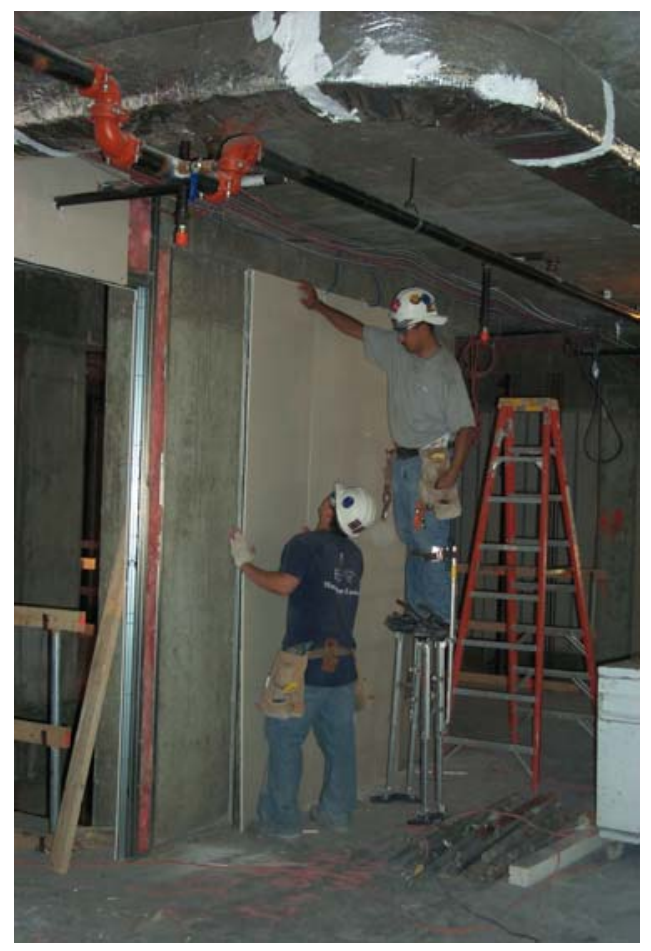

KEYWORDS: Traumatic injuries, safety, ergonomics

\section{RECENT CITATIONS:}

Pan, C.S., S. Chiou, H. Hsiao, and J. Wassell. 1999. Assessment of perceived traumatic injury hazards during drywall hanging. International Journal of Industrial Ergonomics, v. 25, no. 1, pp. 29-37.

Pan, C.S., and S. Chiou. 1999. Analysis of biomechanical stresses during drywall lifting. International Journal of Industrial Ergonomics, v. 23, pp. 505-511.

Chiou, S., C.S. Pan, and P. Keane. 2000. Traumatic injuries among drywall installers, 1992 to 1995. Journal of Occupational and Environmental Medicine, v. 42, no. 11. 


\section{ANALYSIS OF CONSTRUCTION FALL ACCIDENTS}

\section{RESEARCHER: Jimmie Hinze}

\section{AFFILIATION: University of Florida (352) 392-4697}

\section{CONSORTIUM: Construction Safety Alliance}

PURPOSE: Analyze the various aspects of construction fall accidents to identify their primary or root causes.

RESEARCH SUMMARY: OSHA analyzed 2,741 fall accidents in the construction industry for the years between 1990 and 2001. Results showed that most occurred at elevations of less than 30 feet and primarily involved the construction of commercial buildings and residential projects. Many were the result of worker misjudgment of hazards in the work environment. Worker experience did not appear to affect the number of fall injuries.

Despite OSHA's emphasis on protecting workers from falls, falls still constitute a growing proportion of all construction accidents.

Falls need not be a part of any construction worker's experience and can be prevented through effective project design and careful evaluation of working conditions. Training and proactive preventive measures can reduce fall accidents in construction.

KEYWORDS: Falls, fall prevention, hazard identification

\section{RECENT CITATIONS:}

Huang, X., J. Hinze, and J.D. McGlothlin. (In press.) Analysis of construction worker fall accidents. Journal of Construction Engineering and Management.

Hinze, J., X. Huang, and J.

McGlothlin. 2002. Review of fall accidents in construction. Presentation at 10th International Symposium on the Organization and Management of Construction, Construction Innovation, and Global Competitiveness, Cincinnati, $\mathrm{OH}$, Sept. 9-13, 2002. 


\section{HAZARD RECOGNITION TRAINING TO PREVENT FALLS IN CONSTRUCTION}

\section{RESEARCHERS: Ted Scharf (513) 533-8170 \\ Division of Applied Research and Technology}

\section{Carol Merry Stephenson (513) 533-8581 \\ Education and Information Division}

\author{
Kathleen Kowalski (412) 386-4531 \\ Lynn Rethi (412) 386-6686 \\ Bill Wiehagen (412) 386-6468 \\ Bobbie Calhoun (412) 386-4652 \\ John Haggarty (412) 386-6464 \\ Pittsburgh Research Laboratory
}

\section{AFFILIATION: National Institute for Occupational Safety and Health}

PURPOSE: Develop and evaluate two training interventions (a simulation exercise and a hazard recognition program) to be carried out in collaboration with safety personnel in a stadium or similar construction setting.

RESEARCH SUMMARY: Falls from heights were the single biggest risk in the construction industry in the 1980 's, accounting for one-quarter of all fatalities. In data compiled in 1998, 32.7\% of all deaths were the result of falls. Among roofers, structural metal workers, carpenters, and painters, one-half of all deaths in 1994 were from falls. This trend continued in the 2000 data where $32 \%$ of all deaths in construction were due to falls. Therefore, developing and evaluating training interventions that can reduce risks for falls is essential if we are to help achieve national safety and health objectives.

The interventions proposed will actively encourage the ability to recognize hazards and respond in an appropriate manner. An approach developed in the mining industry will be customized for the work environment in heavy construction by promoting (1) the ability of construction workers to recognize hazards in the workplace and (2) active judgment and decision-making by construction workers in hazardous conditions.

Under an existing collaborative project between NIOSH and Pennsylvania State University, two training interventions that will help reduce the risk of falls in construction are nearing completion. The first is a fully documented hazard recognition training exercise related to risks for falls from heights during heavy construction. The second is a companion simulation exercise that focuses on decision-making and how people integrate hazard recognition and communication with response alternatives in a heavy construction work setting. Both interventions require one or two more field validation tests.
KEYWORDS: Hazard recognition, intervention evaluation, falls, heavy construction

\section{RECENT CITATIONS:}

Ramani, R.V., M.C. Radomsky, J.P. Flick, G. Russell, T. Scharf, K. Kowalski, B. Calhoun, L. Rethi, W. Wiehagen, C.M. Stephenson, and J. Haggerty. 2002. Hands-on fall prevention hazard recognition training using degraded 3-D images. In Power Through Partnerships: 12th Annual Construction Safety and Health Conference, Proceedings (May 21-23, 2002, Rosemont, IL). 


\title{
DYNAMIC SCAFFOLD MODELING FOR FALL PROTECTION
}

\author{
RESEARCHER: Mathew Hause
}

\section{AFFILIATION: Division of Safety Research National Institute for Occupational Safety and Health (304) 285-5982}

PURPOSE: Develop a methodology for determining force magnitude and direction on a fall protection anchorage point as a function of variables such as anchorage point rigidity and type of fall protection equipment.

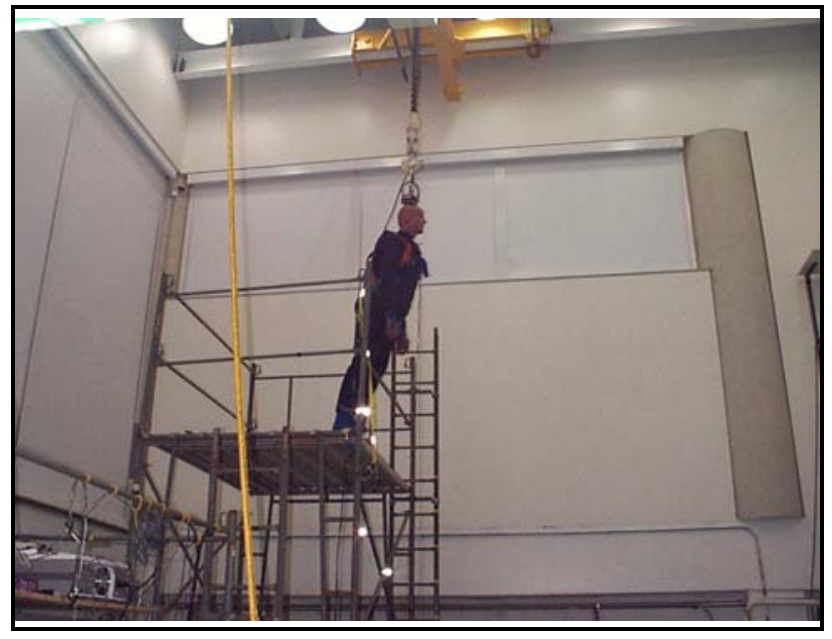

RESEARCH SUMMARY: Falls continue be one of the leading causes of fatalities in the construction industry. OSHA regulations require that a competent person determine the feasibility and safety of fall protection for employees erecting or dismantling supported scaffolds. One method of providing this protection in the absence of an anchor to a permanent structure would be to tie off to scaffolding. This project is intended to help determine whether scaffolding has sufficient stability to serve as fall protection anchorage in the absence of other anchorage during scaffold erection and dismantling and is based on inquiries from external partners.

Current methods do not measure the direction of the force on an anchor and therefore cannot be used to determine scaffold stability for a variety of scaffold configurations. Laboratory investigations and computer modeling will be used to develop methods of determining the forces (directions and magnitudes) on fall protection anchor points as a function of variables such as anchor point rigidity and fall protection equipment type. Methods will be developed for measuring the force in a lanyard and the direction of that force as functions of time. A fully instrumented, articulated, 95th-percentile manikin will be used for drop tests.

The results of this project will be used in a follow-on study to determine the family of forces on anchor points as a function of point rigidity. This family of curves will help determine under what conditions, if any, scaffolding may be used as a fall protection anchor and therefore may influence OSHA's nonmandatory recommendations for fall protection during scaffold erection.

KEYWORDS: Scaffolding, falls, protective equipment

\section{RECENT CITATIONS:}

Hause, M. 2001. Dynamic scaffold modeling for fall protection. Poster session, NIOSH Morgantown High Bay Laboratory Tours.

National Institute for Occupational Safety and Health. 2000. Worker deaths by falls: A summary of surveillance findings and investigative case reports. DHHS (NIOSH) Pub. 2000-116. 


\section{INFLUENCE OF VISUAL CUES WORK AT HEIGHTS}

\section{RESEARCHER: Douglas Ammons}

\section{AFFILIATION: Division of Safety Research National Institute for Occupational Safety and Health (304) 285-5910}

PURPOSE: Study the effects of the visual cues of height and restricted space on worker performance as a predictor of falls.

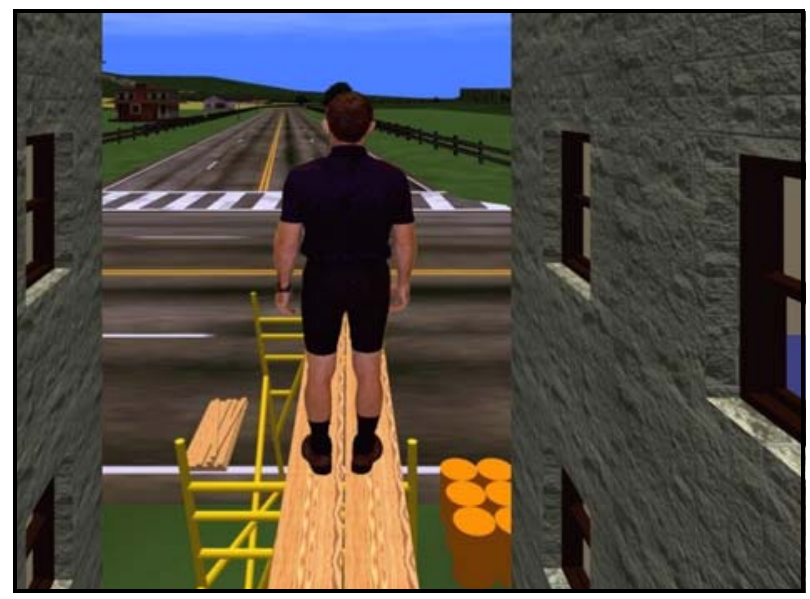

RESEARCH SUMMARY: Falls from elevated work surfaces are the major cause of construction-related injuries and fatalities. NIOSH's National KEYWORDS: Falls, scaffolding, Traumatic Occupational Fatalities (NTOF) surveillance system confirms that virtual reality the construction industry suffers a disproportionate number of fatalities resulting from falls from elevations. From 1980 through 1989, 6,012 fatal falls were recorded in the NTOF surveillance system. Of these fatal falls, 2,551 $(42 \%)$ were falls from elevations and occurred in the construction industry.

It is suspected that a worker's perception of height and a restricted work space contribute significantly to falls. The effects of the visual cues of height and restricted space on workers' performance will be investigated through the use of a virtual workplace created by a mini-supercomputer and virtual reality software. The subjects will be immersed in this virtual workplace where they will stand on an elevated scaffolding board. The effects of changes in plank and platform widths will be examined at various virtual heights and walking speeds while workers perform various work tasks. It is hypothesized that standing instability, walking unsteadiness, and cardiovascular reactivity will increase as the perceived work space width is decreased, height is increased, or lighting level is diminished.

The information from this study will lead to a better understanding of the minimum and optimal width requirements of platforms for scaffold workers to safely perform their tasks at various heights and under different environmental conditions. Results will also provide information regarding the benefits and possible limitations to incorporating virtual reality systems into occupational safety research. 


\section{FALL PREVENTION RESEARCH IN CONSTRUCTION}

\section{RESEARCHER: Michael McCann}

\section{AFFILIATION: Center to Protect Workers' Rights (301) 578-8500}

PURPOSE: Develop and implement a fall prevention research program in construction.

RESEARCH SUMMARY: In 1999, falls were the leading cause of death in construction, causing 31\% of work-related deaths. An analysis of Census of Fatal Occupational Injuries data from the Bureau of Labor Statistics for the years 1992-1999 showed that the major causes of deaths from falls were falls from roofs $(33 \%)$, scaffolds (18\%), ladders $(14 \%)$, and girders or other structural steel $(10 \%)$. One finding was that at least $16 \%$ of what were classified as falls were actually collapses or tipovers of the surfaces the workers were standing on. For example, $54 \%$ of the falls from suspended scaffolds, $19 \%$ of the falls from supported scaffolds, and $19 \%$ of the falls during the erection of steel structures were due to collapses.

One-hundred-thirteen supported scaffolds across the eastern United States were inspected using a detailed checklist that included information about the "scaffold-competent" person on the site and the structural stability and fall hazards of the scaffolds. There was a strong correlation between structural flaws and missing planks, guardrails, and/or inadequate access. Correlations were found between proper scaffold safety practice and (1) the presence of a competent person who claimed to have had scaffold safety training, (2) nonframe scaffold types, and (3) erection of the scaffold by a separate contractor trained in the process.

A fall protection system for workers installing decking inside a controlled decking zone is being evaluated. This system consists of running a cable through predrilled holes in columns $7 \mathrm{ft}$ above deck level, with a third cable attached to the two other cables. Shock-absorbing lanyards can be attached to any of the three cables, providing fall protection for workers. The effectiveness of erecting stable columns during the set-up of steel structures is being evaluated also.

A third intervention involves collaborating with NIOSH researchers in developing and implementing checklists for extension ladder set-up and use. These checklists are ready for field evaluation as toolbox talks.

Other collaborators on this project include the Ironworkers Union, Capaco Steel Industries, the University of Kentucky, Kentucky Employers Mutual Insurance, and Werner Co.

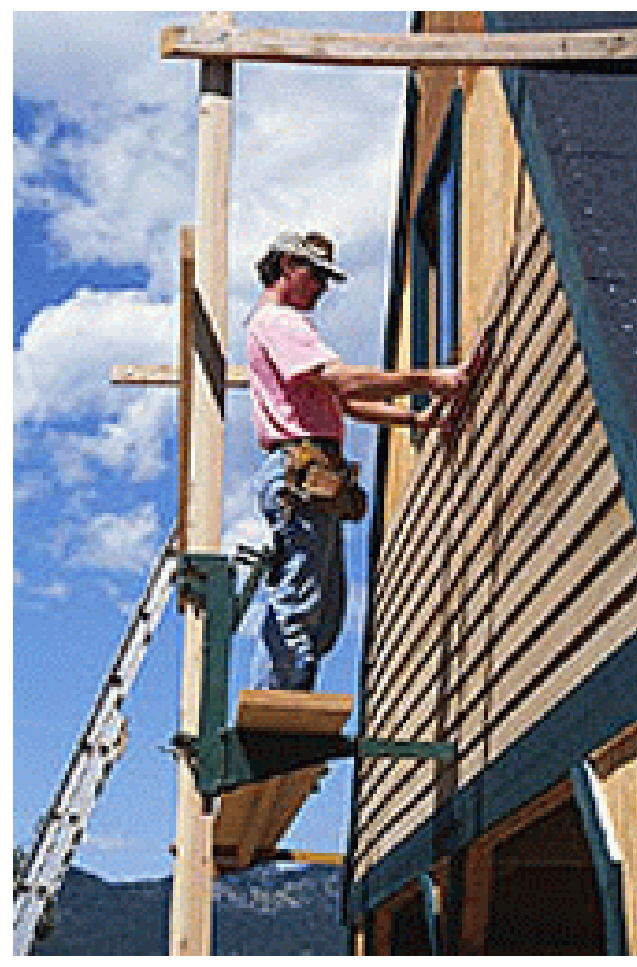

KEYWORDS: Scaffolds, structural steel, falls, collapses, tipovers, ladders, competent person

\section{RECENT CITATIONS:}

McCann, M., and D. Paine. 2002. When is a fall not a fall? In Power Through Partnerships: 12th Annual Construction Safety and Health Conference, Proceedings (May 21-23, 2002, Rosemont, IL).

Halperin, K., and M. McCann. 2002. An evaluation of supported scaffold safety. In Power Through Partnerships: 12th Annual Construction Safety and Health Conference, Proceedings (May 21-23, 2002, Rosemont, IL).

Lineberry, G.T., T. Scharf, R. Jameson, M. McCann, R. Sulecki, and W. J. Wiehagen. 2002. An educational intervention for extension ladder set-up and use. In Power Through Partnerships: 12th Annual Construction Safety and Health Conference, Proceedings (May 21-23, 2002, Rosemont, IL). 


\section{PREVENTION OF FALLS FROM ELEVATIONS IN THE CONSTRUCTION INDUSTRY}

\section{RESEARCHERS: James D. McGlothlin Purdue University \\ Jimmie Hinze \\ University of Florida (352) 392-4697 \\ CONSORTIUM: Construction Safety Alliance}

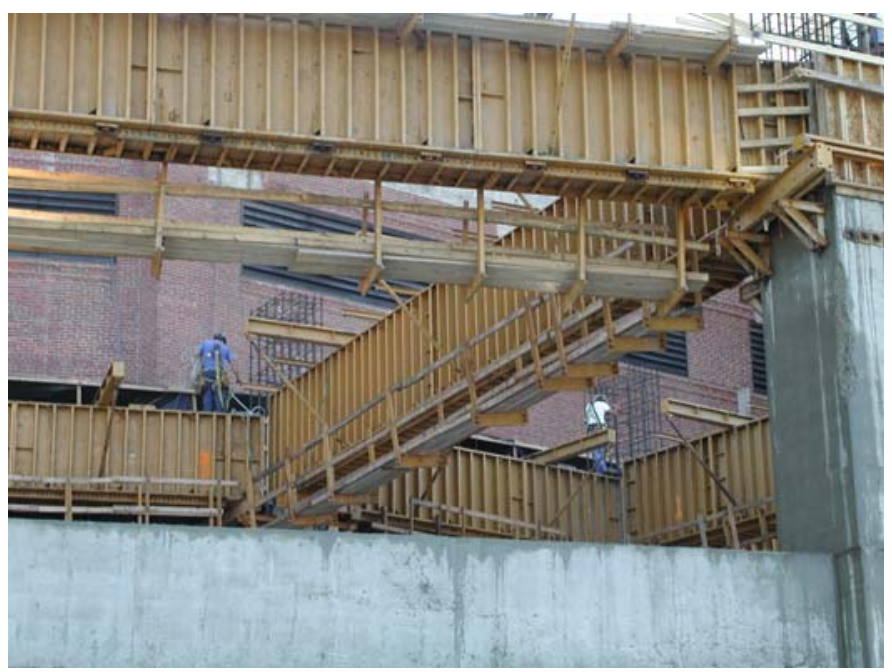

PURPOSE: Identify key elements leading to worker injuries and fatalities resulting from falls from elevations in the construction industry and devise strategies to prevent them.

RESEARCH SUMMARY: More than a million people suffer from a slip, trip, or falling injury each year. Slips, trips, and falls account for $15 \%$ to $20 \%$ of all workers' compensation cases, with older construction workers having a higher percentage of falls compared to younger workers. Of those who suffer fatal injuries, more were involved in falls than in any other single cause. This has been a consistent statistic for many years. In a study of construction workers between 1985 to 1989, it was determined that falls accounted for 33\% of worker deaths. More recently, analyses of data from OSHA data show a slight increase in fall fatality incident rates in this industry.

This study investigated 15 large construction and four residential roofing companies. The construction companies were selected by Purdue researchers based on their strong safety programs and low incidence rates of "falls from elevations." Many of these companies had won safety awards from the Association of General Contractors (AGC).

The investigation has three goals.

1. To investigate the relationship between safety program effectiveness (using a standardized questionnaire) between large construction companies and small residential roofing companies.

2. To develop an information database on work risk factors associated with falls from elevations among residential roofers.

3. To conduct a laboratory study to evaluate differences between balance and age among active residential roofers.

Preliminary findings indicate that companies with exemplary fall prevention programs can reduce and prevent work-related falls, and that targeting good work practices and using proper personal protective equipment and engineering controls can reduce risk factors associated with falls during construction. Interviews with residential roofing companies indicate that fall prevention is emphasized more by stressing safe work practices during on-thejob training and enforcement of safe practices by the job foreman. However, such practices and enforcement vary widely among companies.
KEYWORDS: Residential roofers, falls from elevations

\section{RECENT CITATIONS:}

Huang, J., J. Hinze, and J.D. McGlothlin. 2002. Analysis of construction worker accidents. Presentation at 10th International Symposium on the Organization and Management of Construction, Construction Innovation, and Global Competitiveness, Cincinnati, $\mathrm{OH}$, Sept. 9-13, 2002.

Potts, S., J.D. McGlothlin, and J. Hinze. 2002. Prevention of fatal falls in the construction industry. Poster session at American Industrial Hygiene Conference, San Diego, CA.

The laboratory study is just beginning, and results are not available at this time. 


\section{AERIAL LIFT SAFETY RESEARCH IN CONSTRUCTION}

\section{RESEARCHER: Michael McCann \\ AFFILIATION: Center to Protect Workers' Rights (301) 578-8500}

PURPOSE: Develop and implement a program on the safe use of aerial lifts in construction.

RESEARCH SUMMARY: Aerial lifts (including both boomsupported lifts and scissor lifts) cause the deaths of about 26 construction workers each year according to Census of Fatal Occupational Injuries data from the Bureau of Labor Statistics for 1992-1999. The leading causes of death were electrocution (33\%), falls (31\%), and collapses/tipovers $(22 \%)$. Issues identified were lack of training in the use of particular models of aerial lifts, lack of personal fall protection devices, maintenance problems, lack of standardization of controls, and traveling while the lift was elevated and occupied.

Aerial lift interventions for 2002-2003 include a study of actual work and maintenance practices involving aerial lifts. This work will involve collaboration with NIOSH and ATL International in a 4-year research project on aerial lifts.

KEYWORDS: Falls, collapses, tipovers, boom, buckets, scissor lifts

\section{RECENT CITATIONS:}

McCann, M. 2002. Aerial lift safety in construction. In Power Through Partnerships: 12th Annual Construction Safety and Health Conference, Proceedings (May 21-23, 2002, Rosemont, IL). 


\section{ASSESSING THE RISKS OF INJURY IN TRENCHING AND EXCAVATION IN THE UNITED STATES}

\author{
RESEARCHER: Patrick J. Coleman
}

\section{AFFILIATION: Spokane Research Laboratory National Institute for Occupational Safety and Health \\ (509) 354-8065}

PURPOSE: Assess the risks of injury to workers digging, working in, and working near trenches and excavations, with a primary focus on risks from the collapse of trench walls, and make recommendations for further research or changes in the regulations dealing with management of hazards caused by trenching practices.

RESEARCH SUMMARY: This pilot study examines the issue of why construction and other workers continue to die in trench collapses despite the existence of extensive OSHA regulations governing the sloping, shoring, and shielding of trenches. The project includes identifying databases of case reports of injuries resulting from trench collapse, gathering and analyzing these data, and applying analytic techniques such as fault-tree analysis. These techniques allow a researcher to identify key variables in the causal chains leading to accidents and to explore ways of controlling hazardous factors and conditions. These studies will be followed by statistical analyses of OSHA and Bureau of Labor Statistics data on trenching fatalities, which will provide a first look at the most common reasons for such accidents. The work will be supplemented by field investigations of selected cases to obtain additional facts. We will interview a number of companies doing trenching work and workers who have been involved in trench collapse accidents.

A parallel effort will be to evaluate common economic activity indicators, such as numbers of new housing starts. Such statistics may provide an index to the number of workers working in and around trenches and to measures of activity, such as the number of "trench feet" opened per month.
KEYWORDS: Trench safety, risk assessment, excavation

\section{RECENT CITATIONS:}

Coleman, P.J. 2002. Assessing the exposures and risks of trenching and trench collapses in the U.S. In Power Through Partnerships: 12th Annual Construction Safety and Health Conference, Proceedings (May 2123, 2002, Rosemont, IL). 


\section{DEVELOPING SAFER TRENCHING OPERATIONS}

\section{RESEARCHERS: Dulcy M. Abraham \\ Purdue University \\ (765) 494-2239 \\ Jimmie Hinze \\ University of Florida \\ (352) 392-4697 \\ CONSORTIUM: Construction Safety Alliance}

PURPOSE: Identify the major causes of accidents and develop strategies to prevent fatalities and reduce injuries in trenching operations.

RESEARCH SUMMARY: Each year, there are over 100 hundred estimated fatalities in the United States associated with excavations and trenching operations. According to a NIOSH analysis of workers' compensation claims in the Supplementary Data System of the Bureau of Labor Statistics (BLS), there are approximately 1,000 work-related injuries each year due to excavation cave-ins. To improve the effectiveness of accident prevention programs in trenching operations, the primary causes of trenching accidents and fatalities have to be identified.

The approach adopted in this study has utilized three major avenues.

1. Analysis of historical fatality data from trenching operations.

2. Interviews with safety directors from construction companies.

3. Job site visits.

The analyses of BLS and OSHA reports provide in-depth insight regarding the causes of fatalities in trenching operations. Interviews with safety directors and field personnel and visits to job sites are essential to identifying difficulties in planning and executing trenching operations and the major challenges in applying current OSHA standards pertaining to trenching operations.

To date, the major causes of fatalities have been correlated using two accident causation models - namely, the Type of Accident Model and the Human Behavior Model. Plans are underway to develop an analytical tool to assist safety directors in the selection of appropriate safety strategies for trenching operations under differing site conditions.

The research findings from Dr. Jimmie Hinze's study on trench shield accidents will be integrated into this project. Dr. Hinze is also conducting a nationwide survey in which information on the use of trench shields is sought directly from contractors who use trench shields.
KEYWORDS: Fatalities, trenches, safety, accidents

\section{RECENT CITATIONS:}

Arboleda, C., D.M. Abraham, R. Wirahadikusumah, and J. Irizarry. 2002. Trench-related fatalities in construction: An analysis of fatality assessment and control evaluation (FACE) records. In First International Conference on Construction in the 21st Century (CITC2002): Challenges and Opportunities in Management and Technology (Miami, FL, April 25-26, 2002.), pp. 277-282.

Lew, J., D. Abraham, R. Wirahadikusumah, J. Irizarry, and C. Arboleda. 2002. In Excavation and trenching safety: Existing standards and challenges. Third International Conference on Implementation of Safety and Health on Construction Sites (Hong Kong/Beijing, China, May 8-17, 2002). (Available on CDROM)

Irizarry, J., D.M. Abraham, R. Wirahadikusumah, and C. Arboleda. 2002. Analysis of safety issues in trenching operations. Presentation at 10th International Symposium on the Organization and Management of Construction, Construction Innovation, and Global Competitiveness, Cincinnati, OH, Sept. 9-13, 2002. 


\section{ELECTRICAL ARC INJURY PARAMETERS AND PREVENTION}

\section{RESEARCHER: Mary Capelli-Schellpfeffer}

\section{AFFILIATION: CapSchell, Inc. (773) $960-5802$}

PURPOSE: Develop computerized three-dimensional models of electrical arcing events and apply these models to a severity rating of blast conditions.

RESEARCH SUMMARY: Electrocution is the second most common cause of construction-related fatalities in the United States. In 1992, the Bureau of Labor Statistics reported over 540,000 electrical workers in the United States. Among those workers, 1994 data show that 11,153 cases of reported days away from work were due to electrical burns, injuries from electrocution/electrical shock, and fires and explosions. The Census of Fatal Injuries noted that out of a total of 6,588 work-related fatalities, 548 employees died because of exposure to an electrical current, fire, or explosion. In the U.S. chemical industry, $56 \%$ of the fatalities over a 5 -year period were attributable to burns, fires, or explosions, many of which were ascribed to an electrical ignition source.

The clinical spectrum of electrical injury ranges from the absence of any external physical sign to severe multiple trauma. Reported neuropsychiatric damage can vary from vague complaints seemingly unrelated to the event to damage consistent with traumatic brain injury. In part, blast effects may explain why patients without external signs of electrical contact may present nervous system or hearing impairments; however, no causal link has ever been established to guide treatment.

This project takes advantage of previously collected data from staged scenarios of electrical arcing events. Three-dimensional models will be used to simulate electrical and workplace conditions to study the interaction of acoustic forces and workers during electrical arcing events. A blast severity rating based on simulation results will be compared to 500 actual electrical injury incidents. The comparison between numerical simulations of acoustic forces and experimental data is expected to result in improved safety standards for work practices around energized equipment.

This project is essential to addressing the lack of data and analysis concerning the interaction of acoustic forces and workers during electrical arcing events.

By obtaining more complete and accurate data, treatment and prevention strategies can be improved with applied technical knowledge in medicine, engineering, and safety management.
KEYWORDS: Fatalities, traumatic injuries, electrical, blast

\section{RECENT CITATIONS:}

Capelli-Schellpfeffer, M., C. Kalina, M. Toney, J. Mitchell, and R.C. Lee. 2001. Partnerships for electrical safety. IEEE Industry Applications Society Magazine, v. 7, no. 3, pp.1722.

Capelli-Schellpfeffer, M. 2002. Electrical arc flashes and unexpected explosions. In Power Through Partnerships: 12th Annual Construction Safety and Health Conference, Proceedings (May 2123, 2002, Rosemont, IL).

Capelli-Schellpfeffer, M., G. Miller, and M. Humilier. 1999. Thermoacoustic energy effects in electrical arcs. Annals of the New York Academy of Science, v. 888, pp. 1932. 


\section{ELECTRICAL SAFETY RESEARCH IN CONSTRUCTION}

\section{RESEARCHER: Michael McCann}

\section{AfFILIATION: Center to Protect Workers' Rights (301) 578-8500}

PURPOSE: Develop and implement an electrical safety research program in construction.

RESEARCH SUMMARY: Electrical deaths in construction were analyzed for the years 1992-1998 using Census of Fatal Occupational Injuries data from the Bureau of Labor Statistics. Of the 1,019 deaths

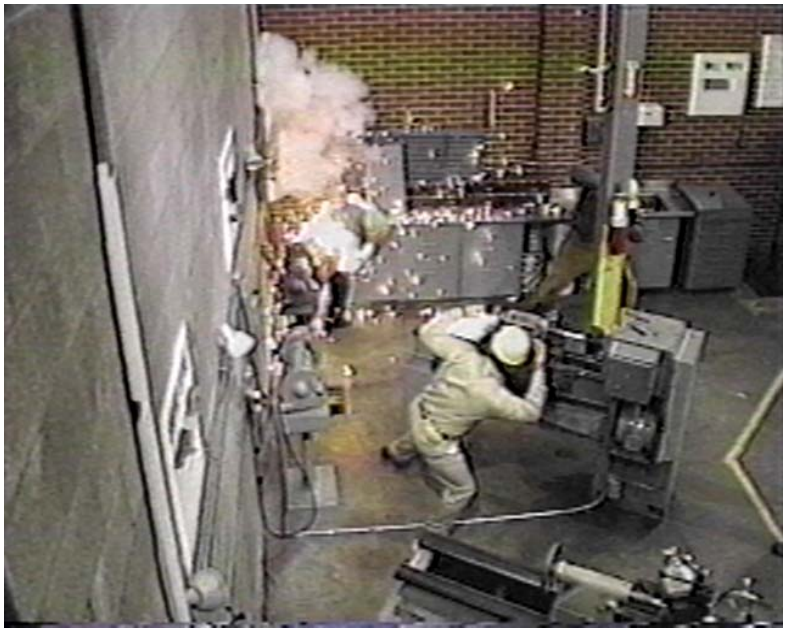
(146 per year), 1,002 were due to electrocutions and 17 were due to electrical arc flashes. Electrical workers (electricians, electrical power installers, and repairers; their apprentices and helpers doing electrical work; and their supervisors) had one-third of the electrical deaths, followed by laborers. The cause of over half of the electrically caused deaths of electrical workers was contact with "live" energized equipment and wiring resulting from failure to de-energize and lockout or tagout electrical circuits and equipment and failure to use appropriate personal protective equipment and tools. For nonelectrical workers, the main cause of electrocution was contact with overhead power lines, which caused over half the electrocutions. Working too close to energized electrical equipment and wiring, failure to lockout or tagout machinery and appliances before working on them, faulty electrical cords, and lack of ground fault circuit interrupters were causes of many of the other electrocutions.

An intervention project for electricians involves computerization of the International Brotherhood of Electrical Workers (IBEW) injury and illness reporting forms. To date, 350 reports have been computerized and analyzed. Problems with standardization and missing data were identified and are being corrected for use in an on-line injury and illness reporting system by IBEW locals. The resulting data will be analyzed for the purpose of targeting highrisk activities. This system could also serve as a surveillance model that could be adapted by other building trades affiliates.

A survey of work practices by electricians has been developed and will be distributed nationally by the IBEW. Other research interventions being developed for electrical workers include training in lockout/tagout procedures and evaluation of a permit system for working with live electrical circuits.

For nonelectrical workers, an intervention has been developed to evaluate the effectiveness of weekly inspections of electrical equipment at construction sites using a detailed checklist. This will include number and types of electrical hazards found, as well as a determination of how long it takes to abate the problems.

George Washington University is also collaborating on this project.

KEYWORDS: Electrical, arc flash, electrocution, lockout/tagout, "live" work permit, checklist, interventions

\section{RECENT CITATIONS:}

McCann, M., and R. Chowdhury. 2002. Causes of electrocutions among construction workers. Poster presentation at NIOSH NOIRS 2000, Pittsburgh, PA.

McCann, M., K.L. Hunting, J. Murawski, R. Chowdhury, and L. Welch. 2002. Why construction workers are getting electrocuted. In Power Through Partnerships: 12th Annual Construction Safety and Health Conference, Proceedings (May 21-23, 2002, Rosemont, IL).

Hunting, K., J. Gittleman, M. McCann, M. Mederos, and J. Tomaseski. 2001. A model approach for union-based injury and illness tracking. Presentation at Workshop on Best Practices in Workplace Surveillance: Identification and Tracking of Workplace Injury, Illness, Exposures, and Hazards, Cincinnati, OH, Nov. 7-9, 2001. 


\section{DEFINITION AND ASSESSMENT OF ENGINEERING NOISE CONTROLS}

\author{
RESEARCHER: Charles Hayden II
AFFILIATION: Division of Applied Research and Technology National Institute for Occupational Safety and Health \\ (513) 533-8152
}

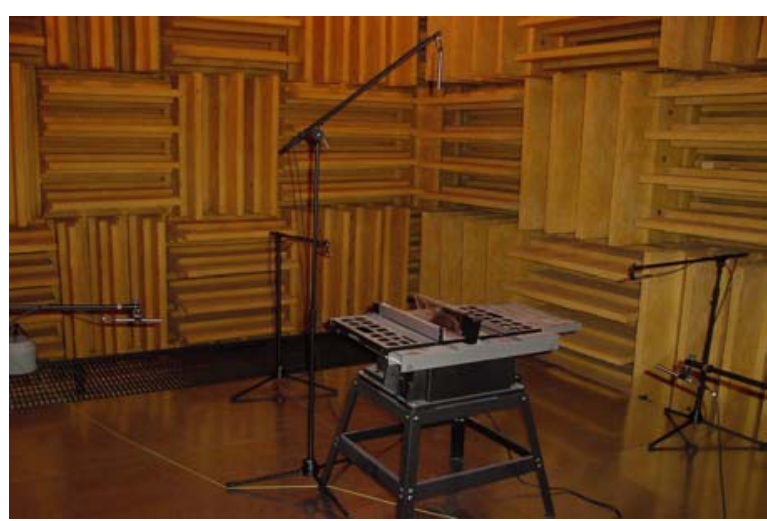

Sound power level of a table saw being measured in a semi-anechoic environment.
PURPOSE: Reduce noise emissions on construction sites, thus reducing noise-induced hearing loss among construction workers. Survey noise levels and the availability and effectiveness of engineering control of noise from powered hand tools and small machinery. Demonstrate noise reduction solutions for these tools wherever feasible.

RESEARCH SUMMARY: Over 2.9 million construction workers are exposed to noise that is harmful to hearing. Studies of carpenters have shown that hearing loss begins early in their working careers and that by age $50,50 \%$ have hearing impairment. Noise control is the best way to prevent noiseinduced hearing loss.

In the construction industry, little, if any, attention has been given to controlling noise through engineering, and thus it is necessary to seek out the availability of controls, assess their effectiveness and feasibility of application, identify those areas for which no engineering noise controls exist, and provide recommendations to reduce these noise emissions. While the construction industry has few resources available to aid workers in selecting quieter power tools, studies have shown these tools contribute substantially to construction workers' exposures to noise.

The two aspects of the project-development of a database on the sound levels of powered hand tools and research on noise reduction - rely on university partners for access to scientific expertise, facilities, and specialized acoustics equipment. The powered hand-tool manufacturing industry is being encouraged to join in this work.

As a result of this project and partnership, a database of quieter tools and machines will be made available to construction workers to assist in making "buy quiet" decisions. Industry is provided with recommendations for product improvement, universities are provided with research opportunities in occupational safety and health, and most importantly, noise exposure and resultant noise-induced hearing loss among construction workers will be reduced.
KEYWORDS: Engineering, noise, power tools

\section{RECENT CITATIONS:}

Hayden, C.S., R. Verma, and S. Leonard. 2002. Student engineering team topic page for the NIOSH Website. http://www.cdc.gov/niosh/ topics/CollegeStudent/index.html.

Date accessed: October 2002.

Hayden, C.S., II, and E. Reeves. 2001. Identification and assessment of engineering noise controls in the mining and construction industries. Presentation at U.S.-India Symposium on Emerging Trends in Vibration and Noise.

Fouts, B.E., J. Kim, C.S. Hayden, II. 2002. Characterization and reduction of noise generated by small industrial power tools. Presentation at Internoise Conference. 


\section{HEARING LOSS INTERVENTION FOR CARPENTERS}

\author{
RESEARCHERS: Mark Stephenson (513) 533-8144 \\ Division of Applied Research and Technology
}

\section{Carol Merry Stephenson (513) 533-8581 Education and Information Division}

\section{AFFILIATION: National Institute for Occupational Safety and Health}

PURPOSE: Collect survey and observational data to assess the effectiveness of NIOSH's hearing loss prevention program in promoting carpenters' worksite hearing health behaviors.

RESEARCH SUMMARY: An estimated 2.9 million workers in the construction industry are exposed to potentially damaging noise levels. A 1995 NIOSH Health Hazard Evaluation of over 600 carpenters revealed that by age 25 , these carpenters had hearing equivalent to a 50 -year-old worker who had not been exposed to noise, and by 55 years of age, most of the carpenters needed hearing aids. The data show that carpenters began to develop occupational hearing loss soon after entering the trade and that this hearing loss continued until they were substantially hearing impaired. When estimating the potential economic impact just for its members, the United Brotherhood of Carpenters determined that it would cost the union half a billion dollars just to provide the first pair of hearing aids to members that needed them. Clearly, preventing noise-induced hearing loss would be preferable to compensation and rehabilitation costs.

A theory-driven program specifically focused on teaching apprentice carpenters how to prevent hearing loss has undergone pilot tests. A new 3 -year effort will determine the effectiveness of this program in positively influencing hearing health behaviors. Carpenters participating in the NIOSH model hearing loss prevention program (HLPP) will be compared to a control group that participates only in the current OSHA compliance program. Information about attitudes, beliefs, and knowledge about hearing loss prevention; behavioral intentions; and worksite behaviors will be collected over a 2-year period and evaluated. This research will enable NIOSH to (1) quantify the extent to which the NIOSH program increases carpenters' knowledge about noise-induced hearing loss and the retention of that knowledge over the 2 years of the study, (2) correlate the relationship between attitudes, beliefs, and behavioral intentions with actual hearing loss prevention behaviors (i.e., the use of hearing protectors), and (3) compare the effects of instructional group size ( 6 or less versus 15-20 or more). Feasibility of program adoption will also be evaluated.

The results of this research will contribute directly to a reduction in noiseinduced hearing loss among construction workers.

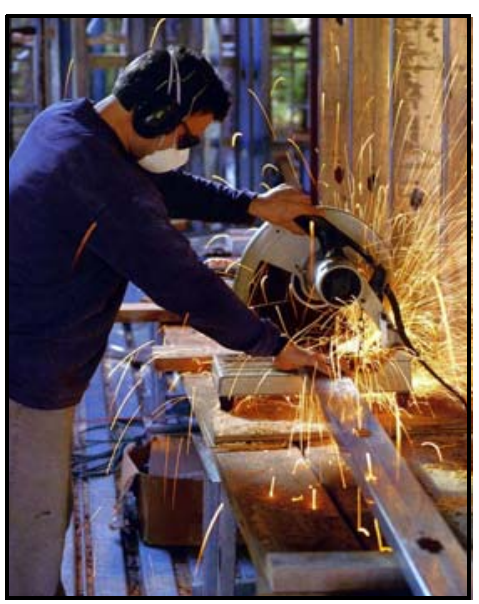

KEYWORDS: Intervention, hearing loss, effectiveness research

\section{RECENT CITATIONS:}

Stephenson, M.R. 2000. Developing a hearing loss prevention program for construction workers. In Proceedings of National Conference of the AFLCIO Building Construction Trades Department (Washington, DC, April 2-4, 2000).

Stephenson, M.R., and C.J. MerryStephenson. 2000. Application of health communication theories. In Proceedings of the U.S. Army $3 r d$ Annual Force Health Protection Conference (Baltimore, MD, Aug. 9, 2000).

Sweeney, M.H., D. Fosbroke, L.M. Goldenhar, L.L. Jackson, K. Linch, B.D. Lushniak, C.J. Merry, S. Schneider, and M.R. Stephenson. 2000. Health consequences of working in construction. In Construction Safety and Health Management, R.J. Coble, J. Hinze, and T.C. Haupt, eds. Upper Saddle River, NJ: Prentice Hall, pp. 211-234.

Merry, C.J. 2001. Why training needs change. In Best Practices in Hearing Loss Prevention, Proceedings (Oct. 28, 1999, Detroit, MI). DHHS (NIOSH) Pub. 2001157. 


\section{FIELD HEARING PROTECTOR TESTING METHODS AND RATING SCHEMES}

\section{RESEARCHER: John Franks}

\section{AFFILIATION: Division of Applied Research and Technology National Institute for Occupational Safety and Health \\ (513) 533-8151}

PURPOSE: Develop the instruments and methods necessary to assess and rate the protection provided by hearing protection devices both in the laboratory and at worksites.

RESEARCH SUMMARY: More than 30 million workers are exposed to potentially hazardous noise and, at present, the primary redress available is use of hearing protective devices. Accompanying each hearing protector sold in the United States is a label showing the Noise Reduction Rating (NRR) of the device. The NRR was developed so that it could be subtracted from a worker's noise exposure level to determine the protected level of exposure. Unfortunately, because of problems with the test method and market pressures for high ratings, they have been inflated to the point where they may not be used reliably to predict protected levels of exposures. Nonetheless, the NRR is still required by law (40 CFR Part 211, Subpart B).

NIOSH and other laboratories have determined that the present NRR for hearing protectors is not predictive of the protection workers actually receive and thus it is not possible to calculate workers' protected exposure levels. In response, NIOSH has been working with other governmental and nongovernmental organizations to design hearing protector rating schemes that will yield a more predictive measure of hearing protector performance. In addition, methods for determining the actual hearing protection received by a worker for the device he or she is using are being developed. Past NIOSH research has resulted in a newer psycho-acoustic test method for hearing protectors that has been embodied in an American National Standards Institute standard. Additional work is necessary to establish the relation between the data obtained with the older and newer test methods. The primary goal is to incorporate the new method into the existing EPA labeling regulation for hearing protection devices.

Key parameters will be determined for test methods that allow accurate characterization of the attenuation of hearing protectors. It is anticipated that it may be necessary to employ rating adjustment factors to make the two methods equivalent and that these rating adjustment factors may need to be applied to laboratory data for each class of hearing protector or even for each hearing protector. Thus, a person or company should be able to select an appropriate protector based on new laboratory data or the worksite test.

In this project, protectors will be tested using both methods, as well as the present method required by EPA, to determine key performance parameters. The results should provide the information necessary for a protector to be chosen that is appropriate for the noise for which the protector is to be worn.

KEYWORDS: Hearing, protective equipment, rating 


\section{HEARING LOSS PREVENTION STRATEGIES PROGRAM COORDINATION}

\author{
RESEARCHERS: Jeff Kohler (412) 386-6601 \\ Pittsburgh Research Laboratory \\ Derek Dunn (513) 841-4293 \\ Division of Applied Research and Technology
}

KEYWORDS: Hearing loss, noise, control technology

\section{AFFILIATION: National Institute for Occupational Safety and Health}

PURPOSE: Coordinate the NIOSH noise program to identify effective hearing loss prevention strategies.

RESEARCH SUMMARY: Noise-induced hearing loss is the most common occupational illness in the United States today, with 30 million workers exposed to excessive noise levels. Of particular concern are the mining and construction industries where over 3.3 million workers are exposed to damaging noise levels. For example, where hearing loss data are available, approximately $90 \%$ of coal miners, nearly $70 \%$ of metal/nonmetal miners, and over $50 \%$ of construction workers exhibit a hearing disability by age 50 . Four out of seven carpenters with at least 20 years of employment have hearing impairment due to noise exposure.

The noise program expands current NIOSH noise research studies to fill the gaps in information for standards and regulatory groups and adds research in noise control to the efforts to improve and disseminate information on hearing loss prevention program strategies and management. The program will focus on assessing the status of noise exposure and hearing loss (cross-sectional and longitudinal surveillance) and noise exposure control technology (including hearing protection), primarily in the construction and mining sectors. The effectiveness of strategies (personal protection, engineering controls, etc.) for preventing hearing loss will be noted as part of the assessment and surveillance activities.

In the next few years, key regulatory actions will be initiated or implemented for preventing occupational hearing loss in the construction and mining sectors. NIOSH has been contacted by OSHA and MSHA to play a central role in developing the requisite information base and recommendations to assure that these noise control and hearing loss prevention efforts are effective and technically sound and feasible. To accomplish this task, an integrated program of assessment, intervention evaluation, and information dissemination is needed.

This program will make it possible to safeguard the hearing of workers by reducing noise exposure and implementing hearing loss prevention programs. It will also provide baseline data for the documentation of progress. Although the initial focus of the program is on construction and mining, the databases, strategies, and programs will also facilitate application of strategies to other occupational sectors. 


\section{PROSPECTIVE STUDY OF HEARING DAMAGE AMONG NEWLY HIRED CONSTRUCTION WORKERS}

\section{RESEARCHER: Noah Seixas}

\section{AFFILIATION: University of Washington (206) 685-7189}

PURPOSE: Monitor noise exposure in a cohort of newly hired construction apprentices and controls and characterize the effects of this exposure on hearing acuity (via standard audiometry) and distortion product otoacoustic emissions (DPOAE) over a 4-year period.

RESEARCH SUMMARY: Noise-induced hearing loss is one of the most common occupational afflictions, especially in construction workers. Hearing loss usually progresses unnoticed until it begins to interfere with communication, decreasing quality of life and often posing a serious safety hazard. Precise exposure-response relationships for noise-induced hearing loss, especially for the highly variable noise exposures found in the construction industry, are lacking. In recent years, the potential for distortion product otoacoustic emissions (DPOAE) as a screening tool for early hearing damage (and possibly as a marker of susceptibility for hearing loss) has been recognized. However, no studies of this technique as it relates to well-characterized noise exposure and standard audiometry have been conducted.

Four-hundred construction apprentices and one-hundred medical students will be recruited for this study. Each subject will be given an audiometric exam and DPOAE measurements every 6 months for 4 years. Baseline and followup questionnaires will be used to characterize risk factors for hearing loss, nonoccupational exposure to noise, characteristics of work, and use of hearing protection devices. Noise exposure will be monitored twice a year on each subject using noise dosimeters in conjunction with time-activity cards. The dosimeters will collect noise levels using 3- and 5-dB exchange rates as recommended by NIOSH and OSHA, respectively, as well as peak exposures. An activity-exposure matrix will be developed from these data to provide estimates of average, peak, and variability of exposure during work and home activities. These data will be used to estimate individual exposures over time. The relationships between noise exposure (using both average levels and variable exposure metrics) will be evaluated, and both audiometric changes and DPOAE's will be analyzed while controlling for co-variants.
KEYWORDS: Hearing loss, hearing, distortion product, otoacoustic emissions 


\section{EFFECTIVENESS OF COMPUTER-BASED HEARING TEST AND TRAINING}

\section{RESEARCHER: OiSaeng Hong}

\section{AFFILIATION: University of Michigan \\ (734) $763-3450$}

PURPOSE: Prevent noise-induced hearing loss in operators of heavy construction equipment by testing the effectiveness of an intervention that would increase use of hearing protective devices.

RESEARCH SUMMARY: Four specific aims will be addressed in this study.

1. Test the effectiveness of an innovative intervention to increase the use of hearing protective devices among heavy equipment operators.

2. Determine the prevalence of hearing loss in these operators.

3. Demonstrate the feasibility of providing computer-based, selfadministrated audiometric screening tests (SAAST's) and hearing protection interventions.

4. Test and refine the "predictors of use of hearing protection" model, which is designed to explain why operators use or don't use protective devices.

To achieve these aims, this research will be conducted in three phases. In phase I, qualitative data on the perceptions, opinions, and attitudes of heavy equipment operators concerning the use of hearing protective devices will be obtained through focus group discussions. The input received will be used to guide development and refinement of an intervention. In phase II, the effectiveness of an individually tailored, interactive, multimedia intervention will be combined with the SAAST's and tested. The intervention will be delivered by computer at a construction worker union training center and the individualized results contrasted with a control intervention. In phase III, workers' feedback on the SAAST and the experimental intervention will be obtained to guide revisions in the program in preparation for national distribution.

This study will build on recent research regarding the effectiveness of individually tailored interventions. The feasibility of using computer-based SAAST's at a union training center will be assessed. Results will provide a model for future intervention research in occupational safety and health and aid in reducing noise-induced hearing loss.
KEYWORDS: Hearing, intervention, heavy construction 


\section{BUILDING TRADES HEARING CONSERVATION PROGRAMS IN WASHINGTON STATE}

\section{RESEARCHER: Chuck Bailey}

\section{AFFILIATION: Building Trades Labor-Management Organization of Washington State (360) 596-9200}

\section{CONSORTIUM: Center to Protect Workers' Rights}

PURPOSE: Develop and implement a common-sense hearing conservation program that can serve all Washington State construction workers and employers.

RESEARCH SUMMARY: All construction workers are exposed to excess levels of noise, and the number of industrial insurance claims made for hearing loss is growing very rapidly. Construction, with roughly $6 \%$ of the work force, now accounts for $25 \%$ of all hearing loss claims, up from $16 \%$ a decade ago.

Hearing loss, and the compensation costs that result from it, can be prevented through a good hearing conservation program. However, in the construction industry, most workers move from job to job and contractor to contractor. Therefore, it is not feasible for most employers to establish effective hearing conservation programs on their own. For these reasons, we are implementing a pilot program to establish the groundwork for the development of an industry-wide program. The program consists of the following:

- Worker and supervisor training using construction-specific instructional materials.

- Training in the fundamentals of noise control.

- Fitting and training in use of hearing protection devices.

- Audiometric surveillance.

- Centralized record keeping.

- Continuous evaluation of program quality and industry penetration.

Many people and organizations are collaborating on this project. Among them are the Washington State Building and Construction Trades Council, University of Washington, Puget Sound Safety and Health Construction Partnership, Laborers Safety and Health Fund, Puget Sound Area Construction Safety Summit, Washington State Apprenticeship Coordinators Association, Western Washington Coordinators Association, and the Washington State Dept. of Labor and Industry.

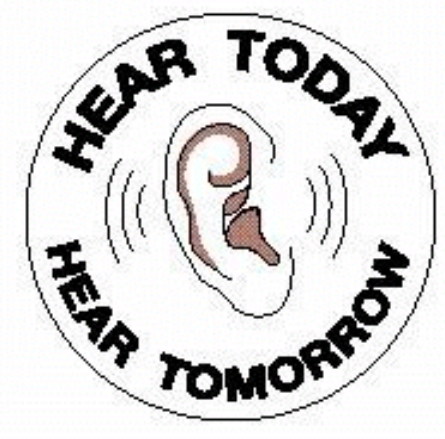

KEYWORDS: Hearing loss, noise control 
KEYWORDS: Asbestos, silicosis,

\section{EVALUATION OF SUBSTITUTE MATERIALS USED IN CONSTRUCTION}

\section{RESEARCHER: Vincent Castranova}

\section{AFFILIATION: Health Effects Laboratory Division National Institute for Occupational Safety and Health}

(304) 285-6032

PURPOSE: Evaluate the cytotoxicity of abrasive substitutes for silica, determine the importance of fiber length in the cytotoxicity of fibers, and elucidate mechanisms for initiation and progression of fibrosis.

RESEARCH SUMMARY: Silica and asbestos are known to cause lung damage and fibrosis. Therefore, there is a great deal of interest in limiting the use of silica as an abrasive material in sandblasting and to create fibers that would replace asbestos as a construction material. However, toxicological information on silica and asbestos substitutes is incomplete or absent, and data are lacking concerning the possible adverse effects of inhalation of abrasive substitutes for silica. Researchers on this project will develop a database on in vitro and in vivo pulmonary toxicity of several abrasive substitutes and characterize the role of physical and chemical properties of fibers in the development of lung disease.

- The toxicity of silica substitutes will be evaluated using assays of lung cell function and viability after both in vitro and in vivo exposure to these materials. To date, the in vivo effects of silica and 10 abrasive substitutes (garnet, iron oxide, starolite, coal slag, treated sand, olivine, copper slag, nickel slag, crushed glass. and steel grit) have been investigated.

- A dielectrophoresis apparatus has been developed that separates fibers according to length. Such a system allows the evaluation of the role of physical dimensions versus chemistry in the development of pulmonary disease and should assist in predicting the potential fibrogenicity of created asbestos substitutes. To date, a strong relationship between fiber length and in vitro toxicity has been shown with fiberglass. Additional experiments evaluated the role of fiber length on the production of inflammatory and fibrogenic cytokines and on transcription events.

- Mechanistic studies (oxidant generation, activation of transcription factors, induction of mRNA for cytokine production) will be used to explain the initiation and progression of pulmonary inflammation, damage, and fibrosis. Such information could be used to evaluate the potential occupational health hazard posed by substitute materials and result in the development of early diagnostic tests for pulmonary disease. silica substitutes, sandblasting

\section{RECENT CITATIONS:}

Blake, T., V. Castranova, D. Schwegler-Berry, P. Baron, G.J. Deye, C. Li, and W. Jones. 1998. Effect of fiber length on glass microfiber cytotoxicity. Journal of Toxicology and Environmental Health, v. 54, Part A, pp. 243-259.

Hubbs, A.F., N.S. Minhas, W. Jones, M. Greskevitch, L.A. Battelli, D.W. Porter, W.T. Goldsmith, D. Frazer, D.P. Landsittel, J.Y.C. Ma, M. Barger, K. Hill, D. Schwegler-Berry, V.A. Robinson, and V. Castranova. 2001. Comparative pulmonary toxicity of 6 abrasive blasting agents. Toxicological Science, v. 61, pp. 135143.

Porter, D.W., D. Ramsey, A.F. Hubbs L. Battelli, J. Ma, M.A. Barger, D. Landsettel, V.A. Robinson, J. McLaurin, A. Khan, W. Jones, A. Teass, and V. Castranova. 2001. Time course of pulmonary response of rats to inhalation of crystalline silica: Histological results and biochemical indices of damage, lipidosis and fibrosis. Journal of Environmental Pathology, Toxicology and Oncology, v. 20, Supplement 2, pp. 1-14. 


\title{
MOLECULAR MECHANISMS OF DISEASE DEVELOPMENT WITH MIXED DUSTS
}

KEYWORDS: Cancer, crystalline silica, pulmonary disease

\author{
RESEARCHER: Val Vallyathan
}

\section{AFFILIATION: Health Effects Laboratory Division National Institute for Occupational Safety and Health}

(304) 285-5770

PURPOSE: Investigate the effects of different metal ions deposited on crystalline silica during sandblasting of metal plates and the independent and synergistic interaction of trace metals associated with exposures to mixed dusts.

RESEARCH SUMMARY: It is estimated that there are approximately 536,000 cancer deaths in the United States each year and that $23 \%$ of these deaths are related to workplace exposures either to a single toxic agent or in synergy with mixtures of agents. Workers are commonly exposed to dust mixtures containing minerals or crystalline silica containing trace amounts of metals during the use of cutting tools, drills, pulverizers, etc. While acute and chronic inhalation of mixed dusts has been shown to affect the pulmonary system adversely and even lead to death, epidemiological studies have also shown that cancer occurrences vary considerably within populations exposed to different sources of crystalline silica.

The relationship between exposures to crystalline silica and lung cancer has been debated since laboratory tests showed that inhaled silica can cause lung cancer in rats at relatively low doses $\left(1 \mathrm{mg} / \mathrm{m}^{3}\right)$. In 1997, the International Agency for Research in Cancer (IARC) published a report concluding that evidence was sufficient to state that crystalline silica is a carcinogen. However, the report also noted that carcinogeneity was not observed in all industries in which workers were exposed to silica, and that some inherent, unknown characteristics of crystalline silica were involved in its biological effects, thus confounding clear understanding as to the mechanisms involved.

Laboratory studies will investigate the early biological and molecular events involved in pulmonary molecular reactions that may lead to carcinogenesis after exposure to pure crystalline silica containing trace amounts of pure metals. Studies on biomarkers may provide some positive identification of groups at high risk when exposed to mixed dusts. 


\section{METHOD DEVELOPMENT FOR FUNGI IN OCCUPATIONAL DISEASES}

\section{RESEARCHER: Millie Schafer}

\section{AFFILIATION: Division of Applied Research and Technology National Institute for Occupational Safety and Health}

(513) 841-4362

PURPOSE: Develop a fast, inexpensive, specific, fungal sampling and analytical method to detect fungi in soil and bird and bat droppings.

RESEARCH SUMMARY: Workers in various construction trades have become seriously ill and some have died from occupationally acquired histoplasmosis. Outbreaks of this and other fungal diseases among construction workers continue to be reported following the demolition of contaminated buildings. Inhalation of spore-containing dust often contaminated with bird or bat droppings is the primary cause of these diseases.

NIOSH has received numerous inquiries and has actively engaged in the preparation of Health Hazard Evaluations pertaining to worker concerns about Histoplasma capsulatum, Cryptococcus neoformans, Blastomyces dermatitidis, and Coccidioides immitis associated with bat and bird droppings or contaminated soil in various occupational settings.

The efficacy of various technologies and methods for preventing these infections has not been adequately evaluated because no reliable, direct, soil isolation method exists for detecting these fungal agents. Small quantities of H. capsulatum are difficult to detect in soil samples. Fast, inexpensive analytical methods for specific fungi would permit their detection in soil and bird and bat droppings. The efficacy of various disinfectants could then be evaluated, as well as environmental control measures such as dust suppression. A method with sufficient sensitivity to detect small numbers of fungi is being developed using state-of-the-art molecular bioanalytical techniques to identify pathogenic fungi from construction and agricultural workplaces. A DNA analytical method, the polymerase chain reaction (PCR), has been developed specifically to detect $H$. capsulatum.

PATENT: Application number U.S.S.N. 60/082,477
KEYWORDS: $H$. capsulatum, PCR, pathogenic fungus

\section{RECENT CITATIONS:}

Reid, T.M., and M.P. Schafer. 1999.

Direct detection of Histoplasma capsulatum in soil suspensions by two-stage PCR. Molecular and Cellular Probes, v. 13, pp. 269-273. 


\section{INITIAL RESPIRATORY RESPONSES IN WELDING APPRENTICES}

\section{RESEARCHER: David Wegman}

\section{AFFILIATION: University of Massachusetts-Lowell (978) 934-3265}

PURPOSE: Investigate the nature of the association between exposures to welding fumes and acute respiratory responses through a study of welding apprentices.

RESEARCH SUMMARY: Despite some inconsistencies in study results, evidence of an association between exposure to welding fumes and occupational asthma has been growing over the past 15 years. Most earlier epidemiological studies concerning exposures to welding fumes and their respiratory effects have been limited by the cross-sectional study design, the selection of study populations with extensive welding experience, and limited information on the timing and nature of exposures to welding fumes.

We propose a study of 200 welding apprentices in which airway reactivity and acute respiratory responses will be measured early in the apprentices' careers, that is, within 6 months of their first exposure to welding fumes. Since welders who experience respiratory problems related to welding are less likely to stay in the welding field over the long term, a study of welding apprentices who are just entering the field has the advantage of including workers who experience respiratory problems early on.

The study design focuses on short-term changes in pulmonary function parameters with simultaneous real-time assessment of exposures to particulates and nitrous oxide (NOx). Average levels of exposure to these variables and to fluoride will be provided during the training session. Recent evidence suggests that there is an acute respiratory response 15 minutes after the first daily exposure to welding fumes, so pulmonary function and respiratory symptoms will be measured before the start of a welding training session, 15 minutes after the first weld, and at hourly intervals throughout the welding session.

The real-time personal exposure measurements will be used to identify peak levels. These exposure variables will be examined in relation to respiratory responses, and airway reactivity will be measured by response to cold-air challenge testing before and after apprentices have learned to weld. In addition, determinants of welding fume exposures will be identified by considering factors such as ventilation, type of welding work, and worker habits.

This study will provide insights into the nature of the association between welding fume exposures and acute respiratory responses. Recommendations will be made for the most effective respiratory and exposure variables to use in epidemiological assessments. Assessment of determinants of exposure will also be useful for consideration of exposure control options.
Welding Fume Concentration

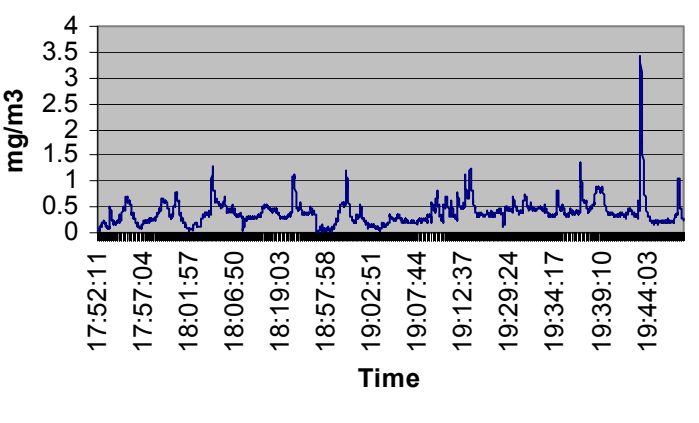

KEYWORDS: Welding, asthma 


\section{ROLE OF $\mathrm{O}_{3}$ IN MODULATING Cr TOXICITY IN THE LUNGS}

\section{RESEARCHER: Judith Zelikoff}

\section{AFFILIATION: New York University Medical Center (845) 885-5230}

PURPOSE: Investigate mechanisms underlying the elevated lung cancer incidence in welders exposed to fumes containing both chromium and $\mathrm{O}_{3}$ (ozone).

RESEARCH SUMMARY: Most studies of occupationally relevant chemical hazards have focused on single contaminants, and so the biological and safety implications of inhaling mixtures have been ignored in evaluations of the effects of contaminants on worker health and safety. A major health hazard from inhalation exposure to chromium- $(\mathrm{Cr})$ containing materials is lung cancer. However, the contribution from other co-inhalants in modulating Cr-initiated responses is not clear. Co-contaminants may change the pulmonary environment, producing conditions that could enhance the formation and survival of $\mathrm{Cr}$-initiated tumors. During welding, $\mathrm{Cr}$ is released with ozone $\left(\mathrm{O}_{3}\right)$. It has been demonstrated that inhaling $\mathrm{O}_{3}$ simultaneously with $\mathrm{Cr}$ increases the retention of insoluble $\mathrm{Cr}$ particles in the lungs. This situation could ultimately give rise to conditions within the lungs conducive to the formation and survival of Cr-initiated neoplasia.

This research will address the hypothesis that the carcinogenic potential of insoluble $\mathrm{Cr}$ in the lungs of welders and other workers inhaling a $\mathrm{Cr} / \mathrm{O}_{3}$ mixture is greater than carcinogenic potential in hosts inhaling $\mathrm{Cr}$ alone. The cause is thought to stem from $\mathrm{O}_{3}$-mediated increases in the lung tissue burdens of $\mathrm{Cr}$ and/or augmentation of one or more documented genetic/epigenetic mechanisms (increased level of DNA damage, chromosomal aberrations, and/or increases in the activity of cell kinases) associated with Cr-induced conversion of normal to abnormal cells. More specifically, the effects of $\mathrm{O}_{3}$ on mechanisms utilized for the intracellular processing of insoluble calcium chromate $[\mathrm{Cr}(\mathrm{VI})]$ particles will be studied.

This project involves exposing rats to atmospheres containing carcinogenic $\mathrm{Cr}(\mathrm{VI})$ alone and in combination with $\mathrm{O}_{3}$. The results of this study should improve our understanding of the mechanisms underlying the interaction between $\mathrm{Cr}$ and $\mathrm{O}_{3}$ in the lungs and the role that mixtures of air contaminants may play in pulmonary disease pathogenesis following exposure.
KEYWORDS: Airborne contaminants, cancer, mixed exposures

\section{RECENT CITATIONS:}

Cohen, M.D., M. Sisco, K. Baker, D. Bowser, L.C. Chen, and R.B. Schlesinger. (In press.) Impact of co-exposure to ozone on the carcinogenic potential of inhaled chromium. I: Effects on retention and on extra- and intracellular distribution. Journal of Toxicology and Environmental Health. 


\section{PREVENTION OF INHALATION HAZARDS IN CONSTRUCTION}

\section{RESEARCHER: Susan Woskie}

\section{AFFILIATION: University of Massachusetts-Lowell (978) 934-3295}

\section{CONSORTIUM: Center to Protect Workers' Rights}

PURPOSE: Reduce respiratory exposures in concrete work and other stages of construction through the development and evaluation of appropriate organizational and technological interventions.

RESEARCH SUMMARY: Highway construction workers and operators of heavy construction equipment are exposed to a variety of inhalation hazards, including dust, diesel exhaust, quartz, welding

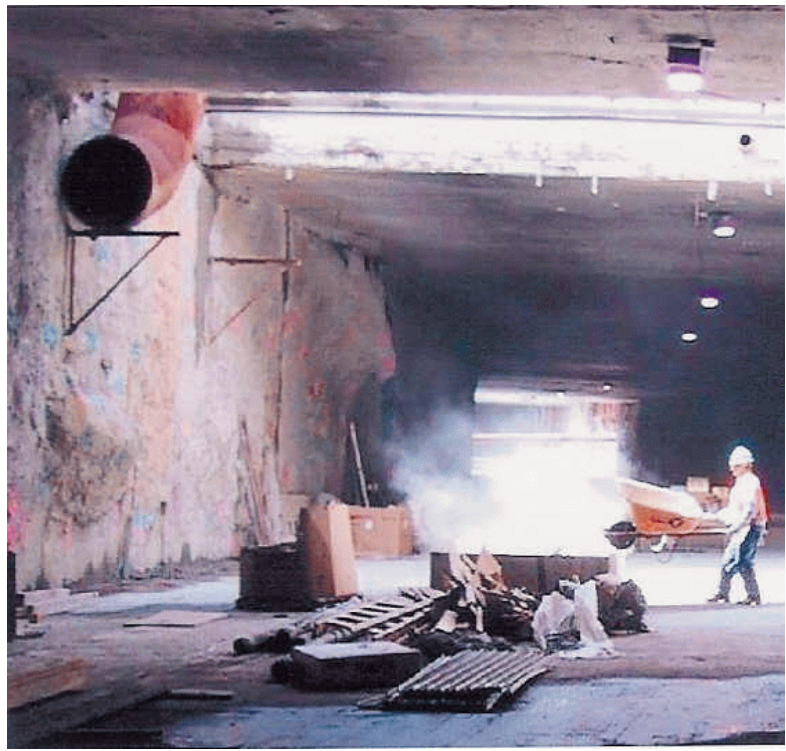
fumes, and lead. Personal samples for exposure to dust, diesel exhaust, quartz, and welding fumes were collected from these workers. The respirable, thoracic, and inhalable fractions of dust and quartz exposures were estimated from 260 personal samples. Respirable quartz exposures exceeded the NIOSH Recommended Exposure Limit (REL) in 7\% to $31 \%$ of the cases in the trades sampled. Over $50 \%$ of the samples from workers finishing concrete and installing drop ceilings and wall tiles exceeded the NIOSH REL for quartz. Thoracic exposures to quartz and dust exceeded respirable exposures by factors of 4.5 and 2.8 , respectively. Inhalable exposures to quartz and dust exceeded respirable exposures by factors of 25.6 and 9.3, respectively. These findings are important because quartz was identified as a carcinogen by the National Toxicology Program and the International Agency for Research on Cancer.

Fourteen percent of the 261 personal samples for elemental carbon collected as a marker for diesel exhaust exceeded the American Conference of Governmental Industrial Hygienists (ACGIH) Threshold Limit Value (TLV) for diesel exhaust. Seventeen of the twenty-two (77\%) samples taken during a partially enclosed welding operation reached or exceeded the ACGIH TLV of $5 \mathrm{mg} / \mathrm{m}^{3}$ for welding fumes.

Given the potential for high exposures to inhalation hazards in construction, efforts to develop and implement exposure controls are needed. Exposure monitoring using videos and quantification of crystalline silica in the respirable, thoracic, and inhalable particle-size fractions will be used to evaluate the efficacy of several engineering control interventions, including the use of local exhaust ventilation and wetting, during the use of power tools on concrete. Worker and management barriers to organizational interventions and engineering controls to reduce exposures will be evaluated.

The New England Laborers Training Center is collaborating on this project. 


\section{REVISED NIOSH GUIDE FOR RESPIRATORY PROTECTION}

KEYWORDS: Recommendations, respirators

\section{RESEARCHER: Carol Merry Stephenson}

\section{AFFILIATION: Education and Information Division National Institute for Occupational Safety and Health}

(513) 533-8581

PURPOSE: Revise the NIOSH Guide to Industrial Respiratory Protection to incorporate important advances in respirator technology, updated OSHA standards, current respirator research, NIOSH recommendations, and information on emerging nuclear, biologic, and chemical threats where the use of respirators may be required.

RESEARCH SUMMARY: In partnership with other federal agencies, NIOSH has a long history of direct involvement in preventing respiratory injury and illness by certifying respirators and disseminating information to workers and health and safety professionals about proper respirator use. Respirators are critical personal protective equipment for workers in many industries - construction, agriculture, mining, firefighting, and health care. For example, it has been estimated that $20 \%$ of U.S. farmers suffer from some form of respiratory aliment. Among construction workers, silicosis is a major concern; among miners, black lung and related respiratory illnesses have not been eliminated. Recently, the rise in drug-resistant tuberculosis has resulted in the need for respirator training and use among many health care workers. Finally, there is new nationwide emphasis on respirator training for police, firefighters, and emergency medical teams in response to the threat of terrorism.

In this project, the NIOSH Guide to Industrial Respiratory Protection, first published in 1987, will be updated. Following a format similar to that in the 1987 publication, the revised edition will incorporate new NIOSH recommendations and policies, describe current advances in respiratory protection, update the OSHA Respiratory Protection Standard, examine trends in respirator research, and address timely issues related to nuclear, biologic, and chemical threats where the use of respiratory protection may be necessary.

A team of respirator experts was convened to outline the document, establish a production timeline, and write the document. When complete, the document will be widely disseminated, both in print and on the NIOSH website, and will be a valuable reference for health and safety professionals working to prevent respiratory illnesses in construction, agriculture, mining, firefighting, health care, and other work sectors requiring protection from respirable hazards. 


\title{
RESPIRATORY PROTECTION FOR CONSTRUCTION WORKERS
}

\author{
RESEARCHER: Carol Merry Stephenson
}

\section{AFFILIATION: Education and Information Division National Institute for Occupational Safety and Health \\ (513) 533-8581}

PURPOSE: Develop a series of informational and educational products on respiratory protection for construction workers.

RESEARCH SUMMARY: More than 20 million workers are potentially exposed to occupational-disease-causing agents. Currently, 6-12 million workers wear respirators on a routine basis as the final method of protection and in a wide range of emergency situations. Workers engaged in the construction trades (e.g., laborers, painters, sand blasters, demolition) are exposed to a wide variety of airborne contaminants such as silica, asbestos, lead, and solvent fumes. However, respiratory protection is only as good as the training the user receives and how well the respirator program is designed, administered, and used. Many of these construction workers receive little or no training on the proper selection and use of respiratory protection.

Respirators serve as the major source of protection for many of these individuals, yet effective respirator use requires considerable training in selecting, fitting, maintaining, and operating them. A series of documents have been produced to provide small business owners, safety professionals, and workers in the construction trades with guidance in setting up an adequate respiratory protection program. Checklists, sample forms, and the information needed for proper selection, use, and maintenance of respirators are a part of the package. In consultation with the Center to Protect Workers' Rights, specific trades at risk from respiratory hazards were identified. Drywallers were chosen as the first construction group for which an instruction package would be prepared on the maintenance and fitting of respirators and the training needed for an effective respirator protection program. 


\section{ASPHALT FUME CHARACTERIZATION AND HAZARD IDENTIFICATION}

\section{RESEARCHER: Larry Olsen \\ AFFILIATION: Division of Applied Research and Technology \\ National Institute for Occupational Safety and Health \\ (513) 533-8543}

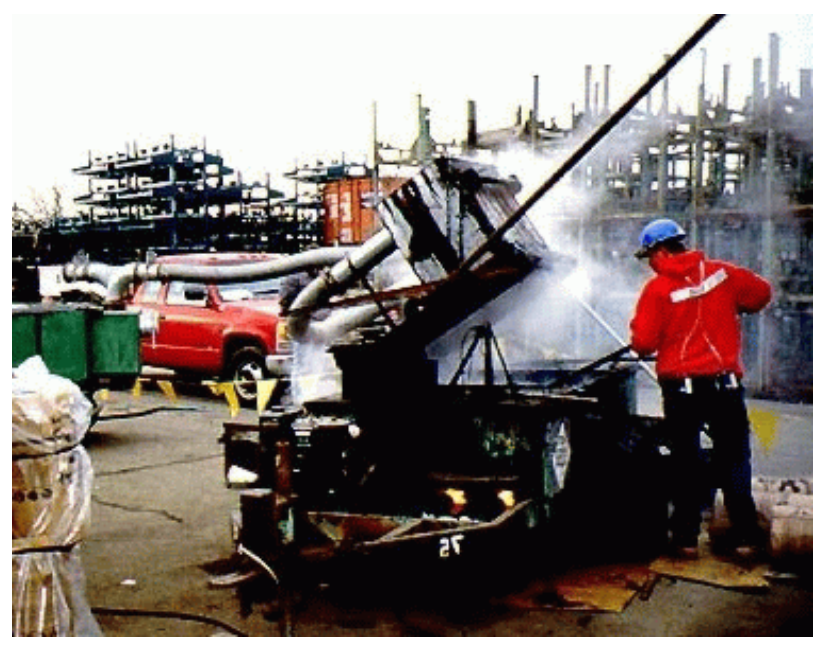

PURPOSE: Identify specific compounds or compound classes in asphalt fumes that may cause irritation or genotoxicity.

RESEARCH SUMMARY: This research will be integral to development of sampling and analytical methods used to assess exposures to asphalt fumes and specific irritants and genotoxins. Laboratory research will be useful in designing better worker exposure protocols, identifying specific biomarkers to assess a worker's true exposure, and designing animal studies to evaluate physiological and toxicological effects associated with exposure.

Specifically, research will focus on the following tasks:

- Fractionate, analyze, and bioassay the biologically active asphalt fume fractions from an earlier study to identify specific genotoxins that may be responsible for observed tumors.

- Conduct research for the Federal Highway Administration to determine if the addition of crumb-rubber to asphalt mixtures results in more-hazardous asphalt fumes.

- Test paving asphalt fume samples for mutagenicity under an interagency agreement with EPA.

- Characterize the chemistry of paving and roofing asphalt fume samples.

- Consult on the chemical characterization and assessment of the asphalt fumes to which animals will be exposed to investigate physiological and toxic responses.

- Collaborate on the development of sampling and analytical methods for the benzene-soluble fraction and total particulates.

- Collaborate on ways to foster better communication regarding asphalt fume research.

- Collaborate with industry researchers to evaluate high-performance chromatography (HPLC)/fluorescence methods for the determination of polycyclic aromatic hydrocarbons (PAH's) in asphalt fumes and compare results with results using gas chromatography/mass spectrometry (GC/MS) techniques.
KEYWORDS: Asphalt, hazard identification, analytical methods

\section{RECENT CITATIONS:}

Butler, M.A., G. Burr, D. Dankovic, R.A. Lunsford, A. Miller, M. Nguyen, L. Olsen, D. Sharpnack, J. Snawder, L. Stayner, M. Haring Sweeney, A. Teass, J. Wess, and R. Zumwalde. 2001. Health effects of occupational exposure to asphalt. NIOSH Hazard Review. DHHS (NIOSH) Pub. 2001-110.

Jaycox, L.B., and L.D. Olsen. 2000. Determination of total sulfur compounds and benzothiazole in asphalt fume samples by gas chromatography with sulfur chemiluminescence detection. Applied Occupational and Environmental Hygiene, v. 15, no. 9, pp. 695-704.

Qian, H-W., W-Z. Whong, L. Olsen, J. Nath, and T. Ong. 1999. Induction of micronuclei in V79 cells by fractions of roofing asphalt fume condenate. Mutation Research, v. 441, no. 2, pp. 163-170. 


\section{MOLECULAR MARKERS OF ASPHALT FUME EXPOSURE}

\section{RESEARCHER: Jin Wang}

\section{AFFILIATION: Health Effects Laboratory Division National Institute for Occupational Safety and Health \\ (304) 285-6329}

PURPOSE: Develop state-of-the-art analytical and bioanalytical methods to study the adverse health effects of asphalt fume exposures.

RESEARCH SUMMARY: Millions of tons of asphalt are produced and used every year in the paving and roofing industries. It has been estimated that crude asphalt contains the most widely distributed class of potent carcinogens present in the human environment. Exposure to these mixtures may pose a health risk to workers; however, specific adverse effects have not been established. In particular, the relationship between exposure and DNA damage is not clear. Also, there is a concern about long-term health effects following chronic exposure.

A sensitive, selective, and reliable analytical method has been developed and validated for characterization of asphalt fumes generated under conditions that simulate road paving sites. The new method could be used as an effective tool to study the adverse health effects of workers exposed to hazardous mixtures.

Polycyclic aromatic hydrocarbons (PAH's) contained in asphalt are an important class of chemical hazards. These compounds or their metabolites can interact with DNA, resulting in covalent bonding between chemicals and biological macromolecules and consequent damage to DNA. In this study, female Sprague-Dawley rats and B6C3F1 mice were exposed to asphalt fumes in a whole-body inhalation chamber. A new bioanalytical method was developed to characterize DNA adducts and PAH metabolites. This method has a wide variety of applications in detecting molecular markers during exposure to a number of different agents.

The information obtained from these studies may assist risk assessment and the development of prevention strategies for people exposed to such mixtures in the workplace.
KEYWORDS: Asphalt fume exposure, biomarkers, analytical and bioanalytical methods

\section{RECENT CITATIONS:}

Wang, J., D.M. Lewis, V. Castranova, D.G. Frazer, T. Goldsmith, S.

Tomblyn, J. Simpson, S. Stone, A. Afshari, and P.D. Siegel. 2001. Characterization of asphalt fume composition under simulated road paving conditions by GC-MS and microflow LC-Q-TOF MS. Analytical Chemistry, v. 73, no.15, pp. 3691-3700.

Wang, J., D.M. Lewis, J. Meade, B.F. Law, S. Tomblyn, and P.D. Siegel. 2001. Characterization of DNA damage and PAHs metabolites in mice lung exposed to asphalt fume by capillary flow Q-TOF MS.

Presentation at 49th annual meeting of American Society of Mass Spectrometry, Chicago, IL, May 2001.

Wang, J., D. Lewis, B.V. Law, D. Frazer, S. Stone, T. Goldsmith, A. Mosley, J. Simpson, and P. Siegle. 2002. Urinary metabolites characterization of asphalt fume exposure. Presentation at 41 st annual meeting of Society of Toxicology, Nashville, TN, Mar. 2002. 


\section{ASPHALT FUMES: INFLAMMATORY EFFECTS AND PULMONARY INJURY}

\section{RESEARCHER: Jane Ma}

\section{AFFILIATION: Health Effects Laboratory Division National Institute for Occupational Safety and Health}

(304) 285-5844

PURPOSE: Investigate the effects of asphalt fumes on pulmonary irritation, inflammation, airway reactivity, and lung injury.

RESEARCH SUMMARY: A 1983 NIOSH report showed that at least 500,000 workers were exposed to asphalt fumes in the United States. Exposure to asphalt fumes during road paving operations has been associated with airway irritation and airway hyperreactivity in some pavers.

It is known that the fumes generated from both paving and roofing asphalts are very complex mixtures, containing particulates and various organic compounds, such as polycyclic aromatic compounds (PAH's). Exposures to mixed materials, such as asphalt fumes, may result in greater pulmonary injury than exposure to a single agent.

In this project, the effects of road paving asphalt fumes on airway irritation, pulmonary inflammation, airway reactivity, and lung damage will be monitored to assess the inflammatory potential of asphalt fumes and oxidative stress in the lungs. Pulmonary injury will be evaluated by measuring oxidant generation, inflammatory cytokine secretion, and metabolic activities in the lung. Airway irritation will be monitored by histological evaluation of the nasal cavity. Airway reactivity will be evaluated by measuring pulmonary function. These studies will characterize in detail the major components of cytochrome 450 , cytochrome $1 \mathrm{~A} 1$, and cytochrome $2 \mathrm{~B} 1$ isozyme levels, and metabolic activities of these isozymes. The results of these studies should aid in better understanding of the mechanism of potential toxicity induced by asphalt fumes and the potential health hazards associated with exposure to asphalt fumes.
KEYWORDS: Asphalt, hazards, mixed exposures

\section{RECENT CITATIONS:}

Gamble, J.F., M.J. Nicolich, N.J. Barone, and W.J. Vincent. 1999. Exposure-response of asphalt fumes with changes in pulmonary function and symptoms. Scandinavian Journal of Work and Environmental Health, v. 25, pp. 186-206.

Jarvholm, B., G. Nordstrom, B. Hogstedt, J.O. Levin, J. Wahlstrom, C. Ostman, and C. Bergendahl. 1999. Exposure to polycyclic aromatic hydrocarbons and genotoxic effects on nonsmoking Swedish road pavement workers. Scandinavian Journal of Work and Environmental Health, v. 25, pp. 131-136.

Ma, J.Y., M.W. Barger, A.J. Kriech, and V. Castranova. 2000. Effects of asphalt fume condensate exposure on acute pulmonary responses. Archives of Toxicology, v. 74, pp. 452-459.

Micillino, J.C., C. Coulais, S. Binet, M.C. Bottin, G. Keith, D. Moulin, and B.H. Rihn. 2002. Lack of genotoxicity of bitumen fumes in transgenic mouse lung. Toxicology, v. 170, pp. 11-20. 


\section{ASSESSMENT OF ASPHALT FUME EXPOSURE FROM ROOFING KETTLES}

\section{RESEARCHER: David Marlow}

\section{AFFILIATION: Division of Applied Research and Technology National Institute for Occupational Safety and Health (513) 841-4204}

PURPOSE: Evaluate existing engineering controls of fume exposures to roofing kettle operators and redesign those controls to reduce worker exposures.

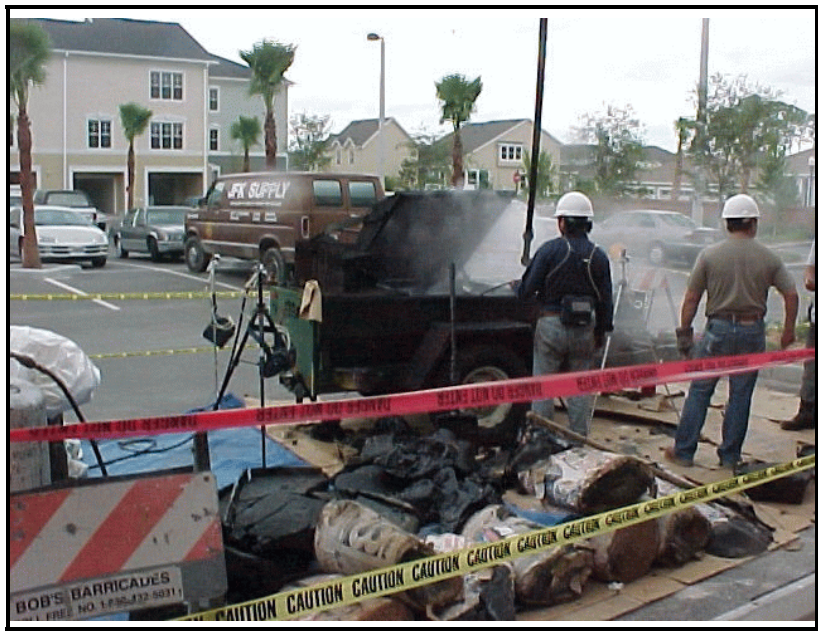

RESEARCH SUMMARY: Because of extreme asphalt temperatures during the roofing process, roofers may be at the highest risk of exposure to asphalt fumes of all industry or trade workers. In 1990, an estimated 46,000 roofing workers in the United States were exposed, most of them employed by small contractors (about $90 \%$ of roofing contractors have fewer than 20 employees) who do not have access to current technology for controlling exposures. Epidemiological data indicate excess mortality from cancer of the respiratory system, digestive system, and urinary system. Health effects from exposure to asphalt fumes include irritation of the respiratory tract and lung diseases such as bronchitis, emphysema, and asthma.

The evaluation and development of practical controls for roofing kettle emissions could significantly reduce worker exposure to asphalt fumes. This will be accomplished through a combination of isolation and local ventilation techniques, changes in work processes, and industry and labor partnerships. Specific recommendations will be based on initial surveys and quantitative analyses of exposure levels. The exposure of roofing kettle operators to asphalt fumes will be evaluated, the efficiency of existing exposure controls will be examined, and recommendations will be provided as necessary. To date, literature searches, discussions with roofing kettle manufacturers and operators, and walk-through surveys have provided pertinent information on asphalt fume generation and control. In-depth studies have been conducted using conventional and real-time air sampling techniques to evaluate worker exposure and the effectiveness of controls.

A pilot study demonstrated a statistically significant reduction of from $55 \%$ to $95 \%$ in the benzene-soluble fraction of total particulates in area and personal exposures when a low-fuming, built-up roofing asphalt (BURA) was used instead of a standard BURA. Low-fuming BURA contains a blend of up to $1 \%$ polymers that form a crust that reduces the release of fumes from asphalt.

Four field surveys were conducted to study whether similar reductions could be seen in the workplace. Personal breathing zone and area air samples were collected from both low-fuming asphalt and standard BURA and analyzed for total particulates, benzene-soluble fraction, and polycyclic aromatic compounds. Results of these surveys showed that when low-fuming BURA was used, kettle operators' mean exposures were reduced by $75 \%, 85 \%$, and
$77 \%$, respectively, and roof-level workers exposures were reduced by $28 \%, 24 \%$, and $27 \%$, respectively.

KEYWORDS: Asphalt, small business, engineering controls, roofers

\section{RECENT CITATIONS:}

Franzen, M.R., and D.C. Trumbore. 2000. Reduction of asphalt fumes in roofing kettles. Environmental Science and Technology, v. 34, pp. 2582-2586. 


\section{CONTROL OF EXPOSURE DURING APPLICATION OF ASPHALT ROOFING MATERIALS}

\section{RESEARCHER: Joann Wess}

\section{AFFILIATION: Education and Information Division National Institute for Occupational Safety and Health}

(513) 533-8342

PURPOSE: Develop a technical document that addresses work practices and methods for reducing exposure to asphalt fumes and other potential hazards during the application of hot asphalt to roofs.

RESEARCH SUMMARY: Approximately 46,000 workers are involved in the application of hot asphalt to roofs. Exposures have been hypothesized to be related to increased incidence of some cancers, as well as lung and skin irritation. A draft document produced jointly by the Asphalt Roofing Manufacturers' Association (ARMA), the National Roofing Contractors' Association (NRCA), the Asphalt Institute (AI), and the United Union of Roofers, Waterproofers, and Allied Workers was presented to NIOSH for review and further development in a collaborative effort.

The document will describe methods to control and reduce asphalt exposure among workers in the asphalt roofing industry. The intended audience is plant managers, safety and health personnel, and engineers in industry and government. Dissemination of the document will be through trade unions, trade associations, the Internet, and other means appropriate for this population.
KEYWORDS: Work practices, asphalt, hazards, roofers

\section{RECENT CITATIONS:}

National Institute for Occupational Safety and Health. 2001. Health effects of occupational exposure to asphalt. NIOSH Hazard Review. DHHS (NIOSH) Pub. 2001-110.

National Institute for Occupational Safety and Health. 2001. Asphalt fume exposure during the manufacture of asphalt roofing products: Current practices for reducing exposures. DHHS (NIOSH) Pub. 2001-127.

Gamble, J.F., M.J. Nicolich, N.J. Barone, and J. Vincent. 1999.

Exposure-response of asphalt fumes with changes in pulmonary function and symptoms. Scandinavian Journal of Work and Environmental Health, v. 25 , no. 3 , pp. $186-206$. 


\section{HEALTH EFFECTS OF ASPHALT EXPOSURE: DEVELOPMENT OF A REL}

\section{RESEARCHER: Joann Wess}

\section{AFFILIATION: Education and Information Division National Institute for Occupational Safety and Health}

(513) 533-8342

PURPOSE: Acquire the documentation and develop a recommended standard that includes an occupational exposure limit for asphalt based on a recently published NIOSH Hazard Review document on asphalt.

RESEARCH SUMMARY: Nationwide, 300,000 workers are involved in the application of asphalt paving materials, and 46,000 workers apply hot roofing materials. These workers include laborers, operating engineers, roofers, and waterproofers.

The information published in a recent NIOSH Hazard Review will be used along with medical and exposure data collected by NIOSH during an evaluation of paving workers to develop a recommended standard for asphalt. The standard or criteria document will include recommendations for medical surveillance and exposure monitoring, the use of personal protective equipment and engineering controls, work practices, and the basis for a Recommended Exposure Limit (REL).

Compliance with the REL should reduce risks of lung cancer and acute and chronic respiratory effects in workers exposed to asphalt during road paving, the manufacture of asphalt products, and the application of hot asphalt roofing and asphalt-containing waterproofing materials.
KEYWORDS: Occupational exposure limits, asphalt, cancer

\section{RECENT CITATIONS:}

National Institute for Occupational Safety and Health. 2001. Health effects of occupational exposure to asphalt. NIOSH Hazard Review. DHHS (NIOSH) Pub. 2001-110.

Miller, A.K., and G.A. Burr. 1998. Health hazard evaluation report: Bardon-Trimount, Stoughton, Massachusetts. NIOSH HETA No. 97-0232-2674. 


\section{CONCISE INTERNATIONAL CHEMICAL ASSESSMENT ON ASPHALT EXPOSURE}

\section{RESEARCHER: Joann Wess}

\section{AFFILIATION: Education and Information Division National Institute for Occupational Safety and Health}

(513) 533-8342

PURPOSE: Develop a Concise International Chemical Assessment Document (CICAD) in partnership with the World Health Organization concerning asphalt fumes from paving, roofing, manufacturing, and other processes.

RESEARCH SUMMARY: In the United States, over 300,000 workers are employed in the asphalt paving and hot-mix industries, 53,000 workers are employed in roofing, and 1,500 are employed in producing asphalt-based roofing materials. Asphalt fumes are a complex mixture of petroleum byproducts. The composition of this mixture and its resultant toxicity is dependent on many factors, including the engineering controls used during various stages of asphalt application. Limited toxicologic data suggest that asphalt fumes composed of polycyclic aromatic hydrocarbons are carcinogenic in animals.

A Concise International Chemical Assessment Document (CICAD) on asphalt exposure will be developed in partnership with the World Health Organization (WHO). CICAD's are concise documents that provide summaries of the relevant scientific information concerning the potential effects of chemicals on human health and the environment. The proposed CICAD will characterize exposures to asphalt fumes and describe their potential effects on human health in both the workplace and the environment. It will be based on information generated by NIOSH research and partnership efforts with the asphalt industry and representatives of workers in that industry. This information has been published, in part, in NIOSH documents on controlling exposure to asphalt fumes and in a Health Hazard Review on the health effects of occupational exposure to asphalt. The project would involve limited searches in additional literature on the environmental transport, distribution, and transportation of asphalt and asphalt by-products. The available information would be compiled and reviewed and developed into a CICAD and disseminated worldwide through our partnership with WHO.

In addition to being an international resource document, this CICAD could serve as concise publication for industrial hygienists in the United States who are involved with construction workers who may be exposed to asphalt fumes.
KEYWORDS: Polycyclic aromatic hydrocarbons, occupational exposure limits

\section{RECENT CITATIONS:}

National Institute for Occupational Safety and Health. 2001. Health effects of occupational exposure to asphalt. NIOSH Hazard Review. DHHS (NIOSH) Pub. 2001-110. 


\section{ENGINEERING CONTROLS/INSTRUMENTS AND EQUIPMENT}

\section{SUMMARY OF BLOOD LEAD MONITORING EVALUATION PROJECT}

\section{RESEARCHER: Lauralynn Taylor}

\section{AFFILIATION: Division of Surveillance, Hazard Evaluations, and Field Studies \\ National Institute for Occupational Safety and Health}

(513) 841-4571

PURPOSE: Validate an anodic stripping voltammetry instrument that analyzes capillary and venous blood lead levels rapidly in the field.

RESEARCH SUMMARY: It is estimated that more than 30,000 individuals in the United States have work-related blood lead levels above $25 \mu \mathrm{g} / \mathrm{dL}$. OSHA, EPA, and HUD require exposure monitoring for both blood lead and environmental lead levels. Currently, the blood monitoring methods require a venipuncture blood draw and shipment to an off-site laboratory for analysis.

An anodic stripping voltammetry instrument has been developed by ESA, Inc., Chelmsford, MA, in conjunction with CDC. This instrument provides a prompt, cost-effective technique to monitor lead exposures for pediatric screening. Although this instrument has only been used with children whose blood lead levels are significantly lower than in exposed adults, its capability to analyze blood quickly on-site makes it potentially valuable to occupational health professionals during on-site investigations, particularly with highly transient workers such those in construction. We will compare instrument results with split samples analyzed according to CDC's Whole Blood Method $1080 \mathrm{C}$ from adult populations exposed to high lead levels. The practicality and cost-effectiveness of using this instrument in the workplace will be assessed and its precision estimated.

A second objective of this project is to collect samples from earlobe capillaries and determine whether these samples can be used to monitor blood lead levels. This sampling and analytical technique is less invasive and could provide quicker results than current methods, guiding efforts to reduce lead exposures rapidly.

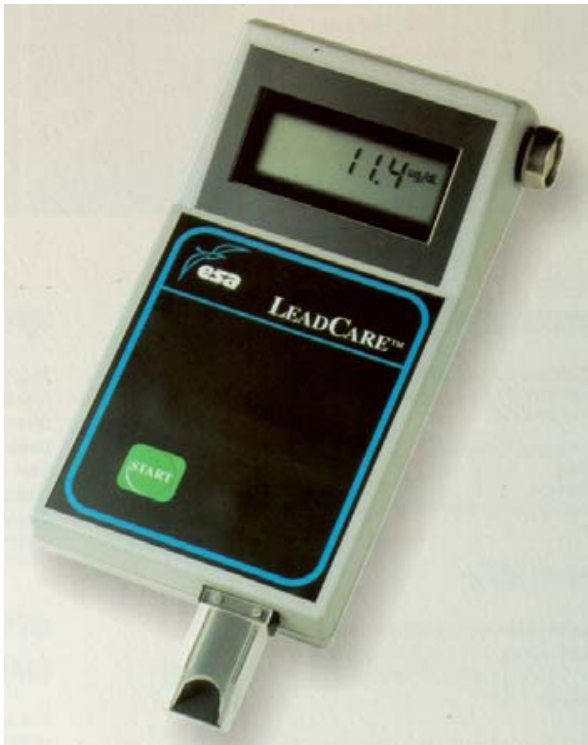

ESA's LeadCare ASV instrument

KEYWORDS: Lead, biomarkers, exposure assessment

\section{RECENT CITATIONS:}

Taylor, L., R.L. Jones, L. Kwan, J.A. Deddens, K.A. Ashley, and W.T. Sanderson. 2001. Evaluation of a portable blood lead analyzer with occupationally exposed populations. American Journal of Industrial Medicine, v. 40, no. 3, pp. 54-362.

Taylor, L., R.L. Jones, L. Kwan, J.A. Deddens, K.A. Ashley, and W.T.

Sanderson. 2000. Blood lead monitoring technologies.

Presentation at Council and State

Territory Epidemiologists Conference, New Orleans, LA, June 2000.

Taylor, L., R.L. Jones, L. Kwan, J.A. Deddens, K.A. Ashley, and W.T.

Sanderson. 2000. Blood lead monitoring: An evaluation of a rapid blood lead analyzer. Presentation at American Industrial Hygiene Conference, Orlando, FL, May 2000. 


\section{LOCAL POSITIONING SYSTEM FOR EXPOSURE ASSESSMENT AND CONTROL}

\section{RESEARCHER: Jennifer Hornsby-Myers}

\section{AFFILIATION: Health Effects Laboratory Division National Institute for Occupational Safety and Health}

(304) 285-6358

PURPOSE: Design and develop prototype personal-location units that can be used in conjunction with appropriate monitoring devices both indoors and outdoors to assess safety and health hazards in the workplace.

RESEARCH SUMMARY: Workers in many occupations move about frequently during a typical workday. Certain workers, such as agricultural and construction workers, are particularly mobile. By linking a worker's location throughout the workday to real-time monitors of hazardous materials, local positioning system (LPS) units with data processing capabilities could identify and document where to focus exposure analyses and control efforts. Postprocessing of LPS data may enable researchers, regulatory inspectors, and industry safety and health personnel to map the location, distribution, and intensity of a hazardous material. In addition, LPS units may allow researchers to explore new means of detecting, analyzing, and controlling safety and health hazards.

An outdoor backpack prototype was reduced to a hand-held prototype. This smaller prototype will be field tested with real-time exposure sensors (dust, noise, temperature, and a gas monitor) to determine its performance. LPS units will use industry-standard connectors to input data from portable exposure monitors. Work conducted in collaboration with the U.S. Coast Guard Academy's Center for Advanced Studies has shown direct-sequence spread-spectrum technology to be feasible for indoor positioning when using military frequencies. The NIOSH LPS design will allow easier set-up at research sites than do existing monitors and will allow the device to be used on unlicensed civilian frequencies. The indoor LPS should provide information on indoor air quality and noise levels.

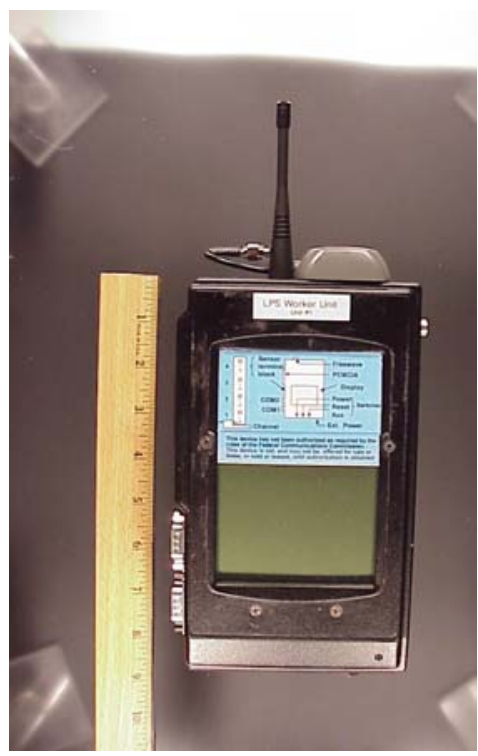

KEYWORDS: Control technology, exposure assessment, hazards

\section{RECENT CITATIONS:}

Hornsby-Myers, J.L., L. Lee, and M. Flemmer. 2002. Field testing of local positioning system. Poster presentation at Salt Fork X, Mineral Wells, WV. 


\title{
SCREENING METHODS FOR AIRBORNE METALS IN CONSTRUCTION
}

\author{
RESEARCHER: Kevin Ashley
}

$\begin{array}{ll}\text { AFFILIATION: } & \text { Division of Applied Research and } \\ \text { Technology } \\ \text { National Institute for Occupational } \\ \text { Safety and Health } \\ \text { (513) 841-4402 }\end{array}$

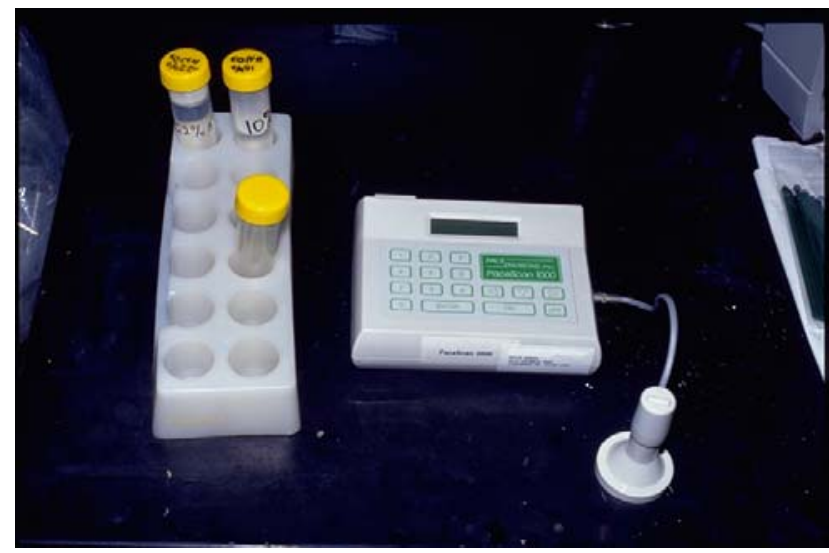

PURPOSE: Provide methods and technologies for on-site screening of metals in workplace samples to allow worker exposure and the effectiveness of control measures to be assessed in a timely manner.

RESEARCH SUMMARY: Several million workers in the United States are exposed to toxic metals on the job. Traditional exposure monitoring techniques requiring laboratory analysis are not always useful in the construction industry because results may not be available quickly enough to avoid overexposures or prolonged shutdown periods. Therefore, new methods for monitoring metals on-site, including metal species not previously investigated, need to be developed and evaluated so that information about worker exposures can be provided rapidly or, in some cases, even before work begins.

Although several portable analysis technologies and methods for measuring concentrations of airborne metals have been developed recently, they have not seen wide use in the workplace. This may be due to expense, complexity, poor limits of detection or accuracy relative to laboratory-based analysis, and nonacceptance by regulatory agencies. For example, portable anodic stripping voltammetry (ASV) and portable x-ray fluorescence (XRF) have recently been field-tested at construction and mining sites in collaborative work with the Spokane Research Laboratory; the Health Effects Laboratory Division; and the Division of Surveillance, Hazard Evaluations, and Field Studies. Other emerging technologies, such as laser- and spark-induced breakdown spectroscopy, show strong potential to provide real-time or near-real-time readings of airborne metal concentrations, but need to be fully developed and evaluated if they are to be considered for use as portable screening technologies for workplace applications. These collaborations will afford more comprehensive development and assessments of the performance and cost-effectiveness of portable technology in many workplace settings.

The refinement and careful testing of existing field-portable methods, along with the development of new ones, could herald a generation of simplified instruments and tools capable of providing rugged, accurate, and cost-effective screening for numerous airborne metals in the workplace on a near-real-time basis.

PATENT: Esswein, E., M. Boeniger, and K. Ashley. 2001. Handwipe disclosing method for the presence of lead. U.S. Patent 6,248,593.

KEYWORDS: Screening methods, exposure assessment

\section{RECENT CITATIONS:}

Sussell, A., and K. Ashley. 2002. Field measurement of lead in workplace air and paint chip samples by ultrasonic extraction and portable anodic stripping voltammetry. Journal of Environmental Monitoring, v. 4, pp. 156-161.

Song, R., P.C. Schlecht, and K. Ashley. 2001. Field screening test methods: Performance criteria and performance characteristics. Journal of Hazardous Materials, v. 83, pp. 29-39.

Ashley, K., T.J. Wise, W. Mercado, and D.B. Parry. 2001. Ultrasonic extraction and field-portable anodic stripping voltammetric measurement of lead in dust wipe samples. Journal of Hazardous Materials, v. 83, pp. 41-50.

Marlow, D., J. Wang, T. J. Wise, and K. Ashley. 2000. Field test of a portable method for the determination of hexavalent chromium in workplace air. American Laboratory, v. 32, no. 15 , pp. $26-28$. 


\section{ENVIRONMENTAL TRACTOR CAB SYSTEM INTEGRITY}

\section{RESEARCHER: Ernest Moyer}

\section{AFFILIATION: Division of Respiratory Disease Studies National Institute for Occupational Safety and Health (304) 285-5962}

PURPOSE: Evaluate aerosol exposure reduction resulting from the use of enclosed cabs.

RESEARCH SUMMARY: Construction workers, as well as workers in numerous other occupations such as mining, farming, and trucking, depend on enclosed environmental cabs to protect them from hazardous aerosols while they are operating equipment. These aerosols are often of unknown concentration and toxicity. This project will provide a critical link in the process of determining the cause(s) of hazardous exposure within enclosed cabs on equipment such as bulldozers, front-end loaders, grapplers, graders, haulage trucks, and tractor cabs.

Particulate filter efficiency has been tested in the laboratory. Now, aerosol particle counters are being evaluated to determine their ability to monitor total cab integrity and will be used in the field to identify leaks in environmental cabs. Equipment manufacturers, equipment operators, and NIOSH researchers will collaborate to measure the degree to which aerosols can penetrate environmental enclosures under real-world conditions. All phases, from manufacturing and design, audits, and routine maintenance, will be studied. Appropriate aerosol test methodology will be incorporated into a total cab performance program.

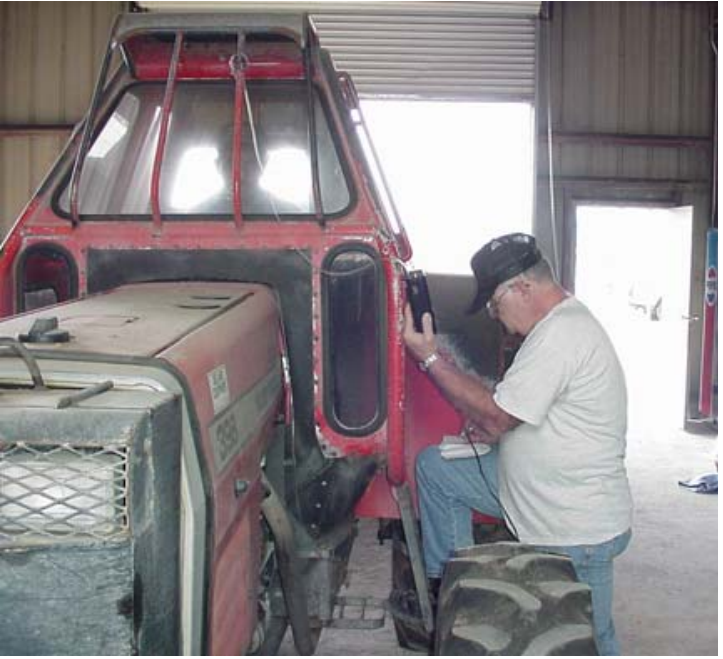

KEYWORDS: Control technology, exposure assessment, heavy equipment cabs, aerosol filtration, respiratory disease

\section{RECENT CITATIONS:}

Heitbrink, W.A., E.S. Moyer, P.A. Jensen, D.S. Watkins, and S.B. Martin. (2002. In press.) Environmental agricultural tractor $\mathrm{cab}$ filter efficiency and field evaluation. American Industrial Hygiene Association Journal. 
AEROSOL SAMPLER DEVELOPMENT

\section{RESEARCHER: Paul Baron}

\section{AFFILIATION: Division of Applied Research and Technology National Institute for Occupational Safety and Health \\ (513) 841-4278}

PURPOSE: Develop and evaluate more accurate fiber and dust samplers.

RESEARCH SUMMARY: Workers are exposed to dust that can include lead, chromium, and silica at virtually every construction site. Road construction and well drilling can create large quantities of silica-containing dust. Sanding and woodworking produce high concentrations of wood dust. Asbestos is still being removed from many facilities, and other fibers, such as refractory ceramic fibers, are still being used commercially.

Improved dust samplers are needed to assess total and respirable dust exposures for personal monitoring and dust control system evaluations. A collaboration between researchers at NIOSH's Division of Applied Research and Technology (DART) and the Health Effects Laboratory Division (HELD) has resulted in a new type of fiber length classifier that helps to analyze the in vitro toxicity of fibers as a function of fiber length. Preliminary tests of several options for a fiber sampler specific for the thoracic portion of aerosols have been carried out. The thoracic sampler will replace the current sampler, which has problems with sample uniformity and losses in the inlet.

Improvements are also needed in ways to determine sampler efficiency so that improvements can be made in determining overall sampler accuracy. Current techniques for evaluating large particles with personal samplers are slow and expensive. A wind tunnel was constructed that can measure airflow around the human body with a laser Doppler velocimeter (LDV). These measurements will be complemented with a particle-imaging velocimeter (PIV) that measures the flow field more rapidly and efficiently. A system that can generate a wide range of aerosol sizes has also been constructed to measure the sampling efficiency of aerosol samplers mounted on a body. Aerosol concentrations are measured at various locations around a manikin with either LDV or PIV systems (which count particles) or with isokinetic samplers (which measure particle concentrations at various distances from a body).

Velocity measurements were taken around the chest and "breathing zone" of a life-size manikin, as well as around a simplified manikin and freestanding samplers. The data are being examined by HELD to develop and validate computational fluid dynamics models of airflow around the samplers on the manikin. The combination of flow field measurements and calculations of particle concentrations will allow less expensive, more direct, and more rapid determinations of sampler inlet efficiency.
KEYWORDS: Aerosols, respiratory disease, sampling methods 


\section{CONTROL OF EXPOSURES DURING CONSTRUCTION}

\author{
RESEARCHER: Leo M. Blade
}

\section{AFFILIATION: Division of Applied Research and Technology \\ National Institute for Occupational Safety and Health \\ (513) 841-4549}

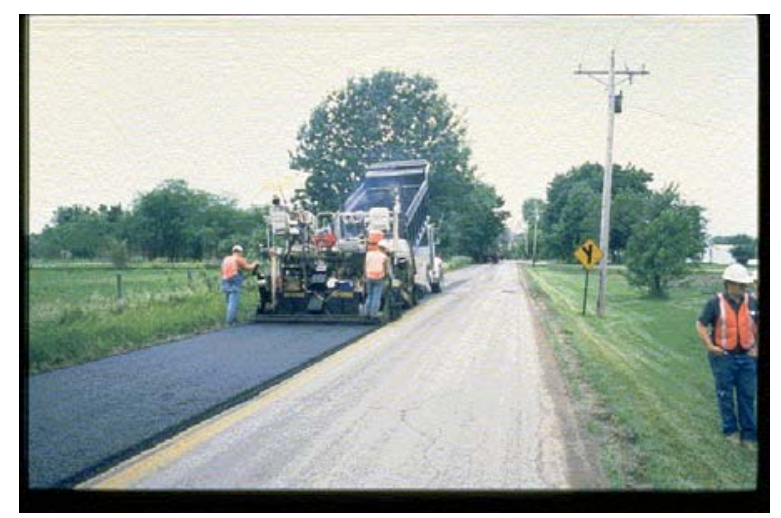

PURPOSE: Investigate the availability of engineering controls for identified construction processes. Assist equipment manufacturers in the design of engineering solutions to reduce exposure to occupational hazards, as well as help employers implement these designs.

RESEARCH SUMMARY: Researchers will assess the efficacy of existing measures to reduce occupational health hazards associated specifically with abrasive blasting, drywall finishing, and asphalt paving and roofing. Such measures include engineering controls and substitute materials and processes.

- An estimated 150,000 workers are employed in abrasive blasting, where they are exposed to a variety of airborne contaminants that may place them at risk of pulmonary disorders and other work-related illnesses. Existing technologies and methods, such as wet blasting, high-pressure water blasting, and the use of personal protective equipment, will be evaluated at active operations to evaluate performance efficacy and worker acceptance. Airborne contaminant exposure levels and environmental emissions controls will also be evaluated. The evaluation will include direct costs of equipment, materials, and environmental controls, and indirect costs affecting productivity associated with each control measure evaluated. When appropriate and feasible, control modifications and optimizations may be recommended. Finally, industry and equipment manufacturing partners receptive to assisting in the development and implementation of the most promising exposure-control measures will be pursued.

- Drywall finishing generates compounds that may contain crystalline silica, and previous research has documented overexposures to total airborne particulates among drywall finishers. Although this research has identified effective dust control devices for drywall sanding, few drywall finishers routinely use them. NIOSH has a cooperative agreement with the United Labor Agency, Cleveland, $\mathrm{OH}$ to address economic and other real or perceived barriers to existing and effective engineering measures for dust control.

- Much of the research to date has focused on the reduction of asphalt fumes associated with highway paving. Asphalt fumes are a known irritant to workers' mucous membranes and skin. Several research studies have suggested links to carcinogenic activity. OSHA recently listed asphalt fume exposures (roofing and paving) as one of 18 OSHA priorities, and the American Conference of Government Industrial Hygienists has proposed a more stringent standard for evaluating exposures to asphalt fumes. A Hazard Review document on asphalt fume exposure has been written.

KEYWORDS: Engineering controls, abrasive blasting, drywall finishing, paving

\section{RECENT CITATIONS:}

National Institute for Occupational Safety and Health. 1999. Control of drywall sanding dust exposures. NIOSH Hazard Controls HC30. DHHS (NIOSH) Pub. 99-113.

Mead, K.R., R.L. Mickelsen, and T.E. Brumagin. 1999. Factory performance evaluations of engineering controls for asphalt paving equipment. American Industrial Hygiene Association Journal, v. 14, no. 8, pp. 565-573. 


\section{ECONOMIC ANALYSES OF ENGINEERING CONTROL INTERVENTIONS FOR DRYWALL SANDING CONSTRUCTION ACTIVITIES}

\section{RESEARCHER: Joseph Ventura}

\section{AFFILIATION: Painters Health and Safety Fund (440) 239-4575}

PURPOSE: Identify the real and perceived obstacles to implementing engineering controls for reducing hazardous exposures to airborne particles among drywall finishing workers and evaluate a methodology for overcoming these barriers.

RESEARCH SUMMARY: Several studies have indicated that drywall finishers are exposed to high levels of total and respirable dust. This research is designed to identify barriers to implementing engineering controls, to train workers and contractors in engineering controls, and to identify and promote incentives to implement healthy work practices.

Jobs and work groups in the drywall industry using current practices and practices will be identified, after which study participants be selected. Next, participants will be interviewed to determine the real and perceived barriers to the use of engineering controls. Surveys will then be developed to determine the production costs of conventional practices. An efficacy study will compare engineering controls and conventional technology, and the economic costs associated with the use engineering controls will be determined. Further research will compare costs of the two technologies on the job.

Throughout this study, training for engineering control intervention will be provided. This project will further knowledge and methods of protecting workers from airborne exposures and encourage contractors and workers to adopt healthy work practices.
KEYWORDS: Dust, economic consequence, engineering controls 


\title{
CONTROL OF SILICA EXPOSURE FROM HAND-HELD CONSTRUCTION TOOLS
}

\author{
RESEARCHER: Alan Echt
}

\section{AFFILIATION: Division of Applied Research and Technology \\ National Institute for Occupational Safety and Health (513) 841-4111}

PURPOSE: Evaluate the effectiveness of several engineering controls in reducing exposure to respirable crystalline silica from selected construction tasks identified during a larger study of silica exposures and controls.

RESEARCH SUMMARY: There are three components to this project.

Tuck-pointing: Tuck-pointing involves the removal of old mortar with a high-speed grinder, which creates large amounts of brick and mortar dust containing silica. Two preliminary evaluations were conducted at construction sites and two more at Bricklayers and Allied Craftworkers Union training facilities. Next, a laboratory study was conducted at the International Masonry Institute, Ft. Ritchie, MD, to determine the ventilation parameters required to control the dust generated during tuck-pointing and brick cutting. Finally, a field study was conducted to verify the effectiveness of the laboratory findings for tuck-pointing ventilation.

Ready-mix concrete truck cleaning: Currently, workers are required to enter the interior of a mixing drum and use a jackhammer to remove cured concrete, generating a cloud of silica-containing dust. NIOSH researchers developed two engineering control options for jackhammers to reduce concentrations of airborne dust produced during this task: a local exhaust ventilation shroud and a water spray attachment. To test the effectiveness of the controls, a jackhammer was retrofitted with the ventilation shroud and tested at a ready-mix concrete plant. Local exhaust ventilation reduced worker exposure to respirable crystalline silica by more than $50 \%$, and local exhaust ventilation combined with general exhaust ventilation reduced exposures by more than $60 \%$.

Concrete grinding: When construction workers use grinders to smooth poured concrete surfaces, they risk overexposure to respirable dust and crystalline silica. Hand-held grinders are used to finish surfaces after forms are stripped, while walk-behind grinders are used on floors. An evaluation of four local exhaust shrouds for use with hand-held grinders found that all four shrouds were equally effective and that all reduced dust by at least $90 \%$. A field study of a vacuum cleaner and shroud system for hand-held grinders found that it controlled exposures within the range of protection provided by a half-mask respirator. Finally, a field study of a job-built control for a scabbler that utilized water to suppress dust found that it achieved an $80 \%$ reduction in exposures to respirable dust, and by inference, resulted in a similar reduction in exposures to respirable crystalline silica. 


\section{EVALUATION OF DUST CONTROL TECHNOLOGIES IN CONSTRUCTION TASKS}

\section{RESEARCHER: Noah Seixas}

\section{AFFILIATION: University of Washington (206) 685-7189}

PURPOSE: Evaluate commercially available but untested masonry tools to determine their effectiveness in reducing dust emissions.

RESEARCH SUMMARY: Elevated occupational exposures to crystalline silica dust can result from using concrete and stone during construction. In particular, masons and concrete finishers can be exposed to unsafe levels of silica dust during the operation of power grinding, drilling, and cutting tools. A series of semi-controlled experiments will be conducted to determine the effectiveness of water and localized ventilation control techniques in suppressing dust. Six different classes of hand-held masonry power tools will be tested. Further characterization of silica exposures during typical masonry activities will be done at a variety of construction sites to evaluate how lessthan-ideal conditions affect tool performance and control dust. The identification of effective control strategies for reducing silica dust exposures will provide practical guidance to the masonry construction industry and reduce the possibility of occupational lung disease related to silica exposure in this industry.
KEYWORDS: Silica dust, power tools, masonry 


\section{ELECTRONIC SAFETY DEVICES FOR CONSTRUCTION WORKERS}

\section{RESEARCHER: Edward Coonly}

AFFILIATION: ViTech Systems, Inc. (716) 689-4025

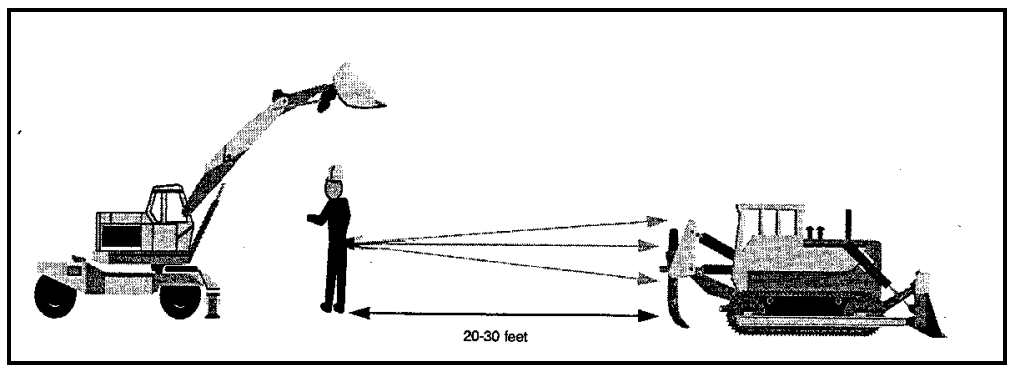

PURPOSE: Develop two electronic safety devices: (1) a moving hazard warning device to protect construction workers from being struck by or trapped between or beneath construction equipment and (2) an edge detector device to prevent worker falls from roofs and open-sided floors and platforms.

RESEARCH SUMMARY: The U.S. construction industry, with $6.0 \%$ of total employment, accounts for $8 \%$ of the total number of injuries and illnesses and $17 \%$ of the total number of fatalities. "Struck-by a moving object" and "caught in, under, or between-" type accidents account for $13.6 \%$ of the total number of accidents at construction worksites and cost \$297 million annually. Falls through floor openings, shafts, decks, and open platforms account for $6.2 \%$ of the total number of construction accidents and cost about $\$ 227$ million annually. At present, engineering controls to prevent these accidents do not exist.

To reduce these accidents, two devices that feature the use of ultrasonic sensors powered by small rechargeable batteries and controlled by microchips are being developed. Each safety device will be the size of a pager and built into the back of a toolbelt. The devices will warn a worker via an audible and/or vibration alarm whenever he or she is too close to approaching equipment or the edge of a roof or open-sided floor.

A prototype device for detecting floor openings and the edges of platforms has been developed. The batteries to power the device for one full work-week of 50 hours are still being investigated. Worker acceptability will be tested after a final design of the device is produced.

A prototype of the moving hazard warning device, which will warn a construction worker if a heavy equipment is approaching from behind, is currently being tested in both the laboratory and the field. Limitations in the distance over which the ultrasonic sensors can detect moving equipment has been a major factor impeding the progress on the device. It may be necessary to customize the ultrasonic sensor. However, if the sensor fails to detect an object at an adequate distance under all weather conditions, we may evaluate the use of radio-frequency sensors.

PATENT: A patent application is in process. 


\section{A DEVICE FOR ELIMINATING ELECTROCUTIONS BY MOBILE CRANES}

\section{RESEARCHER: Satish Mohan}

\section{AFFILIATION: ViTech Systems, Inc. (716) 689-4025}

PURPOSE: Develop and field-test an electronic sensor system that can detect voltage intensity of overhead highvoltage powerlines and their distance from mobile cranes.

RESEARCH SUMMARY: In 1981, a year for which a

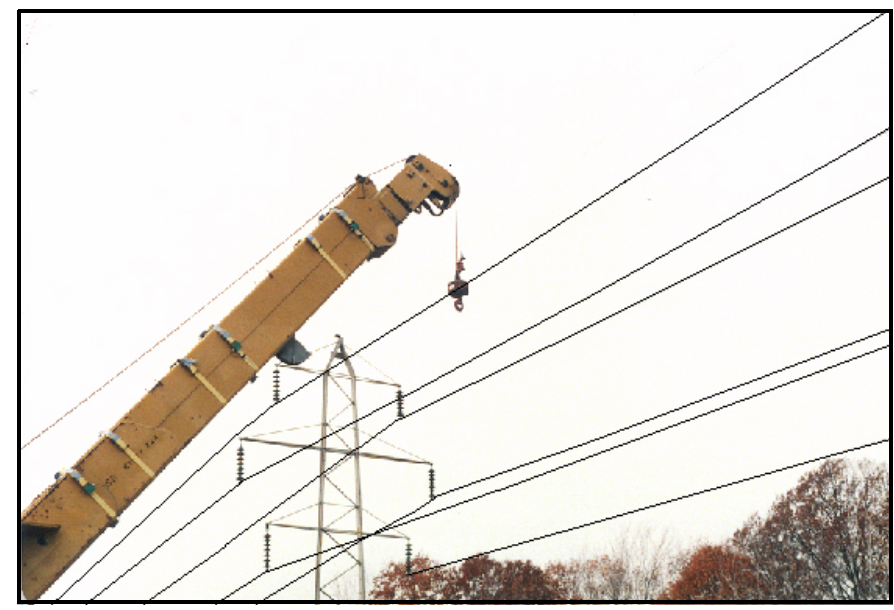
complete data set is available, approximately 2,300 lost workdays, 115 fatalities, and 200 permanent total disabilities resulted when a mobile crane came into contact with a powerline. Forty-seven workers were killed in 1991 KEYWORDS: Crane safety, crane electrocutions when scaffolds composed of metal or other conductive materials came into contact with powerlines. On average, seven workers are electrocuted every year in aerial lifts during tree trimming. The cost of these accidents is estimated at \$259 million.

In this project, researchers will develop a sensor system that will warn a crane operator when the crane boom gets too close to a powerline. If the boom gets dangerously close, the system will trigger a loud alarm and a flashing light to warn the crane operator and those working in the vicinity of the crane. The alarm system will be designed as a number of sensors attached to the crane boom. These sensors will be connected to each other by a powered sensor bus and then to a microprocessor located in the operator's cabin. A second smaller system using a similar design will be developed for conductive scaffolds, aerial man-lifts, boom trucks, and other self-propelled machinery that could make physical contact with a powerline.

A prototype has been developed and tested on $4-\mathrm{kV}$, three-phase powerlines. The system measures electric fields precisely and can estimate both voltage and the distance of powerlines from the crane. Operating Engineers Local 17 and an electric utility company are cooperating in this work. The final version will include a video display terminal within the viewing area of the operator that will show the crane boom and powerlines in the vicinity of the crane.

PATENT: A patent application is in process. 


\section{FIELD STUDIES WITH INNOVATIVE SAFE EXCAVATION TECHNOLOGIES}

KEYWORDS: Confined space, traumatic injuries, excavation

\section{RESEARCHER: Leonhard Bernold}

\section{AFFILIATION: North Carolina State University (919) 515-3677}

PURPOSE: Evaluate new excavation technologies that promise to reduce radically several hazards related to backhoe excavation during construction.

RESEARCH SUMMARY: Previous research successfully demonstrated the feasibility and applicability of safe excavation and pipe-laying. This research "ruggedized" prototype technologies and demonstrated each as fullscale field experiments at actual construction sites using construction crews. From the lessons learned, new questions and further research topics have arisen. To achieve these goals, the following specific aims will be pursued.

- Extend the capabilities of the excavator-mounted, buried utility detection system (EM-BUDS). Currently this device can locate metallic pipes and powerlines; what is needed is a device that can locate plastic and concrete pipe.

- Address questions raised as to whether the pipe manipulator (PIPEMAN) can be used to place bedding remotely.

- Design and fabricate a smaller version of PIPEMAN (PIPEMAN, Jr.) that can lay smaller-diameter polyvinyl and steel pipes. Investigate issues

regarding joints in these types of pipes, which have very different requirements than do concrete pipes.

- Integrate the expanded EM-BUDS and PIPEMAN, Jr.

- Improve the human-machine interfaces of EM-BUDS, PIPEMAN, and PIPEMAN, Jr.

- Demonstrate technologies at field sites. 


\section{CROSS-CUTTING RESEARCH AND INTERVEN- TIONS IN HAZARDOUS WORK ENVIRONMENTS}

\author{
RESEARCHERS: Ted Scharf (513) 533-8170 \\ Division of Applied Research and Technology \\ Bill Wiehagen (412) 386-6468 \\ Pittsburgh Research Laboratory
}

\section{AFFILIATION: National Institute for Occupational Safety and Health}

PURPOSE: Evaluate and implement safety and health interventions that reduce workload or workplace hazards, reorganize the work, and/or provide new information to change how workplace hazards are managed. Enhance the development of cross-cutting research and interventions that focus on the complex relationship among workload, stress, and risks for injury in agriculture, construction, and mining.

RESEARCH SUMMARY: Agriculture, construction, and mining are three of the most hazardous industries in the United States. These three industries consistently rank among the top four for deaths per 100,000 workers. In addition, children and adolescents are at high risk for work-related deaths and injuries in family farming and fishing operations. Standard operating procedures in hazardous industries typically reflect the specific demands and requirements of the tools and hazards that are present in the work environment. But often how these procedures are carried out on the job reflects other, more immediate, demands to maintain productivity.

The work crew performance model (WCPM), developed by the Pittsburgh Research Laboratory, is being implemented in agriculture and construction. Ladder set-up and use has been selected as an application of this model to a small construction setting, while a County Cooperative Extension project dealing with beef cattle farming has been selected to apply the model to agriculture. In the construction component, extension ladder set-up and use checklists have been prepared for evaluation using (1) training at construction sites through a 10-minute toolbox talk, (2) reminders posted on the ladders or on a pocket card about everyday use, and (3) investigations of occupational injuries and fatalities involving extension ladders.

The application of the WCPM has shown that there is a great deal of variability in both set-up and use. The checklists have been designed to address this problem. In FY03, the ladder set-up and use checklists will be evaluated and validated prior to submission for printing as NIOSH numbered documents.

The results from this interdisciplinary effort are expected to lead to (1) interactive tools for workers in the industries under study, (2) improved communication and collaboration among NIOSH scientists and other safety and health professionals working in hazardous industries, and (3) an ongoing exploration of cross-cutting approaches to common problems in the three industries.

KEYWORDS: Intervention, work organization, work practices

\section{RECENT CITATIONS:}

Lineberry, G.T., T. Scharf, R. Jameson, M. McCann, D. Sulecki, and W. Wiehagen. 2002. An educational intervention for extension ladder set-up and use. In Power Through Partnerships: 12th Annual Construction Safety and Health Conference, Proceedings (May 21-23, 2002, Rosemont, IL).

Scharf, T., C. Vaught, P. Kidd, L. Steiner, K. Kowalski, W. Wiehagen, L. Rethi, and H. Cole. 2001. Toward a typology of dynamic and hazardous work environments. Human and Ecological Risk Assessment, v. 7, no. 7 , pp. 1827-1841. 


\title{
EVALUATING ROADWAY CONSTRUCTION WORK ZONE INTERVENTIONS
}

\author{
RESEARCHERS: David Fosbroke (304) 285-6010 \\ Division of Safety Research
}

Gary Mowrey (412) 386-6594
Pittsburgh Research Laboratory

Todd Ruff (509) 354-8053

Spokane Research Laboratory

\section{AFFILIATION: National Institute for Occupational Safety and Health}

PURPOSE: Further field development, evaluation, and demonstration of interventions aimed at reducing worker exposure to equipment and moving vehicles operating inside the boundaries of work zones and other work areas.

RESEARCH SUMMARY: Highway and street construction workers are at risk of fatal and serious nonfatal injuries when working near passing motorists, construction vehicles, and equipment. From 1992-1998, 841 highway and street construction workers were fatally injured. In 465 of these 841 cases $(55 \%)$, the death was either vehicle- or equipment-related and either clearly or probably occurred in the work zone. In 318 of the 465 vehicle and equipment-related fatalities within work zones, a worker on foot was struck by a vehicle. Victims were as likely to be struck by a construction vehicle as by a passing traffic vehicle.

Road construction is expected to increase by $40 \%$ due to increases in federal highway funds under the Transportation Equity Act for the 21st Century. Work zone safety is a priority for labor, industry, and federal and state agency officials who express concern that increases in road construction and structural changes in the industry will lead to increases in worker fatalities. Internal traffic control plans and a variety of proximity warning devices are promising, yet unproven, interventions for preventing fatalities and injuries associated with mobile vehicles and equipment. If proven to be effective, adoption of these interventions could substantially reduce exposure of workers to moving vehicles and equipment, thus reducing fatalities and injuries.

This collaborative project involves the Division of Safety Research, the Pittsburgh Research Laboratory, and the Spokane Research Laboratory. The project consists of four phases: evaluation methods development, intervention development, intervention evaluation and demonstration, and information dissemination and technology transfer. Specific aims include evaluation and design of traffic control plans and methods to reduce worker exposure to moving equipment; assessment of off-the-shelf proximity warning sensors on construction equipment; modification and evaluation of the Hazardous Area Signaling and Ranging Device (HASARD) to prevent collisions between pedestrian workers and construction equipment; and design, development, and assessment of a work zone analysis system for recording and analyzing time and motion studies.
KEYWORDS: Work zone safety, intervention effectiveness, HASARD, proximity warning

\section{RECENT CITATIONS:}

Pratt, S.G., D.E. Fosbroke, and S.M. Marsh. 2001. Building safer highway work zones: Measures to prevent worker injuries from vehicles and equipment. DHHS (NIOSH) Pub. 2001-128, 71 pp.

Schiffbauer, W.H. 2001. An active proximity warning system for surface and underground mining applications. Presentation at SME annual meeting, Denver, CO, Feb. 26-28, 2001. Preprint 01-117, 8 pp.

Ruff, T.M. 2002. Evaluating roadway construction work zone interventions - project summary. Presentation at 35th annual meeting of North American Association of Transportation Safety and Health Officials, Overland Park KN, Aug. 12. 


\section{EFFECTIVENESS OF ACTIVE SPEED CONTROLS IN HIGHWAY WORK ZONES}

\section{RESEARCHER: Satish Mohan}

\section{AFFILIATION: State University of New York at Buffalo \\ (716) 645-2114}

PURPOSE: Evaluate the effectiveness of two interventions on the reduction of travel speeds in highway work zones.

RESEARCH SUMMARY: While the injury rate in the U.S. construction industry has declined by $2.9 \%$ a year and the fatality rate in the U.S. transportation industry has declined by $3.2 \%$ a year, the number of severe injuries and fatalities in highway work zones has stayed constant at approximately 37,000 and 800 a year, respectively, for the last several years, at a cost of $\$ 4.0$ billion a year. Excessive speed and driver inattention are considered to be the two major causes of highway work zone accidents.

The effectiveness of two interventions - rumble strips and variable message signs - are expected to reduce $50 \%$ of the injuries and fatalities caused by "excessive speed" and "driver inattention." Rumble strips consist of raised asphalt, pavement grooves, and masking tape. Messages include work zone speed and driver speed.

Active speed controls were applied on 65-mph highways in western New York during 1999-2001. All highways had posted speed limits of $45 \mathrm{mph}$ in work zones. Pneumatic road tubes with portable traffic counters were used to monitor speeds. Six types of variable message signs were tested; the effectiveness of each type is given below in order of effectiveness.

- WORK ZONE 45 MPH - PLEASE SLOW DOWN-reduced vehicle speeds by $6 \mathrm{mph}$.

- WORK ZONE MAXIMUM SPEED 45 MPH - BE PREPARED TO

STOP - reduced passenger car speeds by 4.2 to $5.5 \mathrm{mph}$ and average speeds of all vehicles by 2.9 to $3.7 \mathrm{mph}$.

- WORK ZONE 45 MPH-STATE POLICE ENFORCED—reduced vehicle speeds by $5 \mathrm{mph}$.

- YOUR SPEED, X MPH-reduced vehicle speeds by $4 \mathrm{mph}$.

- RIGHT LANE CLOSED-KEEP LEFT and LEFT LANE CLOSEDKEEP RIGHT-were both effective in reducing vehicle speeds by $2.3 \mathrm{mph}$.

The tests also showed that the signs reduced the percentage of vehicles traveling above $45 \mathrm{mph}$ by about $8 \%$.

Rumble strips proved effective for the driving lane only, reducing average speeds by 1.2 to $2.2 \mathrm{mph}$. A different brand of rumble strips combined with POLICE ENFORCEMENT signs reduced vehicle speeds significantly, by 3.0 to $4.5 \mathrm{mph}$, while standard deviations of the speed of all vehicles decreased by $25 \%$ in both in the driving and passing lanes.
KEYWORDS: Work zones, highway safety, highway accidents, intervention effectiveness

\section{RECENT CITATIONS:}

Zech, W., and S.B. Mohan.

Enhancing work zone safety by implementing speed controls. Washington, DC: National Academy of Sciences, Transportation Research Board. (Submitted)

Ghorpade, B., and S.B. Mohan. Active speed controls for highway work zone safety. Washington, DC: National Academy of Sciences, Transportation Research Board. (Submitted) 


\section{ECONOMIC AND JOB HAZARD ANALYSIS OF SANDBLASTING SUBSTITUTES}

\section{RESEARCHER: Beth Rosenberg}

\section{AFFILIATION: Tufts University (617) 636-6709}

PURPOSE: Investigate the range of interventions used to decrease silica exposure in the sandblasting industry and study their health and economic impacts.

RESEARCH SUMMARY: Silicosis is a disabling and often fatal lung disease that is completely preventable. The recent designation of silica as a lung carcinogen by the International Agency for Research on Cancer (IARC) makes the control of silica urgent. The connection between silica and tuberculosis is well known, and, with the rise of drug-resistant tuberculosis, the need to control silica is clear.

Sandblasting results in high silica exposures. NIOSH has produced excellent research on the industrial hygiene aspects of using blasting substitutes, yet there has been little research into the health effects of substitutes not associated with chemical exposures.

With all the much-needed focus on technologies to reduce silica exposure, we must be mindful that we do not introduce new hazards into the workplace. There have been numerous cases of unintended consequences resulting from well-intentioned interventions because the focus has been on controlling a single hazard rather than assessing the full range of impacts in a work environment. To evaluate an intervention fully, we need an integrated approach to the workplace. Furthermore, before any research can be useful in helping contractors decide which method to choose, the economics of each technology must be assessed.

This study will address the potential health and economic impacts associated with substituting other materials for silica sand and the technologies to deliver those substitutes in abrasive blasting.
KEYWORDS: Effectiveness research, sand, silica substitutes, sandblasting

\section{RECENT CITATIONS:}

Rosenberg, B.J., E.M. Barbeau, R. Moure-Eraso, and C. Levenstein. 2001. The work environment impact assessment: A methodologic framework for evaluating healthbased interventions. American Journal of Industrial Medicine, v. 39, no. 2, pp. 218-226.

Kriebel, D., and B.J. Rosenberg. 2001. Lung cancer: Another good reason to control silicosis. Cancer Causes and Control, v. 12, pp. 785-787. 


\section{A STRONG CONSTRUCTION INJURY PREVENTION INTERVENTION AT THE SUBCONTRACTOR LEVEL}

\section{RESEARCHERS: Pete Stafford and Buck Cameron}

\section{AFFILIATION: Center to Protect Workers' Rights (301) 578-8500}

PURPOSE: Lower injuries in construction through the use of methods that can be easily replicated by the entire construction industry. Significantly reduce traumatic injuries related to the great majority of construction accidents by focusing on work planning and specific work practices and controls.

RESEARCH SUMMARY: The proposal aims to show that introducing strong injury prevention methods at the level of the subcontractor can improve safety practices and lower the number of injuries. In the initial phase of the intervention, information will be gathered on industry best practices, which will then form the basis for the intervention safety program. Contractor, foreman, and trade worker responsibilities will be specified. Targeted injuries will include falls, electrocutions, and "struck by" and "caught between pieces of equipment" accident types that account for $90 \%$ of construction fatalities.

Forty medium-to-large contractors (that is, contractors with more than 50 fulltime-equivalent employees) who do not currently have a strong safety program will be enlisted. These contractors will be drawn from four geographical regions and from a full range of trades represented by the AFL-CIO Building and Construction Trades Department. A like number and type of contractors will be sought as controls.

The intervention will consist of-

- Provision of an OSHA-compliant safety program,

- Provision of supporting training materials,

- Bi-monthly site visits by researchers to audit program compliance,

- Semi-annual progress reports to participating contractors and building trades councils, and

- Collection and analysis of injury data based on OSHA logs and hours worked at the construction sites. While injury data will also be sought from control contractors, experience has shown this to be problematic.

The expectation is that work conditions and safety practices at the intervention sites will improve significantly compared with safety practices and work conditions at the control sites. It is also anticipated that injury rates at the intervention sites will decline significantly.
KEYWORD: Intervention, work organization

\section{RECENT CITATIONS:}

Stafford, P., and B. Cameron. 2002. Presentation, Southeast Regional Building and Construction Trades Council, New Orleans, LA, Feb. 18, 2002.

Stafford, P., and B. Cameron. 2002. Presentation, Western Regional Building and Construction Trades Council, Las Vegas, NV, March 2002.

Stafford, P., and B. Cameron. 2001. Presentation, Puget Sound Safety Summit, Seattle, WA, Dec. 2001. 


\section{CONTACT DERMATITIS PREVENTION}

\section{RESEARCHER: Christina Trahan}

\section{AFFILIATION: Center to Protect Workers' Rights (301) 578-8500}

PURPOSE: Evaluate the effectiveness of job site interventions aimed at the reduction of contact dermatitis among construction workers and the economic impact of occupational contact dermatitis in construction workers.

RESEARCH SUMMARY: As described in the National Occupational Research Agenda, skin diseases are the leading nontrauma-related occupational illnesses in the United States, accounting for $12 \%$ to $15 \%$ of all occupational illnesses. The exact incidence rate is unclear; estimates range from 67 to 1,700 cases per 100,000. Skin diseases may be recurrent and chronic and result in high direct and indirect costs that may reach up to $\$ 1$ billion annually. The most common occupational skin diseases are allergic and irritant contact dermatitis, which are preventable diseases. Construction workers are exposed to many harmful substances that can cause contact dermatitis, including portland cement, epoxies, solvents, and preservatives.

Some believe that skin problems affect up to $80 \%$ of the workers who have continual contact with products containing portland cement. Found in concrete, mortar, and related construction materials, portland cement is known to cause irritant and allergic contact dermatitis. The alkalinity of wet cement contributes to irritant contact dermatitis, and hexavalent chromium is a strong sensitizing agent responsible for allergic contact dermatitis in cement workers worldwide.

In this project, surveillance activities involve analyses of data from the published literature, occupational exposure surveys, and collection of injury and illness statistics to identify construction workers' exposure to potential dermal hazards. Economic analyses of jobsite and industry-wide interventions are performed, as well as economic characterization of the impact of disease on contractors, workers, workers' compensation systems, private insurance, and society. These interventions are also evaluated as to their effectiveness in reducing contact dermatitis symptoms among the target population.

Materials have been developed aimed at employers, workers, and safety and health professionals regarding the issues and recommended controls relating to contact dermatitis caused by portland cement. A training program has been developed for use by union training centers and employers whose workers come in contact with wet portland cement. Information and publications about contact dermatitis are disseminated to the construction community through a number of CPWR avenues, including employer associations, international unions representing workers in the construction industry, and CPWR's electronic library of construction occupational safety and health (http://www.elcosh.org).
Professional Skin Protection For Work With Wat Cement in Construction

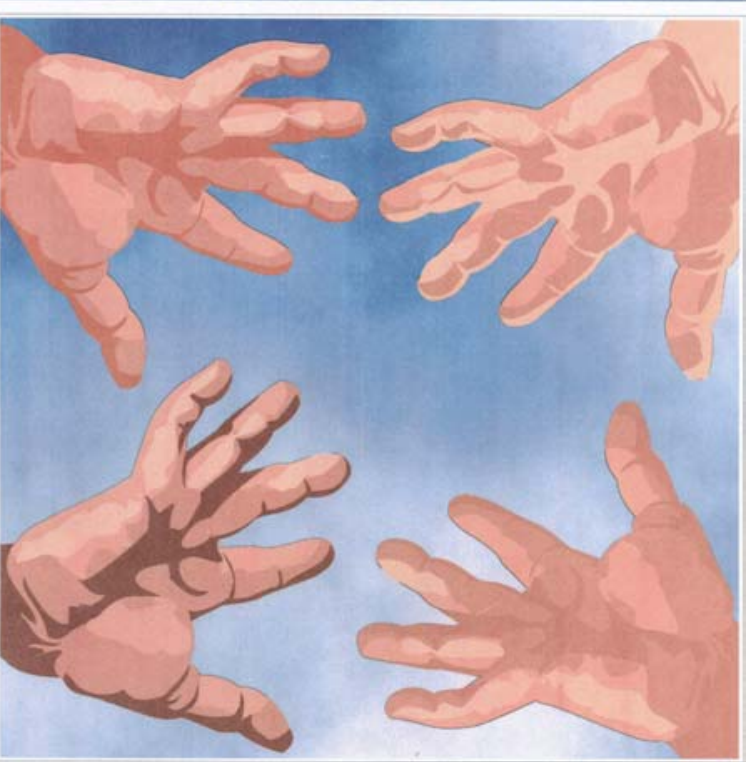

KEYWORDS: Intervention, skin disorders, allergic contact dermatitis, irritant contact dermatitis, portland cement, epoxy, solvents

\section{RECENT CITATIONS:}

Professional Skin Protection for Work with Wet Cement in Construction Training Program, PowerPoint presentation with accompanying instructors' guide for 1- and 2-hour training.

Manuals: Employers Guide to Skin Protection for Work with Wet Cement in Construction; Safety and Health Practitioners Guide to Skin Protection for Work with Wet Cement in Construction.

Pamphlets: Save Your Skin-A 15Minute Tool Box Session; Save Your Skin Glove Wear for Wet Cement Work; Physician's Alert for Occupational Contact Dermatitis Among Construction Workers. 


\section{CREW-BASED WORK OBSERVATION PROGRAM TO IMPROVE CONSTRUCTION SAFETY PERFORMANCE}

\section{RESEARCHER: Steven Hecker}

\section{AFFILIATION: University of Oregon (541) 346-2788}

\section{CONSORTIUM: Center to Protect Workers' Rights}

PURPOSE: Implementation and evaluation of a modified behavior-based work observation and sampling process to increase construction worker involvement in safety and improve hazard recognition and abatement.

RESEARCH SUMMARY: Construction projects are typically complex undertakings that require extensive coordination among many contractors, trades, and work tasks. Traditional command and control management structures rely on safety policies and procedures developed by the construction manager or general contractor. The transient nature of construction sites means that environmental conditions change rapidly and worker turnover is high. Efforts to involve workers in the safety process may take place through toolbox meetings, safety committees, or suggestion systems, but the high turnover of workers on a construction site inhibits continuity of participation.

This study introduced and evaluated a crew-based work observation process at a large construction site in the Pacific Northwest. The process, Best Practices Sampling (BPS), draws on work sampling and observation elements from behavior-based safety programs implemented in fixed industry. The distinguishing feature of BPS is that the crew is responsible for designating the critical safety items it will monitor and defining best-practice criteria.

Crews from four trade contractors representing four different crafts and working under a single general contractor on the same project participated in the study. Following a 2-hour training session during which crew members were introduced to performance management and self-management concepts, the crew or work team, in a facilitated process, developed a list of best practices required for safe performance of their work tasks. Each crew member was instructed to take 5 to 10 minutes at random every day to observe the work area, tools and equipment, work methods, and worker behavior. The observer noted each time an item was observed and marked it either "best practice" or "needs improvement." All crew members were expected to participate in the development of this list and in defining the best practice for each item based on their knowledge and experience in the trade. Sampling cards also provided space for written comments on any safety matter observed.

The initial findings suggest that worker-based safety processes hold great potential but are extremely fragile. Crews that perceived the highest levels of organizational support for the intervention provided the highest number and highest quality comments concerning existing safety procedures and conditions. Likewise, perceived supervisor and foreman support for the BPS process was also associated with higher levels of BPS activity among crew members.

Results were largely consistent with the determinants of success for other nonhealth- and safety-related worker involvement programs in other industries, suggesting that general research on worker involvement may be relevant to worker-centered safety interventions.

KEYWORDS: Employee involvement, work observation, hazard identification, behavior-based safety, performance management, best practices

\section{RECENT CITATIONS:}

Hecker, S., W. Gibbons, and A. Barsotti. 2000. Best practices sampling: A participatory approach to improve construction safety performance. In Proceedings of the 14th Congress of the International Ergonomics Association (Santa Monica, CA). V. 5, pp. 683-686. 


\section{ASSESSMENT OF A SAFETY-IN-DESIGN INTERVENTION ON AN INDUSTRIAL CONSTRUCTION SITE}

\section{RESEARCHER: Steven Hecker}

\section{AFFILIATION: University of Oregon (541) 346-2788}

\section{CONSORTIUM: Center to Protect Workers' Rights}

PURPOSE: Evaluate processes and outcomes of a collaborative safety-indesign process implemented by owners, construction managers, and design firms to reduce safety hazards in all life cycles of the facility being constructed.

RESEARCH SUMMARY: Evidence from studies of construction accidents and injuries suggests that a significant proportion of such events originates upstream of the building process, i.e., they are connected to such processes as planning, scheduling, and design. One European analysis attributed up to $60 \%$ of construction accidents to decisions or behaviors that took place prior to the construction work itself.

In the course of a number of construction projects, Intel Corp. incorporated elements of a safety-in-design approach. These include "lessons learned" and development of a safety-in-design checklist based on issues identified in the construction and operation phases of earlier buildings. In the design of a prototype semiconductor factory, the company, in collaboration with the project's construction manager and design firm, launched a comprehensive process of safety in design, labeled Life Cycle Safety (LCS), which introduced explicit evaluations of design options in programming and three stages of detailed design. LCS is intended to look at all cycles of the structure: construction, commissioning, operations, maintenance, retrofit, and demolition. A major goal is to involve trade contractors with relevant experience prior to construction when their input can identify potential risks at stages where these risks can be addressed by design changes or, if not, be mitigated in the field. Focus groups were held with journeymen and superintendents from four crafts in the early stages of LCS to develop lists of design considerations having safety, quality, and productivity implications.

To evaluate this process, semi-structured interviews were conducted with a large sample of members of the disciplinary work groups who conducted the LCS reviews during programming. Interviews and focus groups have been held with the LCS team that directed the process, representatives of the three organizations who facilitated LCS evaluations in the design phase, and the designers of the project. The comments generated by the LCS evaluations are being coded for analysis. Craft foremen from all disciplines are being debriefed as their scope of work ends to collect data to compare to the design items identified in prior focus groups. Injury data from the construction phase will be compared to similar data from earlier projects, and incident data from the current construction project will be analyzed to link incidents and injuries to design issues either identified in the LCS process but not modified or missed by the process.

KEYWORDS: Safety, design, construction, life cycle

\section{RECENT CITATIONS:}

Hecker, S., B. Gibbons, and A. Barsotti. 2001. Making ergonomic changes in construction: Worksite training and task interventions. In Applied Ergonomics, D. Alexander and R. Rabourn, eds. London: Taylor \& Francis, pp. 162-189. 


\section{ZERO-ACCIDENT WORKSITES: THE ROLE OF OWNERS IN CONSTRUCTION SAFETY}

\section{RESEARCHER: Jimmie Hinze}

\section{AFFILIATION: University of Florida \\ (352) 392-4697 \\ CONSORTIUM: Construction Safety Alliance}

PURPOSE: Examine owner practices as they pertain to construction safety. Evaluate the effectiveness of owner involvement in construction safety through contractor selection, contractual requirements, and active participation during the construction process.

RESEARCH SUMMARY: Owners of facilities being constructed play a pivotal role in construction safety. This role begins with selecting a contractor(s) and the contractual requirements imposed on the contractor. It continues during the construction phase through the active involvement of the owner in construction safety.

Information on the nature of owner involvement in construction safety was obtained through personal interviews with owner representatives for over 70 large construction projects. This phase, data collection, is nearing completion.

The next phase of the research will be to compile various owner practices employed to promote construction safety. This will reveal the nature of the variability that exists in owner practices on different projects. The data will then be examined to identify those practices associated with better injury rates as defined as the number of OSHA-recordable injuries incurred per 200,000 hours of worker exposure.

The data analysis will be conducted in the fall of 2002, and the research report will be completed by the end of spring 2003 .
KEYWORDS: Facility owners, contractor selection, contract requirements, monitoring safety, safe procedures 


\section{A BLUEPRINT FOR INTEGRATING HEALTH HAZARD CONTROL PROGRAMS INTO INFRASTRUCTURE REHABILITATION}

\section{RESEARCHERS: Mark Goldberg (212) 481-7555 Hunter College, City University of New York \\ Stephen Levine (212) 241-7811 \\ Nancy Clark (212) 241-0108 \\ Mt. Sinai School of Medicine \\ CONSORTIUM: Center to Protect Workers' Rights}

PURPOSE: Develop a guidance system, or blueprint, comprised of best practices that contractors can use to link health hazard controls with the planning and everyday management of construction activities. Assess engineering and work practice controls to reduce lead and silica exposure and enhance the role of labor in implementing control programs.

RESEARCH SUMMARY: Control measures designed to reduce exposures to lead and silica during infrastructure rehabilitation are often difficult to implement or sustain successfully. The blueprint project employs a comprehensive three-pronged approach to improve the integration of health hazard controls into construction projects by (1) developing, implementing, and assessing blueprint guides; (2) assessing the de facto role that labor plays in the implementation of health hazard control programs and enhancing labor's role with a view toward improving health hazard control integration; and (3) assessing lead and silica engineering and work practice controls. In developing and assessing each of these project components, both qualitative and quantitative data collection methods will be employed, including discussion groups with employers and workers; interviews with contractors, supervisors, workers, and union representatives; health hazard control program audits; and industrial hygiene assessments, including biological monitoring where appropriate. This project builds upon a growing body of investigations that suggest that the most effective interventions are those in which workers participate, which stress the importance of management leadership, and which employ multiple exposure control strategies - engineering controls, work practices, and respiratory protection.

The blueprint itself consists of a number of guides that provide practical guidance to project managers, safety personnel, and workers on day-to-day management of health hazard control programs. It is designed to be process oriented, that is, capable of anticipating health hazard control needs within the phases of a construction project, while being flexible enough to protect workers during the constant readjustments typical of construction rehabilitation work.

Each blueprint guide is uniformly structured and provides a brief statement of its purpose followed by sections on planning and scheduling, identification of employer and employee roles and responsibilities, and how to implement and evaluate a "best practice." A resource section contains references, forms, checklists, and lists of readily available information, useful Web sites, and supplies and vendors.

KEYWORDS: Health hazard control management, management control guides, labor participation in hazard control, work site organization, silica control, lead control

\section{RECENT CITATIONS:}

Clark, N., and M. Goldberg. 2002. Construction blueprint: Best practices for health hazard controls. Applied Occupational and Environ-mental Hygiene, v. 17, no. 5, pp. 326-328.

Zuckerman, N., M. Goldberg, and N. Clark. 2002. A blueprint guide for managing silica exposures among workers engaged in concrete and rock, drilling, chipping and crushing. In Power Through Partnerships: 12th Annual Construction Safety and Health Conference, Proceedings (May 21-23, 2002, Rosemont, IL).

Goldberg, M., and N. Clark. 2001. A blueprint for integrating health hazard controls for lead and silica into infrastructure rehabilitation projects. Presentation at American Industrial Hygiene Conference, New Orleans, LA, June 2001.

Clark, N. 2001. Workers' role in lead health and safety programs.

Presentation at 11th annual Construction Safety and Health Conference, Rosemont, IL, Feb. 2001. 


\section{INTEGRATING SAFETY INTO CONSTRUCTION CPM SCHEDULES}

\section{RESEARCHERS: Jimmie Hinze (352) 372-4697 University of Florida}

Jeffrey Nelson (352) 372-9712

Conceptual Arts, Inc.

\section{CONSORTIUM: Center to Protect Workers' Rights}

PURPOSE: Develop a software program, SalusCPM, that facilitates the incorporation of explicit safety-related guidelines into construction schedules.

RESEARCH SUMMARY: Critical path method (CPM) scheduling software has become a ubiquitous and indispensable tool in commercial construction project management. Construction schedules are typically developed around work activities that contribute to installing the components to complete a structure or facility. These activities are typically organized sequentially as they occur in the actual construction process and represent a logical progression of work. For most commercial construction projects, it is the schedule, more than concerns for costs or quality, that drives and influences management decisions.

Increasingly, safety has become a major concern on construction projects. However, CPM schedules typically do not address safety issues or concerns, despite a high level of interest in promoting safety. Since most injuries occur during a work activity, it is logical that safety should be emphasized in conjunction with the activities being planned. Some activities have more inherent risks than others. Presumably, if safety concerns were linked with planned activities and explicitly incorporated into schedules, it is more likely that the activities would be performed with a greater focus on safety. If widely practiced, this could ultimately result in a significant reduction in constructionrelated injuries, illnesses, and deaths.

SalusCPM is a software plug-in that works in tandem with scheduling software, allowing the user to incorporate a project-specific safety plan directly into the schedule. There are four components of SalusCPM: Safety Database, Safety Planner, Safety Integrator, and Safety Manager.

- The Safety Database component currently contains about 2,500 individual safety guidelines prepared by safety specialists and organized into checklists. Each checklist contains a series of guidelines related to a specific type of construction activity.

- The Safety Planner allows the user to select, add, delete, and modify (i.e., customize) the checklist database to suit the safety needs of a particular construction project.

- The Safety Integrator works with the CPM scheduling software and allows the user to insert specific checklists as activities into the CPM schedule. This resulting schedule can serve as the heart of a site-specific safety plan, a regulatory requirement for large construction projects.

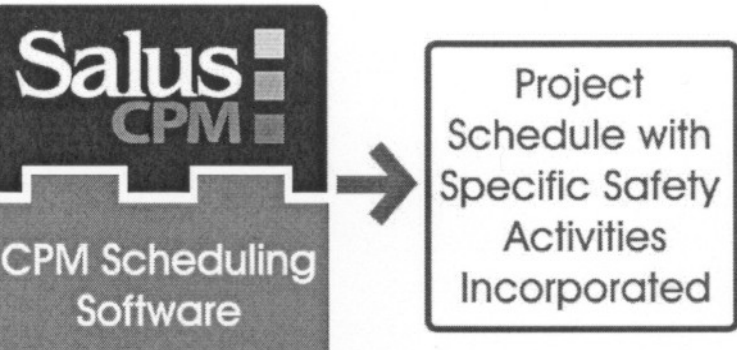

Software safety, scheduling
KEYWORDS: Checklist, planning,

- The Safety Manager assists in managing the individual items on the checklist that arise as work progresses according to the schedule.
SalusCPM works with CPM scheduling software to incorporate explicit safety-related guidelines into construction schedules 


\section{RESEARCHER: Paul Becker}

\section{AFFILIATION: West Virginia University (304) 293-3096}

\section{CONSORTIUM: Center to Protect Workers' Rights}

PURPOSE: Determine whether a partnership between thirdparty safety and health organizations and construction contractors can reduce fall hazards at construction sites through implementation of a fall hazard management program that includes training, safety committees, inspections, accountability, and third-party oversight.

RESEARCH SUMMARY: Falls are the leading cause of fatalities and a major cause of injury in construction work. While construction workers represent $5 \%$ of the nation's workforce, they account for $49.6 \%$ of fall fatalities. In West Virginia, the construction industry accounts for more than a third of all occupational falls, both fatal and nonfatal.

A partnership between West Virginia University (WVU) (and more recently St. Paul Insurance and Construction Safety Council) and construction contractors has been established in which contractors obtain "Fall-Safe" status by implementing a fall hazard management system developed by the university. Important elements of the system are development of company policies, training of supervisors and workers, development of site-specific fall hazard control plans, development of communication and accountability systems on-site to manage fall hazards, and regular site inspections by contractor personnel. Contractors maintain Fall-Safe status by achieving a minimum score on site program and site fall hazard control audits. The audits also act as a service to the contractor by providing feedback to the safety director to further assist in the control of fall hazards on the jobsite.

The research methodology employs a quasi-experimental model that compares outcome measures in an intervention group with measures in a control group. These measures include surveys of employers, supervisors, and employees; audits of construction site fall prevention plans and site fall hazard control efforts; and analyses of fall-related claims to workers' compensation systems. Statistical analysis of the data collected from 16 contractors (10 intervention, 6 control) in a pilot phase of the research indicates that the intervention group of contractors has shown more improvement in site program and site hazard control scores than the control group. Results also indicate that scores for site hazard control audits can be associated with scores on the site program audit.

An unexpected result of the research suggests that a less-intensive intervention such as a user-friendly computerized auditing tool might also lead to changes in contractor safety performance. Given that WVU estimates it will cost approximately $\$ 10,000$ per year for a contractor to implement the Fall-Safe program (internal costs and fees to the third-party partner), this finding is particularly important.

The study has now been expanded to include 40 additional contractors and the two participating partners of the St. Paul Insurance and Construction Safety Council. The current study tests whether the intervention can succeed when implemented by other third-party organizations in other regions of the country. The higher number of participants will permit the use of workers' compensation injury claims data as an outcome measure.

KEYWORDS: Falls, intervention research, occupational injury

\section{RECENT CITATIONS:}

Becker, P., M. Fullen, M. Akladios, and G. Hobbs. 2001. Prevention of construction falls by organizational intervention. Injury Prevention, Supplement, July, pp. 64-67.

Becker, P., M. Fullen, A. Akladios, M. Carr, and W. Lundstrom. 2000. Use of a hand-held computer to audit construction fall prevention effectiveness. International Journal of Computer Integrated Design and Construction, Special Issue on Computerized Safety Management. 


\section{QUALITATIVE RESEARCH AND INTERVENTION}

\section{RESEARCHER: Susan Moir}

\section{AFFILIATION: University of Massachusetts-Lowell (978) 934-3258}

\section{CONSORTIUM: Center to Protect Workers' Rights}

PURPOSE: Introduce technical and organizational interventions into the construction work environment and evaluate the effective-

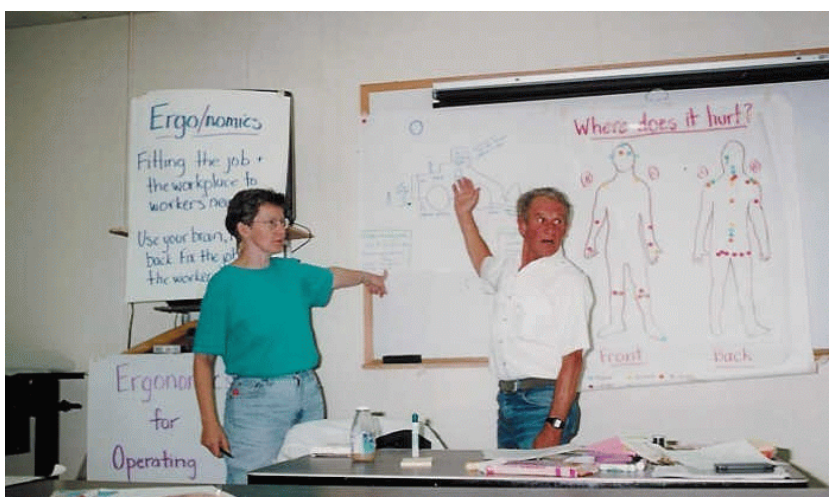
ness of these interventions in reducing exposures among concrete workers to respiratory hazards and musculoskeletal injuries.

RESEARCH SUMMARY: Partnering with area construction unions and contractors and joint labor-management training programs has resulted in participatory research activities carried out with workers at regional training centers and on construction sites. Three studies were conducted.

- Hardhat Ergonomics was a training program in which popular education methods were used to facilitate classes where workers conducted ergonomic job analyses, identified key agents of change, and role-played strategies for making changes at their workplaces.

- Health Trak was a joint labor/management participatory action research project. Small groups of workers and frontline supervisors met weekly over a 2-month period to identify current hazards on their site and design and propose solutions.

- The Boston-Area Health and Safety for Women in Construction (HASWIC) Research Circle was a standing focus group of tradeswomen who drew on their extensive experience to evaluate working conditions and analyze the roles of workers, unions, contractors, and government in making and impeding changes.

Each of these activities used a mix of qualitative and quantitative participatory research methods to examine the role of change in the construction work environment. The resulting exchange of information demonstrated that workers are able to analyze their jobs and design interventions to reduce hazards, but are hindered in making their proposed changes by organizational factors.

Four contexts that influence intervention effectiveness have been identified: organizational context in which the intervention is being introduced, attributes of the intervention itself, the process by which the intervention is introduced, and approaches to health and safety issues by participating trade unions.

To assess each of these contexts, approximately 50 factors influencing intervention effectiveness have been identified, defined, and organized into a matrix describing the specific information sought, source of that information, time (pre- or post-intervention), and method of data collection. This matrix will be used to develop specific protocols for collecting both quantitative and qualitative data for a working model of the effectiveness of intervention studies. 


\title{
EVALUATING TOOLBOX TRAINING IN CONSTRUCTION AND MINING
}

\author{
RESEARCHERS: Herb Linn (304) 285-5900 \\ Division of Safety Research \\ Carol Stephenson (513) 533-8581 \\ Terri Heidotting (513) 533-8325 \\ Education and Information Division
}

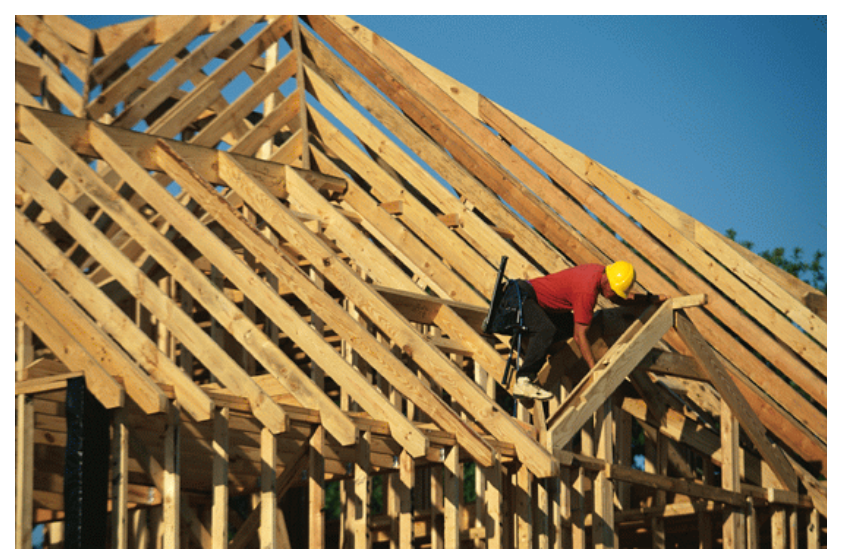

\section{Lani Boldt (509) 354-8006 \\ Spokane Research Laboratory}

\section{AFFILIATION: National Institute for Occupational Safety and Health}

PURPOSE: Identify and review existing toolbox/tailgate training materials and programs, prepare new toolbox talks for high-risk construction and mining sectors based on injury and fatality investigation reports, evaluate the effectiveness of these training materials for small construction and mining companies, and use evaluation results to expand toolbox series and distribute them widely to target sectors.

RESEARCH SUMMARY: Construction and mine workers face higherthan-normal risks of fatal injury, nonfatal injury, and illness resulting from onthe-job exposures. During the period from 1980 through 1995, among major industry sectors, construction had the highest number of deaths resulting from workplace injury - over 17,000 deaths, or more than 1,000 deaths per year.

Dun and Bradstreet reports that there are over 213,000 residential building construction companies in the United States. Ninety-six percent of these contractors employ less than 15 workers, and over $80 \%$ employ less than five. These small companies do not have the resources to support an on-site safety professional to identify and apply risk and prevention information relevant to their operations or the facilities or resources to provide their workers with formal training programs addressing workplace safety and health.

This research will evaluate the toolbox training approach in the high-risk residential building construction and sand-and-gravel mining sectors.

"Toolbox" or "tailgate" training — short (usually 10 to 15 minutes) weekly sessions conducted on-site prior to work shifts and involving work crews-is a primary mode of worker occupational safety and health training employed in small construction companies. Each toolbox talk in the series will contain a narrative "story" of one or more serious or fatal injuries based on available injury and fatality investigative reports from NIOSH, MSHA, OSHA, and other sources. A series of field evaluation studies in sand-and-gravel mining and residential building construction will be conducted to determine whether the NIOSH narrative-based toolbox talks can produce desired results-such as increased knowledge, appropriate changes in attitude, positive changes in behavior and work practices, and sustained changes - when compared to standard, nonnarrative toolbox talks.
This project will fill gaps in current knowledge regarding the effectiveness of short, on-site workplace training sessions for construction work crews, and the critical elements, formats, and approaches of such training sessions that contribute to desired results. A companion project involves developing toolbox training materials for the sand-and-gravel mining sector.

KEYWORDS: Effectiveness research, training 


\section{SAFETY CHECKLISTS PROGRAM FOR SMALL BUSINESSES IN THE CONSTRUCTION INDUSTRY}

\section{RESEARCHER: John Palassis}

\section{AFFILIATION: Education and Information Division National Institute for Occupational Safety and Health \\ (513) 533-8136}

PURPOSE: Develop and evaluate a prototype document containing checklists of occupational safety and health requirements for small, tradespecific construction businesses.

RESEARCH SUMMARY: The construction industry continues to be one of the most hazardous industries in the United States. Workers of all ages are victims of fatal and nonfatal injuries associated with construction, and each year, approximately 500,000 out of 5.6 million construction workers (which includes many young and new workers) are injured at construction sites.

A prototype document containing checklists on safety and health will be developed for specific construction trades and the owners of small construction businesses. The document will include information on how to implement a safety checklist program and how to establish and maintain an effective safety and health and environmental safety program. The document will be designed as an easy self-assessment procedure that will assist business owners, supervisors, and workers in how to recognize workplace hazards and safety and health deficiencies in construction and determine the proper course of regulatory compliance by remediating or controlling hazards. A separate safety checklist for each specific federal occupational safety and health or environmental regulation pertinent to small construction businesses will be included.

The project will build upon a program in vocational safety and health containing 82 safety checklists for administrators and supervisors in vocational education. It will also be made available on CD-ROM with many occupational safety and health databases from other agencies.

The prototype document will be sent to national and international partners for review and evaluation.

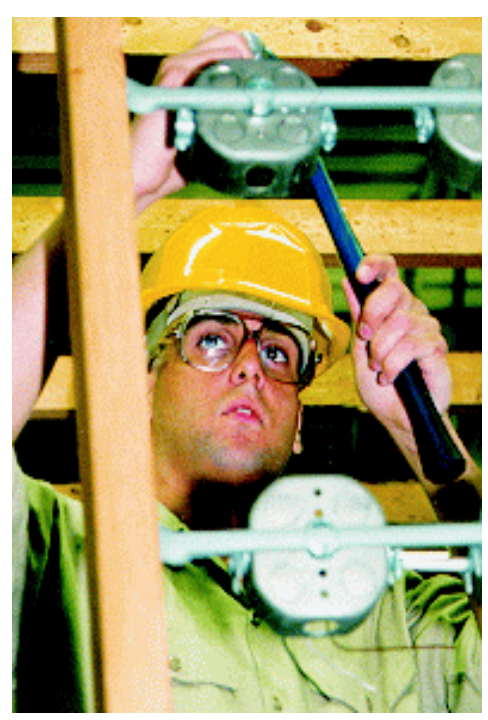

KEYWORDS: Safety, small business

\section{RECENT CITATIONS:}

Palassis, J., and M. Haring Sweeney. 2001. NIOSH Safety Checklists Program for schools and small businesses. Presentation at Ohio Safety Congress, Columbus OH, April 4, 2001.

Palassis J., and M. Haring Sweeney. 2000. Minimizing injury risk in vocational schools: Safety Checklist Program. Poster paper at American Public Health Association conference, Boston, MA, Nov. 14, 2000 .

Palassis J., and M. Haring Sweeney. 2000. NIOSH Safety Checklists Program. Presentation at Alabama Governor's Occupational Safety and Health Conference, Orange Beach, AL, Aug. 29, 2000. 


\section{SAFETY CHECKLISTS FOR VOCATIONALI TECHNICAL SCHOOLS}

\section{RESEARCHER: John Palassis}

\section{AFFILIATION: Education and Information Division National Institute for Occupational Safety and Health \\ (513) 533-8136}

PURPOSE: Increase awareness of safety and health in young workers.

RESEARCH SUMMARY: In the United States, there are approximately 11 million students enrolled in vocational-technical education programs. Most will graduate to work in a trade shop. The latest estimate from the National Electronic Injury Surveillance System (NEISS) indicate that over 240,000 young workers receive injuries in the workplace each year; of these, 84,000 were treated in hospital emergency rooms in 1999, and in the next year, 73 died from fatal occupational injuries.

Researchers will build upon a vocational safety and health document containing 82 safety checklists developed for NIOSH by the Environmental Occupational Health and Safety Institute in New Jersey. The project proposes to finalize, evaluate, and disseminate a document (in CD-ROM format) to administrators, supervisors, and teachers in vocational-technical schools designed to increase the level of occupational and environmental safety and health within these schools. It will be designed as an easy-to-use selfassessment procedure to recognize workplace hazards and safety deficiencies in vocational-technical school shops. Specifically, it will contain information on how to (1) establish and maintain an effective safety and health and environmental safety program, (2) implement a safety checklist program to identify occupational or environmental hazards, and (3) determine the proper course of regulatory compliance by remediating or controlling the hazard. Safety checklists will address federal occupational safety and health and environmental regulations pertinent to vocational schools.

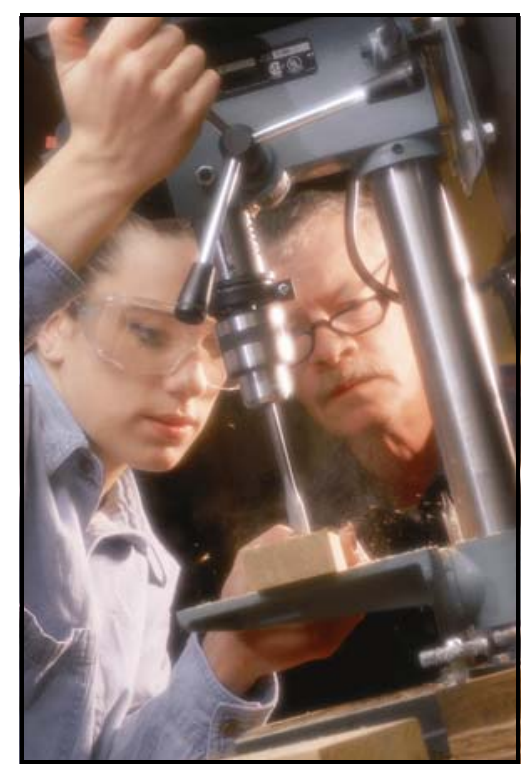

KEYWORDS: Safety, young workers, hazards, vocational education

\section{RECENT CITATIONS:}

Palassis J., and M. Haring Sweeney. 2000. NIOSH Safety Checklists for Vocational-Technical Programs. Presentation at Association for Career and Technical Education Conference, San Diego, CA, Dec. 8, 2000.

Palassis J., and M. Haring Sweeney. 2000. Reducing injury risk of students in vocational-technical schools and young workers in small businesses. Presentation at National Occupational Injury Research Symposium, Special Populations session, Pittsburgh, PA, Oct. 18, 2000 .

Palassis, J. 2000. NIOSH Safety Checklists. Presentation at Ohio Safety Congress, Technology and Adult Education session, Columbus, OH, April 6, 2000. 


\section{EVALUATION OF ELECTRICAL SAFETY HIGH SCHOOL CURRICULUM}

\section{RESEARCHERS: Thaddeus Fowler (513) 533-8530 Carol Merry Stephenson (513) 533-8581}

\section{AFFILIATION: Education and Information Division National Institute for Occupational Safety and Health}

PURPOSE: Assess the effectiveness of NIOSH-developed occupational safety and health training for young workers in secondary vocational education programs and the benefits of using alternative instructional strategies to increase students' knowledge of and improve attitudes toward occupational safety and health.

RESEARCH SUMMARY: Nearly one-half (48.1\%) of all occupational injuries are sustained by employees with less than 1 year of work experience. NIOSH has estimated that over 240,000 adolescents are injured on the job each year; of these, about 84,000 injuries result in emergency room visits in 1999, and 73 young workers died because of work-related injuries.

Little research has been conducted indicating effective strategies for imparting knowledge about safety and health to high school students, nor has there been sufficient evaluation of the effects of a targeted curriculum in changing students' attitudes, beliefs, and behavioral intentions concerning health and safety. Pre-job training in occupational safety and health is one form of intervention that may reduce the disproportionately high rate of injuries occurring in new and young workers. Its effectiveness, however, depends upon how the curriculum is delivered to the students and integrated into their trade programs.

In this project, at least 50 vocational education classrooms will use a newly developed NIOSH curriculum on electrical safety. A critical element that was evaluated was the value added to the curriculum by a motivational/ informational videotape. Students' knowledge gain, safe-work attitudes and beliefs, and behavioral intentions on the job were assessed and compared to students who completed a generic training program in the electrical trades. Assessments were made before instruction began (baseline), post-study, and (as a measure of retention) after summer recess. Both students and teachers had an opportunity to critique the new curriculum.

Study results will be published and disseminated in peer-reviewed literature. Revised curricula have been made available to vocational education programs nationwide, providing guidance for future vocational education programs in other trades. The ultimate goal is to improve the incorporation of safety and health into the 11-million-student vocational-technical system. 


\section{SUPERVISORY TRAINING IN CONSTRUCTION}

\section{RESEARCHERS: Jacqueline Villnave and Steven Hecker}

\section{AFFILIATION: $\quad$ University of Oregon (503) 725-8424 \\ CONSORTIUM: Center to Protect Workers' Rights}

PURPOSE: Identification and implementation of best practices in supervisor training in construction, with an emphasis on the integration of leadership skills training with specific safety and health information.

RESEARCH SUMMARY: In the construction industry, the inherent difficulty of managing employees is complicated by the nature of work organization in the skilled trades. In contrast to other industries, construction foremen are drawn from the ranks of journeymen, and such journeymen may move in and out of supervisory positions, which can lead to role conflict among supervisors.

A variety of factors, including owner and customer demands, increasingly complex technologies, compressed schedules, safety and health concerns, and a more educated work force, are placing increasing demands on construction foremen. The industry has begun to recognize the need for higher levels of leadership and organizational skills, in addition to production skills, for foremen to perform their supervisory tasks effectively. Recognizing the lack of leadership training for foremen as a potentially serious problem, particularly when related to the introduction of worker-based health and safety training, we are assessing the current state of supervisory training and will develop interventions to address current deficiencies.

We identified four Joint Apprenticeship Training Centers (JATC) that offer training for supervisors and three contractors that have internal supervisory training programs. Information about these programs was obtained as a result of direct observation of classroom instruction; interviews with training coordinators, instructors, and participants; and analyses of course material and curricula. We are also gathering data on supervisory training programs developed by national unions and contractor associations. Our initial analysis confirms that safety and health content is limited in these courses, with the emphasis being on production and quality issues, but some are beginning to address leadership and communication skills. Barriers to participation have also been identified, including scheduling, cost, and uncertain rewards for completion.

Based on these data, our research team will develop or adapt a training intervention that combines leadership skills with specific safety and health information. The intention is to create a program that would be viewed as practical by contractors and training centers. Information on specific safety and health risks - for instance, the prevention of sprain and strain injurieswill be incorporated along with skills in communication, motivation, coaching, and dealing with difficult people. We will evaluate the training intervention through questionnaires and interviews with both foremen and the workers they supervise and through an assessment of workplace changes and injury outcomes on projects for which these supervisors are responsible.

KEYWORDS: Supervisor training, foreman training, leadership skills 
CONSTRUCTION CHART BOOK

\section{RESEARCHER: Sue Dong}

\section{AFFILIATION: Center to Protect Workers' Rights (301) 578-8500}

PURPOSE: Characterize the industry for researchers, workers, and others and highlight issues warranting more attention, including the high toll in injuries, illnesses, and deaths in construction.

RESEARCH SUMMARY: An expanded and improved edition has been published. The book has more than 170 charts, 61 of them in the safety and health section, which is comprised of 18 topics.

Since 1995, when the first edition was published, the chart book has been a key reference on the construction industry. The volume, the only source of its kind, provides comprehensive data to characterize the industry. It describes information on sources in federal and state government, private industry, the nonprofit sector, and other countries. Sections include an Industry Summary, Labor Force Characteristics, Employment and Income, Education and Training, and Safety and Health. One new page describes problems with data on safety and health in detail. The book can help anyone interested in construction, from researcher to worker. The format is user friendly, and all pages are posted on the Web at www.cpwr.com and www.elcosh.org.
KEYWORDS: Chart book, data, statistics, industry, safety, health

\section{RECENT CITATIONS:}

Dong, S., with R. Chowdhury, M. McCann, C. Trahan, and J. Gittleman. J. Seegal, editor. 2002. The Construction Chart Book: The U.S. Construction Industry and Its Workers, 3rd ed. Silver Spring, MD: The Center to Protect Workers' Rights.

Grob, H., X. Dong, E. Pollack, S. Schneider, and J. Seegal. 1998. The Construction Chart Book: The U.S. Construction Industry and Its Workers, 2nd ed. Washington, DC: The Center to Protect Workers' Rights.

Grob, H., X. Dong, E. Pollack, S. Schneider, and J. Seegal. 1997. The Construction Chart Book: The U.S. Construction Industry and Its Workers, 1st ed. Washington, DC: The Center to Protect Workers' Rights. 


\title{
CONSTRUCTION SAFETY RESEARCH DEVELOPMENT
}

\author{
RESEARCHER: David Fosbroke \\ AFFILIATION: Division of Safety Research \\ National Institute for Occupational Safety \\ and Health \\ (304) 285-6010
}

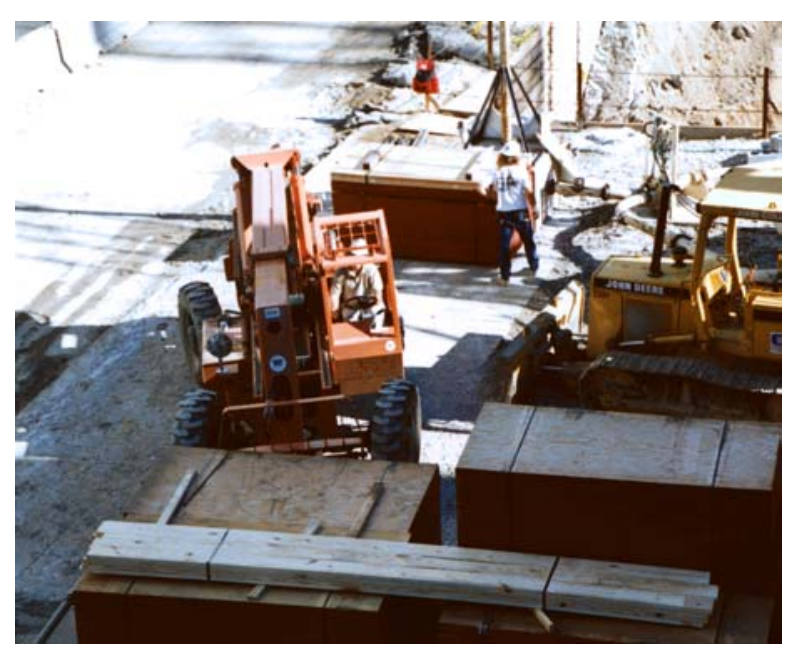

PURPOSE: Focus future construction safety research on high-risk sectors to address the industry's most pressing injury problems.

RESEARCH SUMMARY: The construction industry is consistently among the industry sectors of the U.S. economy with the highest rate of fatal and nonfatal injuries. In 1996, the Bureau of Labor Statistics reported 1,047 fatal injuries and 492,500 OSHA-recordable injuries in the construction industry, of which 227,400 involved lost or restricted work days.

Over the past decade, NIOSH has developed surveillance systems for fatal and nonfatal injuries; conducted injury analyses in construction; conducted field investigations and reported on construction workers killed in falls, electrocutions, confined spaces, and machinery incidents; established model construction safety and health programs in three states; and initiated the assessment and redesign of several manual materials-handling tasks. Using this information, Division of Safety Research (DSR) will focus on construction research on high-risk sectors of the construction industry to address the industry's most pressing injury problems. Traditional research techniques (e.g., literature review, data analysis, and field evaluations) will be integrated with information obtained from collaborations with internal and external partners to identify and prioritize injury research needs.

Research initiated under this project covers a variety of construction topics, including estimating the working lifetime risk of fatal occupational injury by occupation and cause of death, developing a guide of worker injury prevention measures for highway work zones, assessing the feasibility of surveying industry trade association members regarding work-related injuries, evaluating the efficacy of toolbox talks, analyzing the stability of scaffolding used for fall arrest anchorage, and evaluating work zone interventions.

Through analysis of the construction industry, this project will provide guidance to DSR research staff for identifying new research projects; provide coordination between DSR, other construction safety research organizations, federal regulatory agencies, and the NIOSH Construction Steering Committee; and expand dissemination of construction research needs and results to the research and construction communities.

KEYWORDS: Work organization, injuries

\section{RECENT CITATIONS:}

Sweeney, M.H. et al. 2000. Health consequences of working in construction. Ch. 10 in Construction Safety and Health Management, R.J. Coble, J. Hinze, and T.C. Haupt, eds. Upper Saddle River, NJ: PrenticeHall.

Chen, G-X., and D.E. Fosbroke. 1998. Work-related fatal injury risk of construction workers by occupation and cause of death. Human and Ecological Rask Assessment, v. 4, no. 6, pp. 13711390. 


\section{HAZARD PREVENTION IN SELECTED CONSTRUCTION SPECIALTY TRADES}

\author{
RESEARCHER: Thomas Lentz
}

\section{AFFILIATION: Education and Information Division National Institute for Occupational Safety and Health \\ (513) 533-8260}

PURPOSE: Identify and characterize injuries and related causes in construction specialty trades; survey small and large construction firms to identify hazards, training needs, and other measures of safety awareness; and develop forums and materials for creating awareness of hazards in construction specialty trades and intervention and injury prevention strategies.

RESEARCH SUMMARY: Of all major industry divisions in 1996, the construction industry experienced the highest rate for nonfatal injuries ( 9.7 cases per 100 full-time workers) with the highest rates among employers having 11 to 49 workers ( 11.3 cases per 100 full-time workers). Among the specialty trades, the highest rates were found for plumbing, heating, and air conditioning; electrical work; roofing, siding, and sheet metal work; and miscellaneous special trade contractors. Employees in the construction trades work predominantly for nonunionized small businesses, with a majority $(56 \%)$ of private sector work performed in residential construction.

The high injury rates within the construction specialty trades will be addressed through three main objectives: (1) Compilation of data on injuries, fatalities, and related hazards in the plumbing, electrical, roofing, and miscellaneous specialty trade industries; (2) identification, review, and evaluation of the effectiveness of regional and national surveillance and intervention programs targeting specific hazards and recommended safe practices in the selected trades; and (3) promotion of hazard and safe practices awareness through presentations to other state and federal agencies at professional conferences; to labor, management, and contractors' groups; and in professional journals and trade publications.

Information will be collected on the nature and magnitude of hazards and related injuries in plumbing, heating, and air conditioning; electrical work; roofing, siding, and sheet metal work; and miscellaneous specialty trade contractors. NIOSH resources (i.e., health hazard evaluations, fatality assessment and control evaluation reports), OSHA accident investigation reports, and Bureau of Labor Statistics data will be used to obtain information on hazards specific to these industries. Data from nonconventional surveillance and intervention programs will also be utilized, such as the OSHA construction accident reduction emphasis program in Florida. Because the construction specialty trades are largely comprised of small contractors, this program will address challenges associated with small businesses. Through a partnership with the Rinker School of Building Construction, University of Florida at Gainesville, surveys of safety programs and work practices for small and large construction firms will be conducted. Data from these surveys will

\section{U.S. Workers by Industry \\ $\mathrm{N}=102,198,900$}

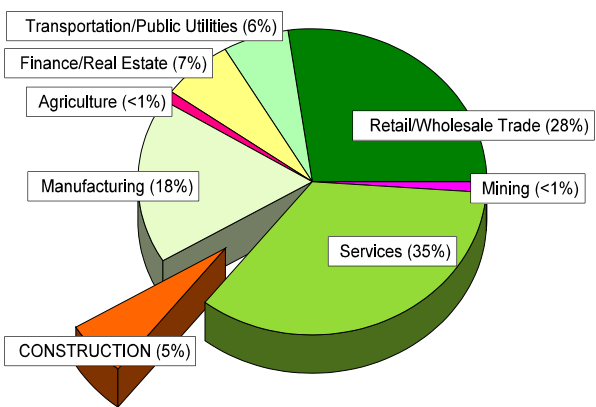

U.S. Injury Incidence Rates by Industry

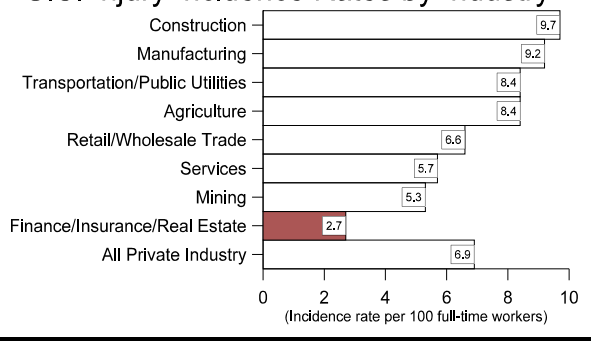

be used to identify differences, if any, between safety practices and related hazards for small and large construction contractors.

KEYWORDS: Injury prevention, information

\section{RECENT CITATIONS:}

Lentz, T.J., and J. Hinze. 2002.

Surveys of occupational safety and health priorities in selected small and large construction firms. Presentation at World Conference on Injury Prevention and Control, Montréal, Quebec, Canada, May 12-15, 2002.

Lentz, T.J., J. Hinze, T. Harrison, R. Medlock, and T. Broderick. 2000. Surveillance and intervention programs targeting injuries in the construction industry. Roundtable session, National Occupational Injury Research Symposium, Pittsburgh, PA, Oct. 17-19, 2000. 


\section{FEASIBILITY STUDY OF RESPIRATOR SURVEILLANCE IN THE CONSTRUCTION INDUSTRY}

\section{RESEARCHER: Bryan Doney}

\section{AFFILIATION: National Personal Protection Technology \\ Laboratory National Institute for Occupational Safety and Health}

(304) 285-6357

PURPOSE: Identify methods for conducting surveillance of respirator use and programs within the construction industry in collaboration with workers and companies.

RESEARCH SUMMARY: OSHA has estimated that approximately $18 \%$ of the 4.4 million workers in the construction industries wear respirators, representing 33\% of the 600,000 construction companies. During October 1997 through September 1998, OSHA issued 427 citations for respirator regulation violations within the construction industry.

This project resulted from observations at a January 1999 meeting of New Jersey highway construction contractors in which the contractors voiced frustration over the conflicts between hiring temporary construction workers from union hiring halls and the OSHA respirator regulatory requirements for fit-testing. It seemed evident that neither the companies nor OSHA were completely comfortable with the feasibility of establishing and administering efficient respirator fitting programs within this sector of the construction industry.

A pilot study was developed to identify feasible mechanisms for surveillance of respirator use within the construction industry. Six focus group meetings were conducted with contractor members of the Society for Protective Coatings (SSPC) from May through November 2000. The meetings allowed NIOSH to learn more about previously reported difficulties with respirator use. The participants conducted abrasive blasting and coatings experiments with different types of respirators, from those using filtering facepieces to those using supplied air. Barriers to respirator protection were categorized as administrative, engineering, medical, and personal. Participants reported that respirators were primarily used for lead, paint vapors, carbon monoxide, oxygen deficiency, acid gas, arsenic, hydrogen sulfide, asbestos, silica, and welding fumes.

Three additional focus groups were held with construction company representatives with the cooperation of the American Road and Transportation Builders Association (ARTBA) in September 2001 through March 2002. Two additional focus groups are planned. A proposal to conduct four focus groups with workers in the road building industry in FY03 has been submitted.
KEYWORDS: Respirators, surveillance 


\section{ADULT BLOOD LEAD EPIDEMIOLOGY AND SURVEILLANCE AND RESEARCH PROGRAM (ABLES)}

\section{RESEARCHER: Robert Roscoe}

\section{AFFILIATION: Division of Surveillance, Hazard Evaluations, and Field Studies National Institute for Occupational Safety and Health (513) 841-4424}

PURPOSE: Assist states in reducing the number of workers having blood lead concentrations of 25 micrograms per deciliter or more to zero.

RESEARCH SUMMARY: During 2001, 9,943 adults with blood lead levels of 25 micrograms per deciliter $(\mu \mathrm{g} / \mathrm{dL})$ or higher were identified by Adult Blood Lead Epidemiology and Surveillance (ABLES) programs in 23 of 25 collaborating states. Extrapolated to the entire United States, this figure indicates that about 15,500 adults had blood lead levels of $25 \mu \mathrm{g} / \mathrm{dL}$ or more.

ABLES is a surveillance program for tracking and preventing elevated blood lead levels among U.S. adults. ABLES data provide the public health community with essential information for setting priorities for in-depth research, intervention, and information dissemination. Reports cover all leadexposed adults, with about $33 \%$ of the reports involving construction workers. Cases identified through ABLES surveillance are frequently referred by state officials to state and federal occupational safety agencies for consultation or enforcement and are used by these officials to target high-risk industries and occupations for interventions and prevention, including bridge repair, home remodeling, residential painting, furniture restoration, and plastics compounding.

In 2002, increased funding allowed the ABLES program to expand to 35 states and collect individual data on age, gender, and industry (but no personal identifiers) rather than aggregate data. These types of data will be more useful to ABLES customers such as OSHA, HUD, and the U.S. Dept. of Transportation.

Typical state-level ABLES interventions include (1) conducting follow-up interviews with physicians, employers, and workers, (2) investigating work sites, (3) providing technical assistance, (4) providing referrals for consultation or enforcement, and (5) developing and disseminating educational materials and outreach programs. NIOSH partners in various lead-reducing initiatives include OSHA (National Emphasis Program on lead), the former Lead Industries Association, Inc. (voluntarily lowering lead exposures), the Center to Protect Workers' Rights, AFL-CIO (training workers about lead safety in construction), and the Council of State and Territorial Epidemiologists (encouraging surveillance on adult exposures to lead in all states). Over the next 3 to 5 years, ABLES plans include improving data standardization,

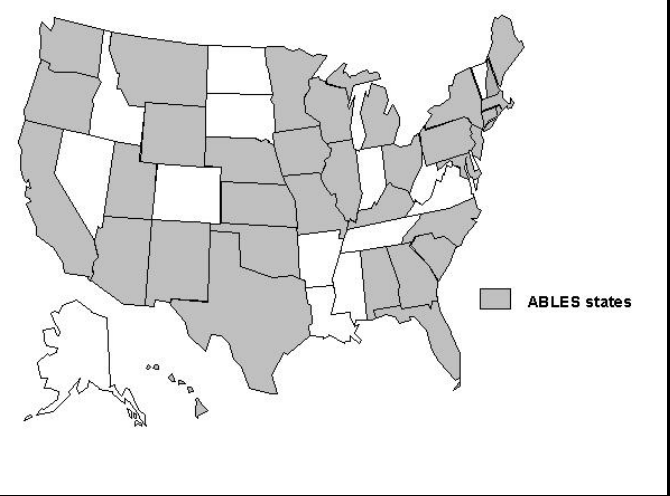

improving the analysis of trends and magnitude of adult lead exposure, and research to better describe effective intervention programs.

KEYWORDS: Lead, surveillance, intervention

\section{RECENT CITATIONS:}

Roscoe, R.J., W. Ball, J.J. Curran et al. 2002. Adult blood lead epidemiology and survellance-United States 1998-2001. Morbidity and Mortality Weekly Report Surveillance Summaries, Dec. 13. V. 51, no. SS-11, 10 pp.

Scholz, P.F., B.L. Materna, D. Harrington, and C. Uratsu. 2002. Residential and commercial painters' exposure to lead during surface preparation. American Industrial Hygiene Association Journal, v. 63, pp. 22-28.

Materna, B.L., D. Harrington, P. Scholz, S.F. Payne, H.A. Stubbs, K. Hipkins, E. Merideth, L. Kirsch, G. Lomax, P. Coyle, and C. Uratsu. 2002. Results of an intervention to improve lead safety among painting contractors and their employees. American Journal of Industrial Medicine, v. 41, pp. 119-130. 


\section{NATIONAL SURVEILLANCE OF NONFATAL OCCUPATIONAL INJURIES USING NEISS}

\author{
RESEARCHER: Larry Jackson
}

\section{AFFILIATION: Division of Safety Research National Institute for Occupational Safety and Health (304) 285-5980}

PURPOSE: Collect nationally representative surveillance data on nonfatal occupational injuries in a timely manner by sampling hospital emergency rooms with the National Electronic Injury Surveillance System (NEISS).

RESEARCH SUMMARY: National surveillance of occupational injuries is an essential prerequisite to the NIOSH mission of developing measures to prevent such injuries. While NIOSH has an effective surveillance system for fatal occupational injuries, nonfatal injury surveillance for the entire U.S. workforce was not established until July 1995. Based on the National Electronic Injury Surveillance System (NEISS), we estimate that about 3.6 million workers are treated annually in emergency rooms for occupational injuries.

NEISS is used to identify and characterize the work-related injury burden in the United States, direct research and intervention efforts, and influence occupational safety and health policy. Using NEISS, demographic information about an injured worker, industry narratives, and a description of the injury event are collected. National estimates of all work-related traumatic injuries can be made, as well as estimates for injuries to special populations (e.g., children, women, African-Americans), industries (e.g., construction), and types of injuries (e.g., eye injuries). Detailed telephone follow-up investigations provide additional information on injury circumstances, worker characteristics, safety precautions, and injury perceptions. The potential for gleaning injury risk information from the NEISS telephone investigations is virtually unlimited.

The use of NEISS as an injury surveillance tool is cost effective because the surveillance system is already established and maintained by the Consumer Products Safety Commission. The NEISS data are collected from hospital emergency department records. Work-related injury case data for all workers are transferred to NIOSH on a monthly basis. Hospitals participating in NEISS were selected from a stratified probability sample of all hospitals in the United States and its territories. Each work-related NEISS record contains information on the characteristics of the victim (e.g., age, sex, race), the injury or illness (e.g., diagnosis, body part injured), source of injury, injury event, and a narrative description.
KEYWORDS: Surveillance, traumatic injuries, special populations

\section{RECENT CITATIONS:}

Morbidity and Mortality Weekly Report. 2001. Nonfatal occupational injuries treated in hospital emergency departments-United States, 1998. V. 50, no. 16, pp. 313-317.

Jackson, L.L. 2001. Nonfatal occupational injuries and illnesses treated in hospital emergency departments in the United States. Injury Prevention, v. 7, Supplement I, pp. i21-i26. 


\section{SURVEILLANCE OF NONFATAL WORK- RELATED INJURIES IN ALASKA}

\section{RESEARCHER: Bradley J. Husberg \\ AFFILIATION: Division of Safety Research National Institute for Occupational Safety and Health (907) 271-5259}

PURPOSE: Support and continue to develop the Alaska Trauma Registry (ATR) so it will become a model trauma registry surveillance system for nonfatal work-related injuries in Alaska.

RESEARCH SUMMARY: From 1980 through 1989, Alaska had a workrelated fatality rate five times greater than the United States as a whole. The arctic and subarctic environments of Alaska provide a very hazardous work setting, exacerbated by great distances, seasonal darkness, cold, and high winds. The Alaska Trauma Registry (ATR) includes information from 1991 through 1999 for 39,143 injures that required hospitalization; 3,951 (10\%) of these injuries were classified as nonfatal work-related injuries. Logging (23/1000 per year) and construction (7/1000 per year) led the industry categories with the highest injury rates. The construction industry also had the highest total number of injuries (740) for the 9-year period.

Surveillance data of nonfatal, work-related injuries can come from various sources. Originally designed for quality control of state trauma programs, trauma registries contain many fields of information useful for injury surveillance: demographics, geographic information, disability, medical cost, payment source, cause of injury, discharge diagnosis, and severity scoring.

Information for the ATR is abstracted from medical record charts from all 23 hospitals in Alaska and sent to the Alaska Department of Health and Social Services to be compiled into the ATR database. Analysis of the trend data and identification of hazardous processes will lead to assessment and implementation of injury prevention strategies targeted to high-risk areas, such as commercial fishing (including aquaculture and diving), seafood processing, logging, aviation, and construction. Specifically, information from the ATR will be used to-

- Reduce morbidity resulting from work-related injuries in Alaska by providing data that would allow the development of appropriate prevention strategies,

- Facilitate comparisons of state, federal, and international data on work-related injuries that permit trend analyses,

- Improve awareness of nonfatal work-related injury as a significant health problem,

- Assist in the evaluation of work-related injury-prevention strategies, and

- Facilitate research for preventing nonfatal work-related injuries.

To help focus on work-related injuries, additional information will be gathered using comprehensive and mutually exclusive industry and occupation codes. Training includes recognition, recording, and use of work-related information for data collectors and hospital staff. Collaboration with external partners will focus on injury prevention, trend analysis, and worker awareness training.

KEYWORDS: Traumatic injuries, surveillance, injury prevention

\section{RECENT CITATIONS:}

Conway, G.A., J.M. Lincoln, B.J. Husberg, J.M. Manwaring, D.M. Bensyl, and D.M. Choromanski. 2001. Alaska's model program for occupational injury prevention:

Applying surveillance for effective public health practice. International Journal of Circumpolar Health, v. 60, pp. 714-726.

Conway, G.A., and B.J. Husberg. 1999. Cold-related nonfatal injuries in Alaska. American Journal of Industrial Medicine, Supplement 1, Sept., pp. 39-41,

Husberg, B.J., G.A. Conway, M. Moore, and M. Johnson. 1998. Surveillance for nonfatal workrelated injuries in Alaska, 19911995. American Journal of Industrial Medicine, v. 34, pp. 493498. 


\section{SURVEY OF SMALL-TO-MEDIUM-SIZED CON- STRUCTION COMPANIES: COMMITMENT TO SAFETY AND HEALTH}

\section{RESEARCHER: Linda Goldenhar}

\section{AFFILIATION: University of Cincinnati Medical Center (513) 558-6936 \\ CONSORTIUM: Construction Safety Alliance}

PURPOSE: Develop a survey instrument to collect safety-related data from owners of smaller (that is, fewer than 100 employees) construction companies.

RESEARCH SUMMARY: Much of the previous construction-related safety research has focused on the unionized sector and on large construction companies. While this work has been extremely valuable in terms of identifying some of the major construction hazards and safety- and health-related issues, it may be limited because approximately $80 \%$ of the construction workforce are not members of a union and $75 \%$ work for companies with fewer than 100 employees. In 2000, a telephone survey instrument was designed to measure the commitment of small-to-medium-sized companies to worksite health and safety. A pilot study using this survey was conducted with a small number of open-shop highway construction contractors. Findings indicated that while most (although not all) companies did provide safety training to their workers, very little, if any, evaluation of the effectiveness of the training was done.

The goal of the current study is to continue learning more about the status of health and safety issues by collecting data from a national sample of small-tomedium-sized contractors in other sectors of the industry. To date, focus groups and interviews have been held with local contractors representative of the target population. They were asked to review the survey instrument and make comments. All comments have been incorporated into the current version. The survey is being redesigned so that it can be self-administered or completed via the Web.

A list of over 9,000 contractors meeting the specific criteria of size and type has been purchased from Dun and Bradstreet. The Association of General Contractors (a trade association for small, medium, and large contractors) has indicated that it is interested in working with the principal investigator to crossreference its membership to the Dun and Bradstreet list and possibly sending a support letter (or e-mail) to the final sample of randomly selected contractors.

Findings from this study should provide health and safety practitioners and members of the construction industry with a more realistic picture of the commitment of small-to-medium-sized, open-shop contractors to health and safety.
KEYWORDS: Construction safety, survey, small business 


\section{RESEARCH ON YOUNG WORKER SAFETY AND HEALTH RISKS IN CONSTRUCTION}

\section{RESEARCHER: Carol Runyan}

\section{AFFILIATION: University of North Carolina (919) 966-2251}

PURPOSE: Examine the work patterns, practices, and injury experiences among young workers in the construction industry in North Carolina. Examine the knowledge and attitudes of parents and employers of teen construction workers with regard to teen work practices, injury risk, training, and supervision.

RESEARCH SUMMARY: U.S. Department of Labor statistics for 19941998 show that young construction workers faced risks of fatalities per hour worked twice the risks of all construction workers aged 25-44. However, youth labor is complex, and youth labor in construction is especially complex because of the structure of the industry (many small-scale firms), the composition of the labor force (growth of Latino workers), and the way work is done (seasonal and multiple activities). No single data set or methodology can capture the complexity of the problem or the diversity of the labor force.

Accordingly, our project involves multiple studies that use both quantitative and qualitative data collection methods and includes collaboration among universities, nonprofit organizations, and state agencies. One study includes two telephone surveys of teen construction workers who worked during the summers of $2000(\mathrm{n}=123)$ and $2001(\mathrm{n}=187)$ (completed), a mail survey of employers of teens who worked during summer of 2001 (on-going), and a telephone survey with parents of the same cohort of teen construction workers interviewed in 2001 (currently underway). Work permits were used as the sampling frame for all these surveys. A second study focused on young Latino construction workers and involved face-to-face interviews with 50 workers. Both quantitative and qualitative data were collected. A third study involved secondary data analyses of injuries among teen construction workers in the home building industry in North Carolina. This study was completed and the findings were published in a journal article.

The teen telephone surveys have revealed that a significant number of teens were engaged in hazardous tasks prohibited by North Carolina child labor laws. For example, in $2001,23 \%$ of the teen sample worked on power-driven lifting equipment, $16 \%$ operated heavy equipment such as graders or excavators, and $35 \%$ used power saws.

Results will be interpreted, and findings will be disseminated at a meeting with various stakeholders so that recommendations for injury prevention can be developed.

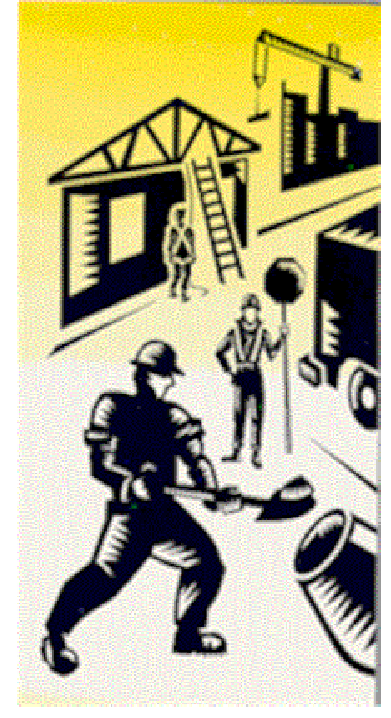

KEYWORDS: Young workers, hazard identification, construction safety

\section{RECENT CITATIONS:}

Bowling, J.M., C.W. Runyan, M.D. Schulman, and J.A. Dal Santo. 2001. Use of work permits for targeted studies and surveillance of high risk low incidence teenage occupations. Presentation at American Public Health Association Conference, Atlanta, GA, Oct. 2001.

Lipscomb, H.J., and L. Li. 2001. Injuries among teens employed in the homebuilding industry in North Carolina. Injury Prevention, v. 7, pp. 205-209.

Treiber, L., M.D. Schulman, C.W. Runyan, J.M. Bowling, J.A. Dal Santo, and H. Lipscomb. 2001. A descriptive study of young workers' experiences in construction. Presentation at American Public Health Association Conference, Atlanta, GA, Oct. 2001.

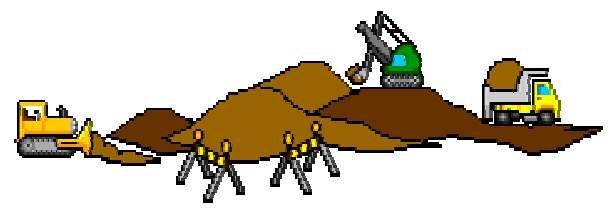




\section{WORKER AND WORKSITE FACTORS IN DENVER INTERNATIONAL AIRPORT CONSTRUCTION INJURY}

\section{RESEARCHER: Judith Glazner \\ AFFILIATION: University of Colorado (303) 315-7939}

PURPOSE: Develop methods for cataloguing and coding data appearing in injury incident descriptions found in standard First Reports of Injury (FRI) and Accident Investigation Reports (AIR) and link these data with existing coded administrative data. Analyze the linked data to identify and quantify factors contributing to injury.

RESEARCH SUMMARY: Construction workers not only have high rates of work-related injuries, but they are among the most likely workers to experience serious injuries. The combination of information from injury reports with an administrative database containing claims, demographic data, and hours worked will provide a rich source for describing injuries and the factors contributing to them. The utility of these data will then be evaluated to test specific hypotheses about factors differentially associated with different types of injury as well as different levels of injury severity. The data will also be used to determine direct costs of injury for high-risk groups of workers and for specific factors contributing to injury.

Study aims will be accomplished by coding and analyzing data from standardized FRI's and AIR's linked with an administrative database from construction of the Denver International Airport. This database contains information on over 4,600 workers' compensation claims, payroll and demographic data on 32,081 workers who worked over 31 million hours on the airport, and company characteristics for 769 contractors.

The results should allow identification of the causes of work-related injuries and provide information useful for focusing specific prevention efforts on the more costly risk factors in the construction industry. In addition, the methods developed should have applicability to data from other occupational groups.
KEYWORDS: Surveillance, injuries, risk factors

\section{RECENT CITATIONS:}

Lowery, J.T., J.A. Borgerding, B.

Zhen, J.E. Glazner, J. Bondy, and K. Kreiss. 1998. Risk factors for injury among construction workers at Denver International Airport. American Journal of Industrial Medicine, v. 34, no. 2, pp. 113-120. 


\section{SOCIAL/ECONOMIC IMPACT OF INJURY/ILLNESS IN CAREER ROOFERS}

KEYWORDS: Roofers, social impacts, economic impacts

\section{RESEARCHER: Laura Welch}

\section{AFFILIATION: MedStar Research Institute (202) 877-5466}

PURPOSE: Develop a credible measure of the amount of disability, disability retirement, early retirement, and job change caused by injury, illness, and musculoskeletal disease among roofers.

RESEARCH SUMMARY: Standard, well-developed instruments and techniques will be used to survey union construction workers at the time they leave their trade and 1 year later. Questions will include reason for leaving, nature of injury or illness if present, functional limitations at the time of leaving and after 1 year, and the social and economic consequences of their decisions. This study will focus on three groups of roofers: (1) those who leave the trade at any time in their careers before retiring, (2) those who take early retirement; and (3) those who apply for disability retirement. A comparable group of roofers who continue to work will be interviewed also. Specifically we will-

- Determine what proportion of roofers leave the union before retirement age, retire early, or apply for disability retirement because of a work-related injury, work-related disease, or chronic medical condition;

- Determine what proportion of roofers who continue to work in the trade have chronic symptoms from a work-related injury, work-related disease, or chronic medical condition;

- Describe the social and economic impact of a work-related injury, illness, or premature retirement caused by a medical condition;

- Evaluate changes in the social and economic status over time in roofers who leave the union, retire early, or take disability retirement;

- Assess and describe the impact of work-related conditions and aging on the ability of roofers to remain employed in their trade. 


\section{ECONOMIC IMPACT OF OCCUPATIONAL INJURY AND ILLNESS}

\section{RESEARCHER: Sue Dong}

\section{AFFILIATION: Center to Protect Workers' Rights (301) 578-8500}

PURPOSE: Estimate costs to workers not covered by workers' compensation and understand the economic impact of injury and illness on construction workers, especially self-employed workers.

RESEARCH SUMMARY: The more than 194,000 annual lost-workday injuries and illnesses in construction result in considerable economic costs to workers, their families, employers, and society, yet little research has been done on describing and measuring these costs. Currently, information on the costs of injuries and illnesses derives mainly from workers' compensation, but workers' compensation does not address all costs, nor does it cover all workers. For example, little information has been available on more than 2 million self-employed workers in the construction industry.

This project is expected to (1) quantify costs of occupational injury and illness and the burden on construction workers and their families, especially the costs incurred by workers not typically addressed in existing approaches to the problem, (2) determine who pays the costs of occupational injury, illness, and disability according to workforce characteristics, and (3) estimate the costs of leading injuries and illnesses in construction. The Medical Expenditure Panel Survey (MEPS) and the National Health Interview Survey (NHIS) will be linked together for this study.

The initial investigation of the data sets has been done. Variables related to work-related injuries and medical expenditures selected from the Medical Condition File and Full-Year Consolidated Data File have been merged. Because of constraints under the confidentiality guidelines of the Agency for Healthcare Research and Quality (AHRQ) (the agency sponsoring the survey), some MEPS data cannot be released to the public. An application for using this confidential data has been submitted and approved. Currently, the linkage file-1996 NHIS/1997 MEPS Public Use Person Record Linkage- has been obtained and will be used to link MEPS and NHIS for the data analysis.
KEYWORDS: Injury and illness, cost, workers' compensation, selfemployment 


\section{TRENDS OF CONSTRUCTION INDUSTRY AND WORKFORCE}

\section{RESEARCHER: Sue Dong}

\section{AFFILIATION: Center to Protect Workers' Rights (301) 578-8500}

PURPOSE: Characterize the construction industry and its workers and provide background information for construction safety and health research.

RESEARCH SUMMARY: As described in the National Occupational Research Agenda, work organization is influenced by factors such as economic conditions, technological changes, demographic trends, and changing corporate and employment practices. These trends may adversely affect work organization and may result in, for example, increased work load demands, longer and more varied work shifts, and job insecurity. However, the actual effects of these trends on the conditions of work and on the well-being of workers have received little study.

This project is designed to characterize the construction industry and workers, to observe the changes and trends, and to study the effects of these trends on the conditions of construction work and on the safety and health of construction workers. The project addresses wide issues using data from various sources, including the Bureau of Labor Statistics, Census Bureau, Dun and Bradstreet, and the Internal Revenue Service. This project will help people better understand the construction industry, its workers, and related issues.

The major findings have been compiled into the third edition of The Construction Chart Book-The U.S. Construction Industry and Its Workers and will be posted on CPWR's Website and eLCOSH - the Electronic Library of Construction Occupational Safety and Health.
KEYWORDS: Workers, employment, job tenure, demographics, education, training, hours worked, overtime, technology, wage, income, unionization, benefits

\section{RECENT CITATIONS:}

Dong, X. 2002. Diversity in the workplace: Trends and their safety and health implications. In Power Through Partnerships: 12th Annual Construction Safety and Health Conference, Proceedings (May 21-23, 2002, Rosemont, IL).

Dong, X. 2001. Demographics of the construction and maintenance workforce. Presentation at Transportation Research Board annual meeting, Washington, DC.

Grob, H., X. Dong, E. Pollack, S. Schneider, and J. Seegal. 1998. The Construction Chart Book, The U.S. Construction Industry and Its Workers, 2nd ed. Washington DC: The Center to Protect Workers' Rights.

Grob, H., X. Dong, E. Pollack, S. Schneider, and J. Seegal. 1997. The Construction Chart Book, The U.S. Construction Industry and Its Workers, 1st ed. Washington DC: The Center to Protect Workers' Rights. 


\section{WORKPLACE SAFETY AND HEALTH OF HISPANIC CONSTRUCTION WORKERS}

\section{RESEARCHERS: Jim Platner and Sue Dong}

\section{AFFILIATION: Center to Protect Workers' Rights (301) 578-8500}

PURPOSE: Examine the trends in the Hispanic construction workforce and analyze the characteristics and relative risks for occupational injuries of Hispanic construction workers.

RESEARCH SUMMARY: In recent years, the Hispanic population has dramatically increased in the United States. Construction has become the sector of the workforce with the highest percentage of Hispanic workers outside of agriculture, more than tripling during the last two decades. At the same time, the incidence of occupational injuries among this group are increasing, indicating that the safety and health needs of Hispanics require special attention.

Injury (both fatal and nonfatal) and demographic (occupation, education, age, and other) data on Hispanic workers in construction will be collected, as well as information on the risk of workplace injuries. The findings will help policy makers and those concerned with safety and health in the construction industry better understand the issues of Hispanic construction workers. The statistical analysis will be based on data from Current Population Surveys, the Census of Fatal Occupational Injuries, and the Survey of Occupational Injuries and Illnesses.

Initial findings show that compared with nonHispanic construction workers, Hispanic construction workers (1) are much younger, mostly noncitizens, less educated, less unionized, and earn less wages, (2) are mostly employed as unskilled or semiskilled workers with few managers or professionals, and (3) have higher fatality rates and lower nonfatal injury and illness rates. Given that both fatal and nonfatal rates should be proportional to exposures to risk, nonfatal injuries and illnesses may be underreported among Hispanic workers. Additional research is needed to evaluate factors that place Hispanic construction workers at higher risk and to evaluate the effectiveness of public health interventions targeted to eliminate this disparity.
KEYWORDS: Hispanic workers, demographics, work-related injury, fatality, safety and health

\section{RECENT CITATIONS:}

Dong, X., and J. Platner. 2002. Workplace safety and health of Hispanic construction workers. In Power Through Partnerships: 12th Annual Construction Safety and Health Conference, Proceedings (May 21-23, 2002, Rosemont, IL).

Dong, X., and J. Platner. 2002. Occupational fatalities in Hispanic construction workers. Presentation at 130th Public Health Association meeting, Philadephia, PA. 


\title{
ANTHROPOMETRY OF CONSTRUCTION AND AGRICULTURE POPULATION
}

\author{
RESEARCHER: Hongwei Hsiao
}

\section{AFFILIATION: Division of Safety Research National Institute for Occupational Safety and Health (304) 285-5910}

PURPOSE: Study the human form to (1) collect data on human sizes in three dimensions for better design of workplaces and personal protective equipment, (2) elucidate the interaction between the human shape and anthropometric design decisions for complex systems, and (3) provide fundamental information for human modeling to evaluate strategies for preventing traumatic injuries.

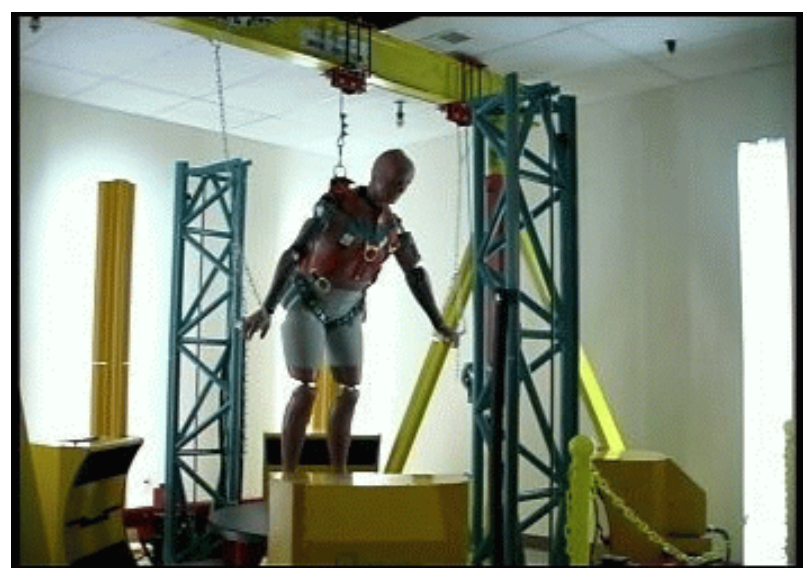

RESEARCH SUMMARY: Many of the anthropometric data available regarding the fit or design of personal protective equipment (PPE) are twodimensional and out of date. Reliable information on sizing for civilians, women, and minorities is limited. PPE's that are physically incompatible with workers' body shapes are not likely to provide the level of protection and comfort required to permit them to work productively.

A state-of-the-art whole-body laser scanner is being used to collect human images and create a database. The scanner uses low-power laser light reflected from the surface of the skin to generate a highly accurate image of the human form. The first study on fall protection harness sizing was completed using 98 subjects. A multivariate accommodation analysis has identified 15 representative body models for the "standard size" harness design. These models can serve as a useful population to test harness design until a larger survey of the nation's construction workers can be done. Data from 96 subjects have been collected for the study on tractor cabs. A technical report on anthropometric criteria for the design of farm tractor cabs will be available next year. The research team continues to work with partners to develop theories for quantifying three-dimensional human shapes and sizing information for PPE designs.

The specific outputs from this project will be (1) an anthropometric guide to aid users in the selection of the appropriately sized fall-protection harnesses, (2) a sizing system for the design of fall-protection harnesses, and (3) anthropometric criteria for the design of farm tractor cabs to increase the safety of farm tractor operation.

KEYWORDS: Protective equipment, fit-sizing, fall protection 


\section{RADIATION GRANTS AND COOPERATIVE AGREEMENT PROGRAM}

\section{RESEARCHER: David Pedersen}

\section{AFFILIATION: Division of Surveillance, Hazard Evaluations and Field Studies National Institute for Occupational Safety and Health \\ (513) 841-4223}

PURPOSE: Provide external support for NIOSH's analytic epidemiology research program concerned with energy-related health effects at DOE facilities.

RESEARCH SUMMARY: NIOSH supports applied field research to identify and investigate the relationships between health outcomes and occupational exposure to radiation and other hazardous agents, epidemiologic research relevant to energy-related occupational health, and research related to assessing occupational exposures to hazardous agents at nuclear weapons facilities and in other energy-related industries.

This program uses academic and nonprofit organizations to propose and support research that focuses on current and former worker populations at energy-related sites and expands the literature on such research. These extramurally generated projects provide a point of view different from NIOSH intramural research concepts. Unique exposures in special populations, such as job stress in downsized workers or lung fibrosis in plutonium workers, and surveillance methods are evaluated by academic researchers and labor, either independently or in collaboration with NIOSH partners. Several studies specifically addressed the occupational exposure characteristics of personnel in the construction trade crafts, including exposure history reconstruction, participatory job task analysis, and mechanisms for hazard exposure identification and surveillance.

Most of the study procedures include meta-analysis, combined analysis methodologies, and combined cohort studies across sites, and provide an opportunity for an intervention component. Results of this study should contribute significantly to the understanding of health effects associated with low-level exposures to ionizing radiation and other hazardous agents at DOE sites. All study records will become part of the DOE Comprehensive Epidemiologic Data Resource.

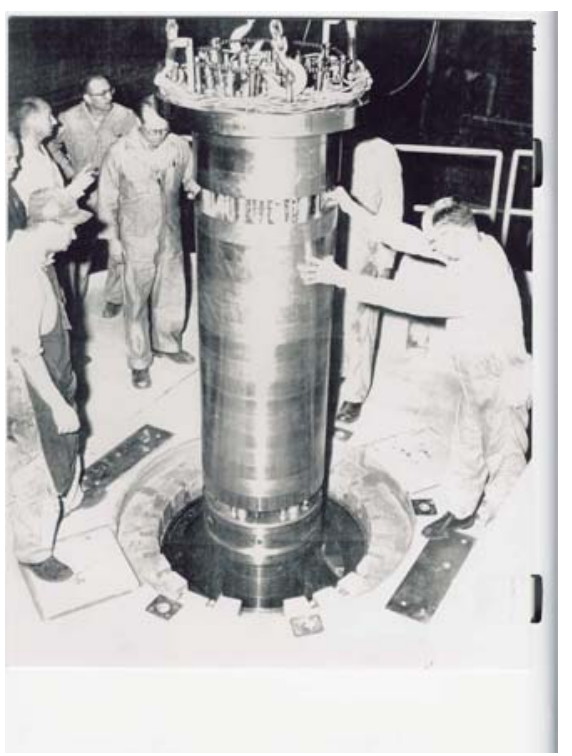

KEYWORDS: Epidemiology, exposure assessment, nuclear workers

\section{RECENT CITATIONS:}

Bingham, E. Work histories evaluating new participatory methods. University of Cincinnati. Available at http://www.cdc.gov/niosh/2001133.html.

Barnhart, S. Comprehensive occupational health surveillance. University of Washington. Available at http://www.cdc.gov/niosh/2001133.html.

Tankersley, W. Improved Systems for worker exposure surveillance. Oak Ridge Associated Universities. Available at http://www.cdc.gov/niosh/2001133.html. 


\section{OCCUPATIONAL LEAD EXPOSURE: RISK TO THE AGING WORKER}

KEYWORDS: Effectiveness research, neurotoxicology, lead

\section{RESEARCHER: Lisa Morrow}

\section{AFFILIATION: University of Pittsburgh}

(412) 624-0762

PURPOSE: Examine long-term changes in neuropsychological performance in a cohort of workers chronically exposed to lead.

RESEARCH SUMMARY: Exposures to lead remain a significant issue for occupational and environmental health, in part because new research continues to demonstrate adverse effects at levels formerly thought to be innocuous. Few studies up to this point have been able to examine the effects of lead in relation to quantitative measures of chronic occupational exposure. The study will also add to our understanding of the effects of lead in older people, which is important as the working population ages.

People with past and current exposure to lead are being compared to a demographically similar unexposed control group. Between 1981 and 1984, 288 lead-exposed workers and 182 unexposed controls were evaluated as part of an epidemiological study of lead carried out at the University of Pittsburgh. At the time of the initial evaluation the workers had a mean age of 35 (range 21-60). The current tests will repeat the neuropsychological test battery, collect information on current and past psychiatric history and current blood lead levels, and measure lead concentration in bones using x-ray fluorescence (XRF). To date, we have re-evaluated 117 subjects. For the current assessment, lead-exposed subjects and unexposed controls do not differ in age, but overall education is higher for controls. Sixty percent of the workers have not worked with lead for over a year, while $40 \%$ are currently working or have worked with lead within the past year.

The specific aims are to test four hypotheses:

1. That exposed subjects will have poorer neuropsychological test scores and more psychiatric dysfunction;

2. That exposed subjects will show steeper performance declines across the age range when compared to controls;

3. That exposure will be predictive of performance, with a dose-response pattern; and

4. That higher bone lead concentrations will co-vary with current blood lead levels. 
APPLICATION OF A TASK-BASED

EXPOSURE ASSESSMENT MODEL

(T-BEAM) TO CONSTRUCTION SAFETY

AND HEALTH PROGRAMS, EDUCATION,

AND TRAINING

\section{RESEARCHER: Pam Susi \\ AFFILIATION: Center to Protect Workers' Rights (301) 578-8500; (856) 985-9300}

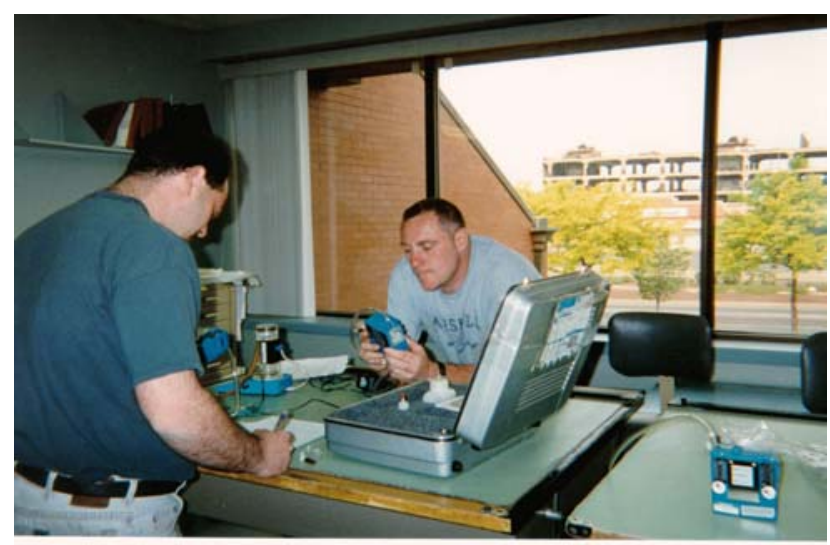

PURPOSE: Develop a health hazard assessment and control methodology for construction that cultivates safety and health expertise within the construction workforce.

RESEARCH SUMMARY: Construction safety and health specialists. Journeymen from several trades have been trained to collect exposure data and assist in control technology evaluations throughout the United States. Educational programs are in place at Marshall University with the International Union of Painters and Allied Trades and at Drexel University with building trades workers in Philadelphia and southern New Jersey to provide collegecredit courses in occupational safety and health for construction.

Silica surveys. Over 40 personal exposure measurements of respirable dust and respirable quartz were collected at 13 sites from painters, bricklayers, operating engineers, and laborers. Exposures to respirable quartz were over 500 times the NIOSH Recommended Exposure Limit (REL) for painters engaged in abrasive blasting, over 20 times the NIOSH REL for bricklayers, and over 10 times the NIOSH REL for operators and laborers engaged in road milling operations.

Welding fume and metal exposure hazard evaluation. Approximately 200 personal exposure measurements of fumes and various metals were collected among welders during welding and torch-cutting. Measurements have been collected with and without ventilation. Use of ventilation showed a statistically significant reduction in exposure. Hexavalant chromium and other metal exposures among construction workers are currently being evaluated based on field surveys of welding and abrasive blasting operations and review of the literature.

Engineering and Work Practice Controls Work Group. CPWR and NIOSH co-chair a standing work group that directs, develops, and evaluates control technologies for construction health hazards. The group convened its tenth meeting in March 2002. Videos graphically demonstrating the effectiveness of local exhaust ventilation for drywall finishing dust and welding have been developed. Low-hazard abrasive blasting methods and materials and engineering controls for masonry work are currently being evaluated.

Other collaborators on this project include the United Association of Plumbers and Pipefitters, the International Union of Bricklayers and Allied Crafts, Philadelphia Apprenticeship Coordinators Association, Harvard University, and the University of North Carolina. 


\section{CONSTRUCTION POLICY RESEARCH}

\section{CONSTRUCTION POLICY RESEARCH CENTER AT HARVARD UNIVERSITY}

\section{RESEARCHER: Robert Herrick}

\section{AFFILIATION: Harvard University (617) 384-8803}

\section{CONSORTIUM: Center to Protect Workers' Rights}

PURPOSE: Serve as the focus for quantitative and qualitative research in the full range of issues affecting the construction workforce.

RESEARCH SUMMARY: The Center will engage faculty, researchers, and students from the Harvard School of Public Health, the Harvard Trade Union Program, and other programs at Harvard University, as well as extramural collaborators such as the Maine Building Trades Council and the Boston School of Management. Faculty will be drawn primarily from the Department of Environmental Health, the Harvard Trade Union Program, and Massachusetts Institute of Technology. The Center will serve as a link between these administratively independent units to foster collaborative arrangements that cross organizational boundaries. The Center will promote the purposes of academic programs, interdisciplinary research projects, and outreach.

The theme of the Center is the integration of policy, engineering principles, and environmental and workplace issues and strategies, with a particular emphasis on human health. A wide range of topics will be studied, such as high-performance building technologies, the management of capital budgets and investments as a factor in construction technology, the economics of labor in modern construction, and holistic approaches to the conception, construction, and operation of "green" buildings. A major goal is to facilitate productive interactions between researchers and practitioners in basic and applied science, engineering and architecture, urban planning, public policy analysis and administration, and construction management.

The work of the Center will be conducted at two sites: the Harvard School of Public Health, Boston, MA, and the Harvard University Trade Union Program, Cambridge, MA.
KEYWORDS: Policy, intervention, management, engineering, architecture, planning, high-performance buildings 


\section{CONSTRUCTION POLICY RESEARCH CENTER AT THE UNIVERSITY OF MARYLAND}

\section{RESEARCHER: Fred Feinstein}

\section{AFFILIATION: University of Maryland (301) 405-2729}

\section{CONSORTIUM: Center to Protect Workers' Rights}

PURPOSE: Development of a Construction Policy Research program to study the effects of construction activities on societal values such as health and safety, quality, cost efficiency, and community development.

RESEARCH SUMMARY: Construction industry contractors, subcontractors, contractor associations, project owners, architects, engineers, safety specialists, construction-related procurement officers in federal and state governments, building trade union members, and university researchers have joined together to discuss how the Construction Policy Research program could best serve the construction community and generate ideas for program projects. An advisory committee has been established to represent the broad range of construction industry interests.

Two research tasks have been developed as part of the program.

Workers Compensation: Meetings were held with the key players involved in the administration and development of policy for the Maryland workers' compensation system. These meetings led to a better understanding of particular interests and concerns about the system in the region. After examination and discussions about the system and its data sources, participants in these meetings have agreed that a significant problem exists concerning the adequacy of the data collected by the system and that deficiencies in the existing data make it difficult to assess system effectiveness. Project staff determined that initial research will focus on examining Maryland's data collection system to determine what changes might be made to assure that sufficient data exist on which to base proposals for policy reform. As part of this work, the workers' compensation data collection systems in other states will be examined to provide a context in which to examine the Maryland system.

Best-Value Contracting: Construction contractors have begun to recognize that the traditional method of low-bid contracting has significant limitations and that the results have often failed to satisfy customer (and their own) needs. Low bids can contribute to poor quality, delayed schedules, accidents, cost overruns, and high accident rates. "Best-value contracting" is an alternative approach that permits project owners to make decisions based on the value of materials and work instead of price alone. Under this bidding method, contracting officials evaluate and select contractors on the basis of key performance and quality factors, including safety records, as well as cost. As a result of project work, a survey is being drafted to collect data on the use of best-value contracting and the different types of systems used. A research and analysis plan will be devised to assess the effect of best-value contracting on several major performance criteria, including safety.
KEYWORDS: Best-value contracting, worker's compensation data, construction policy development 


\section{CONSTRUCTION POLICY RESEARCH CENTER ON INTEGRATED SAFETY SYSTEMS}

\section{RESEARCHER: Peter Hoonakker}

\section{AFFILIATION: University of Wisconsin-Madison (608) 263-2520}

\section{CONSORTIUM: Center to Protect Workers' Rights}

PURPOSE: Establish a multidisciplinary Construction Policy Research Center (CPRC) applying Quality Management (QM) techniques and principles, human factors engineering, and industrial and construction engineering approaches to occupational safety and health in the construction industry.

RESEARCH SUMMARY: Trends in the safety community suggest that Quality Management (QM) or Total Quality Management (TQM) principles can provide an appropriate framework for improving worker safety and health. A growing body of industry experience also supports the effectiveness of the QM approach to safety and the correlation between quality and safety performance.

Many companies that adopted QM have benefitted from the unexpected side effect of lower injury and illness rates. For example, safety team members at a Georgia Gulf plant in Delaware City, DE, reported a downward trend in both incidents and quality problems since 1989 when the "Use Your Head To Erase All Dangers" program was initiated. Another example comes from the Phelps Dodge copper mine in Morenci, AZ, which, after changing its management approach, tripled its copper production per employee while reducing the number of injuries sevenfold. A QM process implemented by Texas Instruments to enhance contractor performance and overall savings achieved the following outcomes: a reduction of reworking from a level in excess of $11 \%$ to less than $1 \%$ of project value, improved safety and health among workers, and reduced workers' compensation insurance.

The implementation of QM principles, practices, and techniques has the potential to benefit quality and productivity, but also to improve occupational safety and health. The building and construction industry could benefit tremendously from lessons learned in other branches of industry. However, it has become clear that it will not be easy to implement QM in the construction industry. Special tools and techniques need to be developed, especially to integrate QM with safety and health procedures. The CPRC will develop an agenda and a program of applied research to safety systems with QM and construction management processes.

The CPRC's first year objectives include-

- Further development and definition of ties to construction companies and unions,

- Building networks, structures, and interfaces among all participating parties,

- Planning education programs addressing integrated safety systems applications to the construction industry,
- Presenting education programs in a variety of ways, including collegelevel engineering courses and short courses, and

- A pilot study using QM techniques and principles in the building and construction industry.

KEYWORDS: Occupational safety and health, safety systems, Quality Management 


\section{ELECTRONIC LIBRARY OF CONSTRUCTION OCCUPATIONAL SAFETY AND HEALTH (eLCOSH)}

\section{RESEARCHER: Jane Seegal}

\section{AFFILIATION: Center to Protect Workers' Rights (301) 578-8500}

PURPOSE: Reduce the high toll in injuries, illnesses, and deaths in construction by making top-quality information on safety and health easily accessible to workers and others.

RESEARCH SUMMARY: eLCOSH is a user-friendly, searchable Website (www.elcosh.org.) containing more than 500 documents on construction safety and health. More than 30 of the postings are in Spanish (along with a Spanish site map), and some documents are provided in other languages, such as Creole, Italian, and Polish. The intended audience is anyone interested in improving construction safety and health in the construction industry, including researchers, but a key goal is to provide workers with information about how to protect themselves. Contributors include federal and state agencies, newspapers, trade magazines, university researchers, and labor unions. The collection includes pocket cards and brochures for workers, Power Point presentations, checklists, statistics, and information on regulations in the United States and elsewhere. Some of the documents are not available anywhere else.

A few one-page postings written by the staff of the Center to Protect Workers' Rights provide basic information that is often hard to pin down, such as "When do you need fall protection?" The site is organized by hazard, trade, (type of) job site, and other, with a separate section on training and more than 40 annotated links to other sites on construction safety and health. eLCOSH is updated quarterly and provides a What's New section. A 7-minute CD-ROM presentation (in English) provides a tour of the site and is available upon request. The site was first posted in August 2000. As of September 2001, eLCOSH had 12,500 visits per month and 57,500 hits.
KEYWORDS: eLCOSH, database, training, hazards, trades, prevention, workers, Web, Internet, safety, health

\section{RECENT CITATIONS:}

Seegal, J., and S. Benjamin. 2002. A Web-based resource for construction safety and health. Applied Occupational and Environmental Hygiene, v. 17 , no. 4 , pp. $244-46$. 


\section{DATA CENTER AT THE CENTER TO PROTECT WORKERS' RIGHTS}

\section{RESEARCHER: Sue Dong}

\section{AFFILIATION: Center to Protect Workers' Rights (301) 578-8500}

PURPOSE: Monitor the health and safety of workers in the construction industry, provide ongoing measures to assess the effectiveness of interventions, and provide detailed data on the health and safety of workers in each construction trade quickly so they can be used to answer questions raised by people in the construction industry, by researchers, and by the general public.

RESEARCH SUMMARY: The data from the Census of Fatal Occupational Injuries (CFOI) and the Annual Survey of Occupational Injuries and Illnesses (both put out by the Bureau of Labor Statistics [BLS]) are used to follow trends in the health and safety of workers. The Center to Protect Workers' Rights (CWPR) has obtained CFOI data on all work-related fatal injuries annually from BLS since 1992 and is completing an analysis that looks at trends in death rates from 1992 through 2000. These data indicate that death rates in the construction industry have remained roughly unchanged at around 14 deaths per 100,000 full-time workers. In those occupations with consistently high death rates-laborers, roofers, ironworkers, and electrical workers - the accident narratives have provided useful clues to aid in the development of targeted interventions.

Since 1992, CPWR has been charting trends in nonfatal injury rates in the construction industry using the annual survey data. Although these data show a downward trend in nonfatal injury rates, questions remain regarding the validity of the trend. About $20 \%-25 \%$ of the workers in the construction trades are self-employed and therefore are excluded from the survey; in addition, the survey includes only the private sector. Others factors that may lead to underreporting of injuries are that (1) many occupational diseases have long latency periods and often go untracked and (2) injuries among temporary workers at work sites are usually reported to staffing agencies that are not considered part of the construction industry. These and other reasons lead us to believe that the number of nonfatal injuries and illnesses in construction are significantly underreported. Discussions are being held with OSHA to study ways to improve record-keeping systems for OSHA's 300 logs that form the basis of the survey.

A third project at the Data Center aims to assess the effects of training interventions on work-related injuries among construction laborers in Washington State. We have been able to link data on workers' compensation claims and safety training received by some 600 members of the Northwest Laborers' Health and Welfare Fund during 1993-1994. Although we are in the initial stages, we hope this study will provide evidence that safety and health training can be an effective intervention.
KEYWORDS: Data analysis, injury, illness, fatalities, rates, trends, training

\section{RECENT CITATIONS:}

Pollack, E.S., and R.T. Chowdhury. 2001. Trends in work-related death and injury rates among U.S. construction workers, 1992-1998. Silver Spring, MD: Center to Protect Workers' Rights. 


\section{DEVELOPING SCALABLE DATABASE FOR CONSTRUCTION SAFETY}

\section{RESEARCHERS: Mark Carrozza and Ronald Freyberg}

\section{AFFILIATION: University of Cincinnati Medical Center (513) 556-5077}

\section{CONSORTIUM: Construction Safety Alliance}

PURPOSE: Develop a scalable database to warehouse data on occupational fatalities, injuries, and illnesses in the construction industry collected from disparate sources.

RESEARCH SUMMARY: Data on occupational fatalities, injuries, and illnesses in the construction industry currently exists in many national, regional, and state data systems. The Bureau of Labor Statistics (BLS) annually reports on the number of workplace injuries, illnesses, and fatalities; state information on fatal accidents is available through NIOSH's Fatal Accident and Circumstance Epidemiology (FACE) system; and the National Center for Health Statistics' (NCHS) National Health Interview Survey (NHIS) produces accident and injury data based on its annual nationwide survey. More-detailed safety and health data are collected at the individual worker level and are maintained by labor unions, individual construction companies, and trade associations.

A single, scalable database was designed and developed that is capable of housing this information from both a summary level (for example, BLS and FACE data) and at the worker level. The database was developed using Microsoft SQL Server, version 7.0, and can grow efficiently and economically as new data are collected.

A limited Web-based application was also developed that allows access to the data over the Internet. The custom application, developed using the Internet "middleware" software ColdFusion, takes the user's selection criteria and builds a query using standard structured query language (SQL) statements. $\mathrm{SQL}$ is then used to query the underlying SQL database and returns the results to the user's Web browser. The combination of Microsoft SQL Server and ColdFusion produces a highly scalable and reliable application that allows users to access and summarize quickly the comprehensive information maintained in the database.

This database will provide a single, comprehensive means of access to data that describe the health and safety status of the construction industry.

Longitudinal data will allow investigations of possible trends over time for selected safety and health outcomes. Individual worker characteristics can be linked to health and safety outcomes. The data could also be used to generate hypotheses for epidemiology studies or, ultimately, to suggest strategies aimed at reducing fatalities, injuries, and illnesses in the construction industry. 


\section{DEVELOPING CONSTRUCTION SAFETY ALLIANCE WEBSITE}

\section{RESEARCHER: Daniel Halpin}

\section{AFFILIATION: Construction Safety Alliance Purdue University (765) 494-2244}

PURPOSE: Provide other construction stakeholders, including small-to-medium-sized construction company managers, health departments, safety professionals, and workers, with practical, up-to-date safety and health information.

RESEARCH SUMMARY: The Website contains pertinent summaries of research from partners in the Construction Safety Alliance (CSA) and safety education and training material relating to the focus areas of CSA's research projects. The Website serves as a clearinghouse for construction safety and health education and information resources. It also provides links to other relevant Websites, such as those maintained by NIOSH, OSHA, the Construction Industry Institute, the Center to Protect Workers' Rights, the Construction Safety Association of Ontario, and the Principal Contractors Safety Alliance. The Website is designed to be user friendly and easily understandable to both safety professionals and construction workers.

The Website also allows users to query the data and download extracts for additional analysis. The data are accessible at two levels.

- The first level includes only CSA access for sharing data and information resources associated with ongoing research and surveillance projects. This access is password-protected for CSA members and their designated collaborators.

- The second level is for general use for accessing all information, published data, and resources as CSA makes it available. This level requires no password and will be advertised in trade journals and other constructionrelated publications.

The Website is currently being tested by construction safety professionals and at this stage primarily serves as a communication portal for CSA members. The prototype Website can be accessed through the link (https://engineering.purdue.edu/CSA). More information will be added as research projects within CSA are developed.

The figure is a reduced view of the Website screen.
KEYWORDS: Website, construction safety, database, safety education, safety training 
HEALTH HAZARD EVALUATIONS AND TECHNICAL ASSISTANCE

RESEARCHERS: Allison Tepper (513) 841-4505 Division of Surveillance, Hazard Evaluations, and Field Studies

Kay Kreiss (304) 285-5800 Division of Respiratory Disease Studies

\section{AFFILIATION: National Institute for Occupational Safety and Health}

PURPOSE: Support the NIOSH Hazard Evaluations and Technical Assistance program.

RESEARCH SUMMARY: NIOSH's Hazard Evaluation and Technical Assistance (HETA) program offers assistance to employers and employees in industry and government at the local, state, and federal level with regard to whether chemical, physical, biological, or other agents found in the workplace are hazardous or pose a health and/or safety risk to workers.

A staff of industrial hygienists, engineers, occupational physicians, epidemiologists, and other health professionals located in Cincinnati and three field offices (Atlanta, Denver, New England), in collaboration with appropriate personnel in other NIOSH divisions, respond to approximately 450 requests for assistance each year. Site visits are conducted if warranted (over 200 site visits were carried out during FY 2000). Interim and final reports are prepared and distributed to employers, employees, and relevant state and federal agencies. The results of these individual evaluations may trigger wider studies of similar exposures in other settings or may stimulate recommendations for implementation or modification of health standards. Control procedures, improved work practices, and medical programs to reduce exposure levels and prevent adverse health effects may be recommended. Other NIOSH documents that are more widely disseminated may also be prepared.

This program is mandated by Section 20(a)(6) of the Occupational Safety and Health Act and implemented by regulations based on 42 CFR 85. More than 10,000 evaluations have been completed since the inception of the HETA program.
KEYWORDS: Hazard identification, exposure assessment, risk assessment, medical evaluation, field investigations 


\section{FATALITY ASSESSMENT AND CONTROL EVALUATION (FACE)}

\section{RESEARCHER: Virgil Casini, Jr. \\ AFFILIATION: Division of Safety Research \\ National Institute for Occupational Safety and Health \\ (304) 285-6020}

PURPOSE: Identify work environments that place workers at high risk for fatal injury, identify potential risk factors, and formulate and disseminate prevention strategies to those who can intervene in the workplace.

RESEARCH SUMMARY: The Fatality Assessment and Control Evaluation (FACE) project is a research program for the identification, investigation, and prevention of fatal occupational injuries through surveillance, on-site investigations, and prevention activities using traditional epidemiologic and public health models. The goals are to prevent fatal work injuries by identifying work situations at high risk of fatal injury and developing prevention strategies for those who can intervene in the workplace.

NIOSH is voluntarily notified of selected occupational fatalities (machinerelated, workers under 18 years of age, and highway construction work zones) by the Departments of Labor in the states of North Carolina, Pennsylvania, South Carolina, Tennessee, and Virginia. Through on-site fatality investigations, FACE personnel then collect agent, host, and environmental information from the pre-event, event, and post-event phases of the fatal incident via a case series designed to facilitate descriptive analyses of the incidents. The resulting analyses identify factors contributing to these fatalities and aid in the development of recommendations for preventing similar deaths. Investigation findings and prevention recommendations are incorporated into health communication documents for broad dissemination and are used by employers to increase worker safety, by manufacturers to modify machinery and equipment to increase worker safety, and by OSHA and other organizations in the promulgation of safety standards and compliance directives.

The project has the unique capability to reach workers at risk and provide timely intervention strategies to targeted areas. Information collected from initial surveillance and subsequent investigations are used by NIOSH, OSHA, and the Wage and Hour Division of the Department of Labor to support the promulgation of safety and labor standards and to develop and disseminate prevention recommendations. These cooperative efforts have led to close working relationships between NIOSH and the participating agencies to improve workplace safety and health.

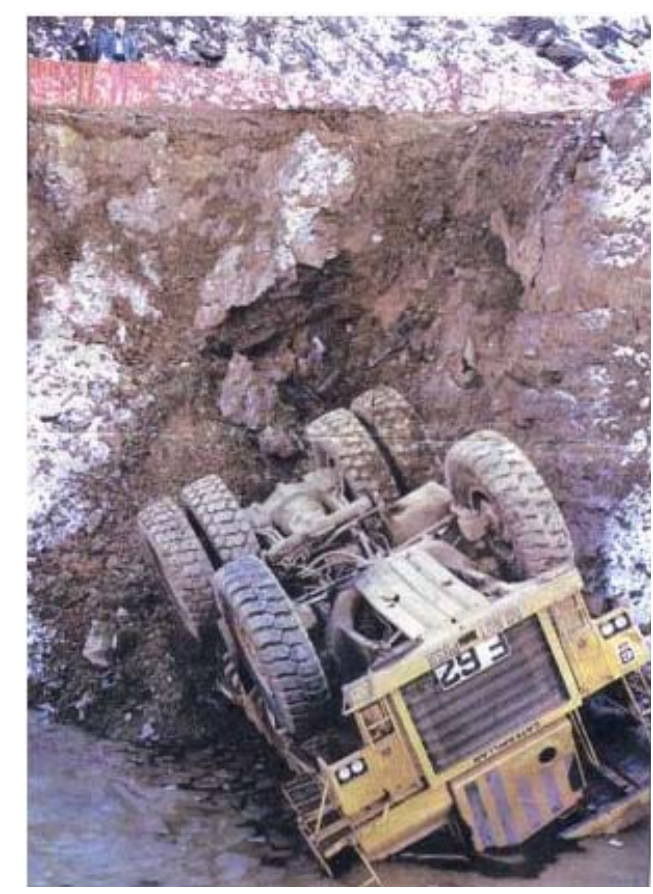

KEYWORDS: Fatalities, hazard identification, intervention

\section{RECENT CITATIONS:}

Higgins, D.N., V.J. Casini, P. Bost, W. Johnson, and R. Rautiainen. 2001. The Fatality Assessment and Control Evaluation program's role in the prevention of occupational fatalities. Injury Prevention, v. 7, Supplement 1, pp. i27-i33.

National Institute for Occupational Safety and Health. 2001. Preventing injuries and deaths from falls during construction and maintenance of telecommunication towers. NIOSH Alert. DHHS (NIOSH) Pub. 2001165.

National Institute for Occupational Safety and Health. 2000. Worker deaths by falls: A summary of surveillance findings and investigative reports. DHHS (NIOSH) Pub. 2000-116. 


\section{STATE-BASED FATALITY ASSESSMENT AND CONTROL EVALUATION}

\section{RESEARCHER: Doloris Higgins}

\section{AFFILIATION: Division of Safety Research National Institute for Occupational Safety and Health \\ (304) 285-6276}

PURPOSE: Identify work environments that place workers at high risk for fatal injury, identify potential risk factors, and formulate and disseminate prevention strategies to those who can intervene in the workplace.

RESEARCH SUMMARY: The State-Based Fatality Assessment and Control Evaluation (FACE) project is a continuing extramural program of surveillance and epidemiologic investigation of selected occupational fatalities. The objective of the FACE project is to prevent fatal work-related injuries through an integrated program of surveillance, on-site investigation, and dissemination and prevention activities. The project is implemented through cooperative agreements with health departments, labor departments, and workers' compensation commissions in 15 states (Alaska, California, Iowa, Kentucky, Massachusetts, Minnesota, Nebraska, New Jersey, New York, Ohio, Oklahoma, Texas, Washington, West Virginia, and Wisconsin).

Cases are identified through active surveillance of all external causes of occupational death. In-depth evaluations are conducted for targeted categories of fatal injuries as determined by national and regional priorities. Detailed information is collected on the circumstances of selected fatalities through onsite investigations using a standardized investigation protocol. Agent, victim, and environmental information is evaluated in relation to the pre-event, event, and post-event phases of the incident. The project's ability to couple case identification with on-site investigations yields detailed information beyond that normally produced by other surveillance systems. Recommendations for preventing similar deaths and injuries are developed for each investigation. Because the project is state based, these recommendations are readily adaptable to specific regional needs and can be disseminated rapidly to the audience best suited to implementing workplace controls.

In addition, NIOSH frequently provides FACE data in response to requests from OSHA in support of the development and promulgation of occupational safety standards and recommendations for intervention and prevention. Since its beginning in FY89, over 10,678 work-related fatalities have been identified and over 1,117 fatality investigations conducted.

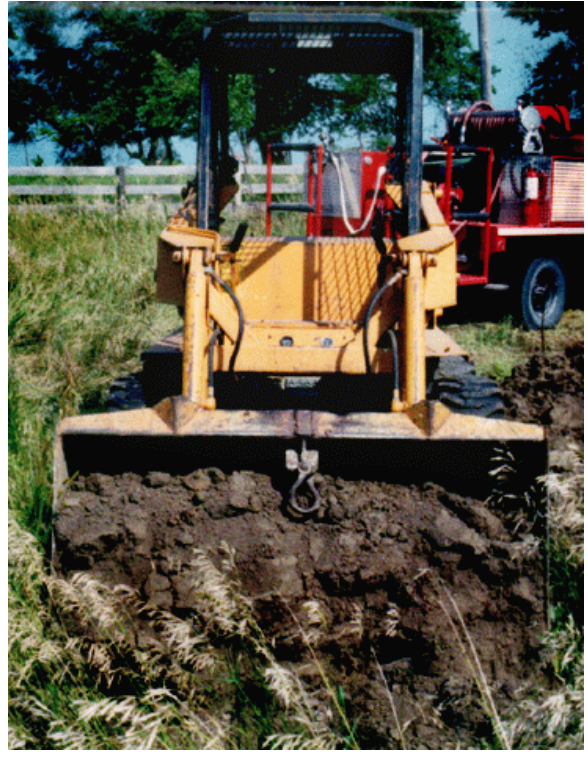

KEYWORDS: Intervention, cooperative agreement, fatalities

\section{RECENT CITATIONS:}

Helmkamp, J., and W. Lundstrom. 2001. Bridge construction-related deaths in West Virginia, 1990-1999.

Professional Safety, Dec., pp. 18-22.

Higgins, D.N., V.J. Casini, P. Bost, W. Johnson, and R. Rautiainen. 2001. The Fatality Assessment and Control Evaluation program's role in the prevention of occupational fatalities. Injury Prevention, v. 7, Supplement 1, pp. i27-i33.

Iowa Department of Public Health. 2001. Worker dies when water tower crashes to the ground. FACE Report No. 01A052-01. 